\title{
Article
}

Mycosphere

Doi 10.5943/mycosphere/8/9/5

Copyright $($ ) Guizhou Academy of Agricultural Sciences

\section{The gymnopoid fungi (Basidiomycota, Agaricales) from the Republic of São Tomé and Príncipe, West Africa.}

\section{Desjardin $\mathrm{DE}^{1}$ and Perry $\mathrm{BA}^{2}$}

\author{
${ }^{I}$ Department of Biology, San Francisco State University, 1600 Holloway Ave., San Francisco, California 94132, USA; \\ ded@sfsu.edu \\ ${ }^{2}$ Department of Biological Sciences, California State University East Bay, 25800 Carlos Bee Blvd., Hayward, California \\ 94542,USA; brian.perry@csueastbay.edu
}

Desjardin DE, Perry BA 2017 - The gymnopoid fungi (Basidiomycota, Agaricales) from the Republic of São Tomé and Príncipe, West Africa. Mycosphere 8(9), 1317-1391, Doi 10.5943/mycosphere/8/9/5

\begin{abstract}
Thirty-one species of gymnopoid fungi are reported from the African island nation, Republic of São Tomé and Príncipe. Ten represent new species (Arrhenia cystidiata, Callistosporium elegans, Campanella burkei, Gymnopus billbowesii, G. hirtelloides, G. irresolutus, G. mustachius, G. ocellus, G. pleurocystidiatus, G. rodhallii), four are new nomenclatural combinations (G. cervinus, G. hirtellus, G. ugandensis, Tricholomopsis aurea), and all 21 previously described species represent new distribution records. Comprehensive descriptions, line drawings, colour photographs, comparisons with allied taxa, a dichotomous key to aid identification, and a phylogenetic analysis of members of the Omphalotaceae based on ITS rDNA sequence data are provided.
\end{abstract}

Key words - Gymnopus - Marasmiellus - fungal diversity - mushrooms - Gulf of Guinea

\section{Introduction}

In April 2006 (two weeks) and April 2008 (three weeks), expeditions led by scientists from the California Academy of Sciences and joined by mycologists from San Francisco State University visited the West African islands of São Tomé and Príncipe to document the diversity of plants, amphibians, marine invertebrates and macrofungi. This is the fifth in a series of papers focused on documenting the basidiomycetous macrofungi from the Republic (Desjardin \& Perry 2009, 2015a, b, 2016).

Gymnopoid fungi, also known as collybioid fungi, have a body form suggestive of members of the white-spored, saprotrophic genus Gymnopus. Currently, they are represented by select genera in the Omphalotaceae, such as Anthracophyllum, Gymnopus, Lentinula, Mycetinis, Marasmiellus, Rhizomarasmius and Rhodocollybia, as well as distantly related genera with similar basidiome body forms such as Callistosporium, Cyptotrama, Lactocollybia, Ripartitella, and others. Prior to the research published here, only five species with a gymnopoid body form were reported from the Republic. The earliest records were from Bresadola and Roumeguère (1890) as Collybia collina (Scop.) P. Kumm. (= Marasmius collinus (Scop.) Singer), Marasmius amadelphus (Bull.) Fr. (= 
Gymnopus ramealis (Bull.) Gray) and Marasmius splachnoides (Hornem.) Fr. (= Gymnopus quercophilus (Pouzar) Antonín \& Noordel.). Later, Coutinho (1925) reported Agaricus xanthopus Fr. (= Gymnopus ocior (Pers.) Antonín \& Noordel.), and described the new species Agaricus diffractus Cout. (= nom. illeg., non A. diffractus Fr. 1838). The latter species, described as having subglobose, rugulose basidiospores and a fibrillose-squamulose pileus remains a nomen dubium. None of these five species have been recollected by us. Our fieldwork yielded ten new species described herein, four new nomenclatural combinations, and 21 new distribution reports for São Tomé and Príncipe.

\section{Materials \& Methods}

Specimens were dried on a Nesco food dehydrator, packed in airtight plastic bags and hand carried back to the US. Macromorphological data were derived from fresh specimens, whereas micromorphological data were derived from dried specimens rehydrated in ethanol followed by distilled water, $3 \% \mathrm{KOH}$ or Melzer's reagent. Colour terms and notations are those of Kornerup and Wanscher (1978). Basidiospore statistics include: $\mathrm{x}_{\mathrm{m}}$, the arithmetic mean of the spore length by spore width ( \pm standard deviation) for $\mathrm{n}$ spores measured in a single specimen; $\mathrm{x}_{\mathrm{mr}}$, the range of spore means, and $\mathrm{X}_{\mathrm{mm}}$, the mean of spore means $( \pm \mathrm{SD})$ when more than one specimen is available; $\mathrm{Q}$, the quotient of spore length by spore width in any one spore, indicated as a range of variation in $\mathrm{n}$ spores measured; $\mathrm{Q}_{\mathrm{m}}$, the mean of $\mathrm{Q}$-values in a single specimen; $\mathrm{Q}_{\mathrm{mr}}$, the range of $\mathrm{Q}_{\mathrm{m}}$ values and $\mathrm{Q}_{\mathrm{mm}}$, the mean of $\mathrm{Q}_{\mathrm{m}}$ values where more than one specimen is available; $n$, the number of spores measured per specimen; $s$, the number of specimens involved. The subfusoid cells that are similar in size to the basidia, arise from the subhymenium on lamellar faces, dominate the hymenium layer, and are present in nearly all gymnopoid (and marasmioid) fungi are herein recognized as "basidioles". These cells have recently been redefined as "pleurocystidia" (Petersen and Hughes 2016). We recognize them as "basidioles" to differentiate them from the scattered, larger cells that arise from the subhymenium or lamellar trama, project beyond the basidia, are often refractive or exudative, and are present in very few gymnopoid fungi, which have been traditionally termed "pleurocystidia". In the line drawings, cross-hatching represents pigmented cell contents while stippling represents pigmented cell walls. All cited specimens are deposited in the H.D. Thiers Herbarium, Department of Biology, San Francisco State University (SFSU).

Total genomic DNA was extracted from dried material using the Extract-N-Amp Plant PCR Kit (Sigma-Aldrich, St. Louis, MO) following the manufacturer instructions. PCR protocols followed those outlined in Perry et al. (2007). For most species included the nuclear ribosomal internal transcribed spacer region (ITS) was amplified using primers ITS1-F/ITS4 (Gardes and Bruns 1993, White et al. 1990). For several taxa, the nuclear ribosomal large subunit gene (nSLU) was also amplified using primers LROR/LR7 (Moncalvo et al. 2002). Amplification products were cleaned using the Exo-SAPit kit (Affymetrix, Santa Clara, CA), and sent to Elim Biopharmaceuticals (Hayward, CA) for sequencing with the same primer pairs used for amplification. Resulting sequencing products were edited and assembled in Geneious 9.0 (Biomatters Ltd., Auckland, New Zealand). All ITS sequences generated as part of this study have been deposited in GenBank (accessions MF100952 - MF100994).

Phylogenetic analyses were performed to further investigate the taxonomic affinities of the African material referable to the Omphalotaceae. ClustalX (Larkin et al. 2007) and Mesquite (Maddison and Maddison 2015) were used to align sequences of the African material of Omphalotaceae within a broader sampling of the family downloaded from GenBank. Parsimony analyses were performed in PAUP* 4.0a 1.52 (Swofford 2002), and consisted of a heuristic search with 500 random stepwise addition replicates, TBR branch swapping, collapse of zero length branches, equal weighting of all characters, and holding no more than 50 topologies per replicate. All remaining phylogenetic analyses were performed within the CIPRES Science Gateway (Miller et al. 2010). Maximum likelihood analyses were run in RAxML 8.2.10 (Stamatakis 2014) under a GTRGAMMA 
model and consisted of 100 alternative runs using the default parameters, with node support estimated by 100 RAxML bootstrap replicates. Bayesian analyses were performed using Metropolis Coupled MCMC methods as implemented in MrBayes 3.2.6 (Huelsenbeck and Ronquist 2001, Ronquist and Huelsenbeck 2003) under a GTR $+\mathrm{G}$ model of sequence evolution as determined under the Bayesian Information Criterion in PAUP* 4.0a.152. Bayesian analyses consisted of two parallel searches, run for 30 million generations and initiated with random starting trees, temperature set to 0.05 and 2 swaps per generation. Eight chains were sampled every 30000 generations for a total of 1001 trees each, sampled from the posterior distribution. Those trees sampled prior to the runs reaching an average standard deviation of split frequencies of 0.01 were discarded as the burn-in, while the remaining trees were used to calculate the posterior probabilities of the individual clades. Default settings were used in MrBayes to set unconstrained branch lengths and uninformative topology priors. The aligned Omphalotaceae ITS dataset and associated tree file have been deposited in TreeBase (submission \#21098).

\section{Results}

After removal of all ambiguously aligned and poorly represented regions, the ITS dataset consists of 548 characters for 134 ingroup taxa, and contains 310 variable positions of which 258 are parsimony informative. Parsimony analyses recovered 1050 equally parsimonious trees (1519 steps; data not shown). Maximum likelihood analyses recovered a single topology (Fig. $1 ;-\ln L=$ 8867.615776) that does not differ significantly from those recovered in the parsimony analyses. Bayesian analyses reached an average standard deviation of split frequencies below 0.01 after 22.5 million generations, and the first 755 trees sampled from the posterior distribution were excluded as the burn-in.

The ITS dataset contains representatives of the Omphalotaceae, and includes 84 species currently recognized as belonging to the genera Gymnopus, Lentinula, Marasmiellus, Mycetinis, Rhodocollybia, Connopus, Campanella and Tetrayrgos. Omphalotus japonicus and O. illudens were used as outgroup taxa. Most of the deep nodes are not strongly supported. Gymnopus, as currently delimited, is paraphyletic when Lentinula, Marasmiellus and Mycetinis are accepted as distinct genera (basal node $<70 \%$ BS, 1.0 PP support). Lentinula species form a well-supported clade (94\% BS, $1.0 \mathrm{PP}$ ) sister to a large number of Gymnopus species, but embedded in a grade with other Gymnopus species whose relationships have low support. The type species of Marasmiellus (M. juniperinus) is sister to $G$. melanopus (70\% BS, $0.96 \mathrm{PP})$ embedded in this Gymnopus grade. Mycetinus (type species $M$. alliaceus) forms a well-supported clade (87\% BS, $1.0 \mathrm{PP}$ ) that is sister (with <70\% BS, $0.92 \mathrm{PP}$ support) to a well-supported clade (82\% BS, $1.0 \mathrm{PP})$ containing numerous Gymnopus species, including the type species of Gymnopus (G. fusipes) and Setulipes (S. androsaceus; accepted by most as a synonym of Gymnopus). Thirteen species of Rhodocollybia, mostly on long branches, form a wellsupported clade (95\% BS, $1.0 \mathrm{PP})$ that is sister to Marasmius pallidocephalus, but with limited support; together they are sister to Gymnopus + Lentinula + Marasmiellus + Mycetinis. Connopus (type $C$. acervatus), on a long branch, is sister to $S$. afibulatus and together are sister to the taxa reported above. At the base of the tree, in a well-supported clade (97\% BS, 1.0 PP), are eleven species currently recognized in Campanella, Tetrapyrgos and Marasmiellus sect. Candidi. None of the latter taxa form well-supported independent clades. Two species with morphology suggestive of $G$. androsaceus (Setulipes), Marasmius pallidocephalus and S. afibulatus, hold isolated positions in the ITS phylogeny. 




Fig. 1 - (below) Maximum likelihood phylogeny of gymnopoid fungi (Omphalotaceae pro parte) based on ITS sequence data $(-\ln L=8867.615776)$. Sequences of species from São Tomé and Príncipe are indicated in bold type. Values separated by / refer to nonparametric ML bootstrap proportions and Bayesian posterior probabilities. Only values greater than $70 / 0.70$ are shown (- designates a value below $70 \%$ or 0.70 ). Nodes receiving support values greater than $90 / 0.95$ are highlighted in bold. 


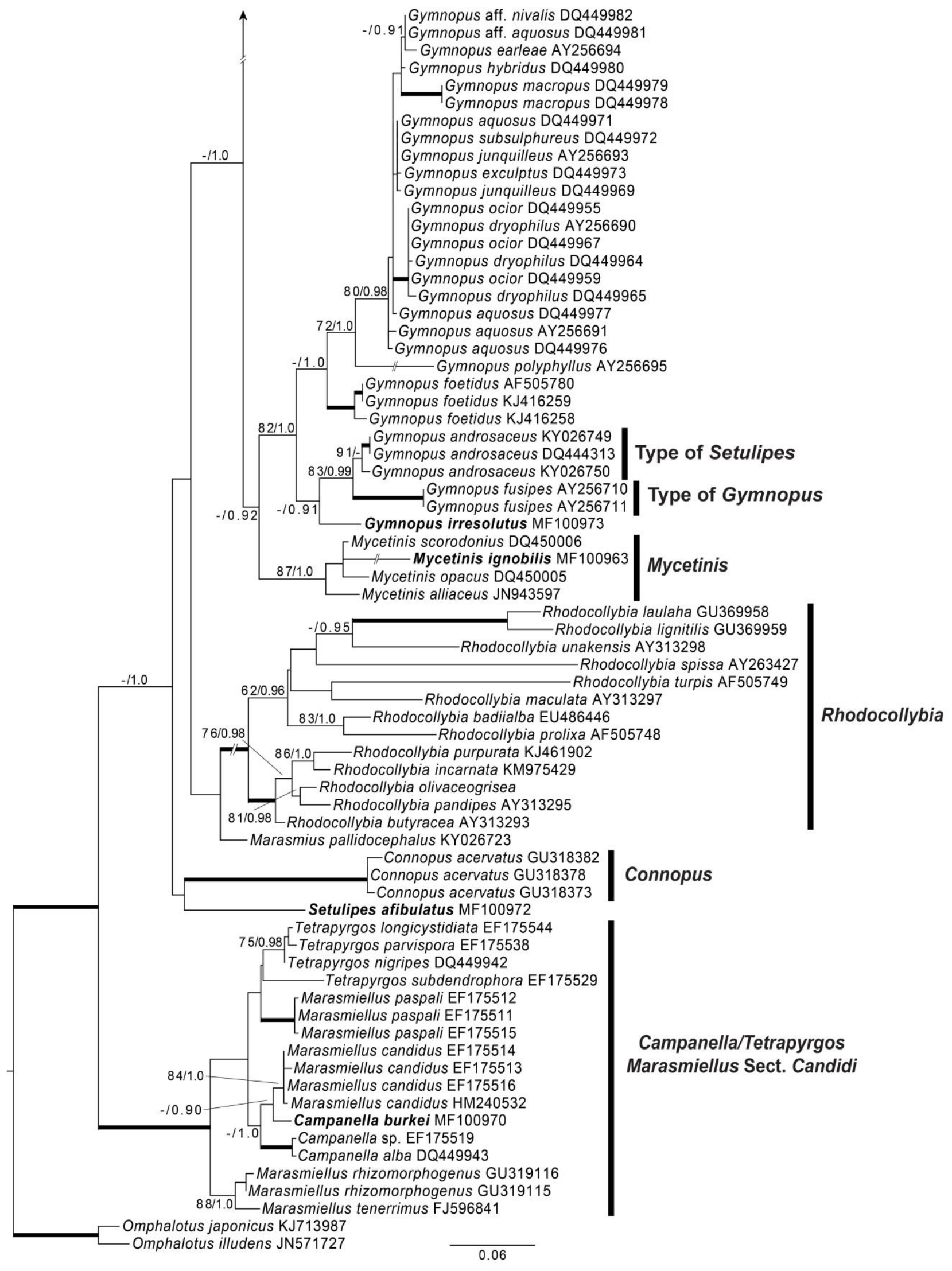

Fig. 1 continued. 


\section{Key to Gymnopoid Fungi of São Tomé and Príncipe}

1. Basidiospores echinulate

1. Ripartitella brasiliensis

1. Basidiospores smooth, lacking ornamentation 2

2. Basidiospores amyloid 2. Heimiomyces tenuipes

2. Basidiospores inamyloid, non-dextrinoid 3

3. Basidiomes pleurotoid, lacking a stipe 4

3. Basidiomes with a well-developed, eccentric or central stipe ........................................... 5

4. Pileus 2-3 mm diam, pale greyish brown; lamellae pale greyish brown; basidiospores $6.8-8 \times 3.8-$ $4.8 \mu \mathrm{m}$; cheilocystidia broadly clavate to sphaeropedunculate, $9.5-16 \mu \mathrm{m}$ diam .. 3. Arrhenia cystidiata 4. Pileus 10-22 mm diam, brownish orange; lamellae greyish orange; basidiospores $2.8-3.5 \times 2.2-2.8$ $\mu \mathrm{m}$; cheilocystidia irregularly cylindrical to flexuous, 2.2-3.5 $\mu \mathrm{m}$ diam ..... 4. Pleurocollybia imbricata 5. Basidiomes purplish brown, violet brown or greyish violet; some basidiospores and cheilocystidia with purple contents (necropigments); clamp connections absent 6. Callistosporium elegans 5. Basidiomes lacking purple tones; basidiospores and cheilocystidia lacking purple necropigments; clamp connections present or absent 6

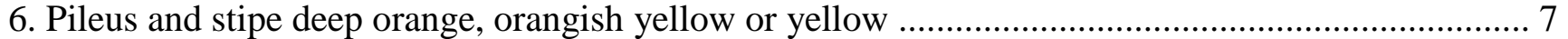

6. Pileus and stipe differently colored, lacking deep orange or yellow tones .................................. 8

7. Pileus and stipe base covered with erect, pyramidal furfuraceous squamules; lamellae subdistant, white; basidiospores 7.5-10 × 6-7.5 $\mu \mathrm{m}$

7. Cyptotrama asprata

7. Pileus and stipe glabrous; lamellae crowded, deep yellow to orangish yellow; basidiospores 5-6.5 $\times$ 4.5-5.2 $\mu \mathrm{m}$ 8. Tricholomopsis aurea

8. Pileus umbilicate to infundibuliform; lamellae decurrent (Trogia) 9

8. Pileus convex, campanulate, plano-convex or shallowly depressed; lamellae adnexed or adnate, sometimes with a short decurrent tooth 12

9. Pileus pale greyish red, deeply infundibuliform, perforate; caulocystidia absent

9. Trogia infundibuliformis

9. Pileus yellowish brown, often with a hint of olive, convex-umbilicate or shallowly infundibuliform, not perforate; caulocystidia present

10. Pileus 35-50 mm diam; hymenophore venose-reticulate; stipe off-white to greyish yellow; pleurocystidia present 10. Trogia anthidepas

10. Pileus 10-22 mm diam; hymenophore typically not venose-reticulate (if so only in older basidiomes); stipe dark yellowish brown to dark brown; pleurocystidia absent 11 11. Stipe 7-10 mm long; lamellae not forked; pileus yellowish brown with a hint of olive ...

11. Trogia aff. brevipes 11. Stipe 15-30 mm long; lamellae forked; pileus pale greyish yellow streaked with yellowish brown .. 12. Trogia aff furcata

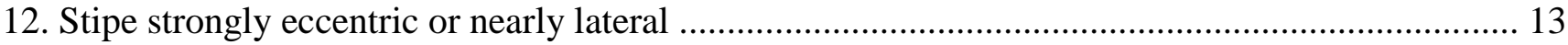

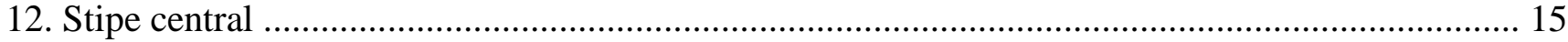

13. Lamellae extremely crowded; pileus canescent, brown, hygrophanous, fading to pale greyish orange; stipe up to $23 \times 3 \mathrm{~mm}$; basidiospores $3.5-4.2 \times 2.5-3 \mu \mathrm{m}$....... 5. Pleurocollybia praemultifolia 13. Lamellae distant; pileus glabrous, orangish white to white; stipe up to $10 \times 1.5 \mathrm{~mm}$; basidiospores $8-11 \times 4.5-5.8 \mu \mathrm{m}$ 14

14. Odor of garlic; basidiomes on dicotyledonous twigs; basidiospore mean $8.4 \times 5.2 \mu \mathrm{m}$

13. Mycetinis ignobilis

14. Odor not distinctive; basidiomes primarily on monocotyledonous debris (palm, banana); basidiospore mean $9-10.2 \times 4.9-5.1 \mu \mathrm{m}$ 14. Marasmius palmivorus 
15. Pileus white

15. Pileus more deeply pigmented

16. Lamellae distant, intervenose; hymenium lacking cystidia; basidiospores $14.5-18.5 \times 5.2-6.5 \mu \mathrm{m}$ 15. Campanella burkei

16. Lamellae close to subdistant, not intervenose; hymenium with large, chrysocystidia-like gloeocystidia 48-75 × 6.5-14.5 $\mu \mathrm{m}$; basidiospores 7.4-9.6 × 5.1-6.4 $\mu \mathrm{m}$. 16. Lactocollybia variicystis

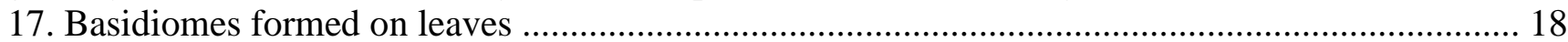

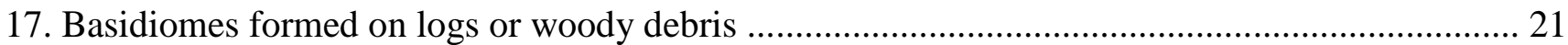

18. Lamellae distant; clamp connections absent ........................................................................... 19

18. Lamellae close to crowded; clamp connections present ……......................................................... 20

19. Cheilocystidia broadly clavate, $8-16 \mu \mathrm{m}$ diam, with numerous apical diverticula; caulocystidia 10 $42 \mu \mathrm{m}$ long, walls $0.5-1 \mu \mathrm{m}$ thick, contents strongly dextrinoid ........................ 17. Setulipes afibulatus 19. Cheilocystidia broadly clavate or irregularly cylindrical, 5-8 $\mu \mathrm{m}$ diam, obtuse or bifid, nondiverticulate; caulocystidia 5-20 $\mu \mathrm{m}$ long, walls up to $0.5 \mathrm{~mm}$ thick, contents non-dextrinoid

18. Gymnopus irresolutus

20. Pileus rugulose-striate to the disc, glabrous, greyish orange in age; cheilocystidia with few knoblike outgrowths; basidiospore mean $6.7 \times 3.5 \mu \mathrm{m}$.......................................... 19. Gymnopus hirtellus 20. Pileus non-striate or seldom striatulate, appressed-felted, dull brown in age; cheilocystidia with numerous knob-like outgrowths; basidiospore mean $7 \times 3.9 \mu \mathrm{m}$.................. 20. Gymnopus hirtelloides 21. Pleurocystidia clavate to fusoid-ventricose, pedicellate, $32-60 \times 8-13 \mu \mathrm{m}$, projecting beyond

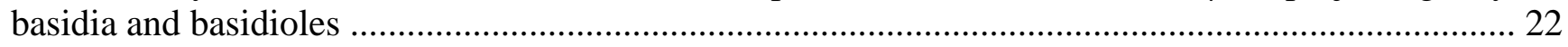
21. Pleurocystidia absent (subfusoid basidioles 18-36 $\times 4-8 \mu \mathrm{m}$ common, not projecting) ................ 23 22. Lamellae crowded, $2-4 \mathrm{~mm}$ broad; pileus disc brown, with brown streaks towards the white margin; stipe 40-70 $\times 2-5 \mathrm{~mm}$; caulocystidia 3-5 $\mu \mathrm{m}$ diam 21. Gymnopus ocellus 22. Lamellae subdistant, $1-2 \mathrm{~mm}$ broad; pileus disc cream with a few brown fibrils; stipe 22-33 $\times 1.5-$ $2.5 \mathrm{~mm}$; caulocystidia $4-10 \mu \mathrm{m}$ diam 22. Gymnopus pleurocystidiatus 23. Pileus typically $>20 \mathrm{~mm}$ diam; stipe $>2 \mathrm{~mm}$ thick, non-insititious ............................................ 24 23. Pileus typically $<20 \mathrm{~mm}$ diam; stipe $<1.5 \mathrm{~mm}$ thick, insititious or subinsititious ......................... 27 24. Pileus non-striate, appressed-fibrillose 23. Gymnopus gibbosus

24. Pileus striate to rugulose-sulcate, glabrous or minutely pruinose 25

25. Cheilocystidia catenulate; pileocystidia common, irregularly cylindrical to clavate

24. Gymnopus aff. polygrammus

25. Cheilocystidia not catenulate; pileocystidia absent 26

26. Pileus 16-40 mm diam; lamellae close, 1-2 $\mathrm{mm}$ broad; stipe dark greyish brown overall, arising from coarse white rhizomorphs; cheilocystidia clavate to nearly sphaeropedunculate $38-66 \times 7-11.5$ $\mu \mathrm{m}$

25. Gymnopus rodhallii

26. Pileus 30-70 $\mathrm{mm}$ diam; lamellae subdistant, $2-5 \mathrm{~mm}$ broad; stipe apex cream, base brown to dark greyish brown, rhizomorphs absent; cheilocystidia irregularly cylindrical to subclavate $24-30 \times 4.8-7$ $\mu \mathrm{m}$........................................................................... 26. Gymnopus aff. brunneigracilis

27. Cheilocystidia with numerous apical diverticula 1.5-5 $(-11) \times 1-3.2 \mu \mathrm{m}$.................................. 28

27. Cheilocystidia non-diverticulate, simple or with a few knob-like outgrowths .............................. 30

28. Pileus 10-25 mm diam, dark brown to brown; lamellae greyish brown; stipe apex brown, base dark brown ................................................................................................ 27. Gymnopus cervinus

28. Pileus $7-15 \mathrm{~mm}$ diam, disc pale brownish grey, orange or white, margin orangish white or white; lamellae white; stipe apex white, base greyish red, reddish brown or dark brown ............................... 29 29. Pileus orange fading to white in age; basidiospore mean 9-10.2 $\times 4.9-5.1 \mu \mathrm{m}$; basidiomes primarily on monocotyledonous debris (palm, banana) 14. Marasmius palmivorus 29. Pileus disc pale brownish grey, margin orangish white; basidiospore mean $7 \times 3.7 \mu \mathrm{m}$; basidiomes 
on dicotyledonous twigs

28. Gymnopus ugandensis 30. Lamellar edge dark brown; cheilocystidia incrusted with dark brown pigments; basidiospore mean $9.2 \times 3.7, \mathrm{Q}_{\mathrm{m}}=2.47$

29. Gymnopus mustachius

30. Lamellar edge concolorous with the face; cheilocystidia hyaline, non-incrusted; basidiospore mean range 5.7-7.7 × 3.9-4.5 $\mu \mathrm{m}, \mathrm{Q}_{\mathrm{m}}=1.33-1.95$ 31

31. Stipe dark brown to black overall; lamellae close to subdistant; basidiospores ellipsoid, mean $7.7 \times$ $3.9 \mu \mathrm{m}$ 30. Gymnopus melanopus

31. Stipe apex white or greyish orange, base brown or dark reddish brown; lamellae distant; basidiospores ovoid, mean $5.8 \times 4.4 \mu \mathrm{m}$...... 31. Gymnopus billbowesii

\section{Taxonomy}

Ripartitella brasiliensis (Speg.) Singer, Lilloa 22: 452.1951 (1949).

Fig. 2

Basionym: Pleurotus brasiliensis Speg., Boln Acad. Nac. Cienc. Córdoba 11(4): 398. 1889.

= Dendrosarcus brasiliensis (Speg.) Kuntze, Revis. Gen. Pl. (Leipzig) 3(2): 463.1898.

Possible heterotypic synonyms: refer to Pegler (1977, 1983).

Facesoffungi number: FoF03727

For a description of African material refer to Pegler (1977).

Habitat and known distribution - Gregarious to subcespitose on decaying wood in primary coastal forest. Africa (Kenya, São Tomé, Tanzania, Uganda), Caribbean region, South America.

Material examined - AFRICA. São Tomé, Macambrara, radio antenna area, N00 ${ }^{16.557 ',}$ E06 36.326', elev. 1300 m, 25 April 2008, coll. by D.E. Desjardin, DED 8323 (MF100952, SFSU).

Notes - Ripartitella brasiliensis is a widely-distributed species in the New World subtropics and tropics, and first reported from Africa by Pegler (1977). The São Tomé specimen, collected in old growth forest at high elevation, matches nicely the description of African material provided by Pegler (1977), although the basidiospores from São Tomé are slightly larger (4.5-5.5 × 3.5-4.2 $\mu \mathrm{m}$ v.s. 3.7$4.5 \times 2.9-3.5 \mu \mathrm{m})$. In age the basidiomes fade from cream (4A3) to pure white and the pileus becomes glabrous from a loss of the squamules.

Pairwise comparisons of aligned, overlapping ITS sequences of the São Tomé specimen of Ripartitella brasiliensis with the top ten BLAST results indicate closest similarity (96.1-96.4\%) with two sequences determined as Ripartitella sp. (JX462554 - Belize; KF727403 - New Zealand).

Heimiomyces tenuipes (Schwein.) Singer, Mycologia 35(2): 159. 1943.

Figs $3,4 \mathrm{a}-\mathrm{f}$

Basionym: Agaricus tenuipes Schwein., Trans. Amer. Phil. Soc. 11. 4: 147. 1832.

= Collybia tenuipes (Schwein). Sacc. Syll. Fung. (Abellini) 5: 213. 1887.

= Gymnopus tenuipes (Schwein.) Murrill, N. Amer. Fl. (New York) 9(5): 361. 1916.

= Xeromphalina tenuipes (Schwein.) A.H. Sm., Pap. Mich. Acad. Sci. 38: 84. 1953.

Synonyms: For a list of potential heterotypic synonyms refer to Pegler $(1977,1983)$.

Facesoffungi number: FoF03728

Pileus 16-80 $\mathrm{mm}$ diam, convex becoming plane in age, margin decurved to uplifted, striate; surface moist, glabrous, subhygrophanous, disc dark orangish brown to orangish brown (6C-D6-7), margin brownish orange (6B-C5-6) to yellowish orange. Context thin, orangish brown. Lamellae ascending-adnate to adnate with a decurrent tooth, subdistant with 2-3 series of lamellulae, moderately broad $(-5 \mathrm{~mm})$, intervenose towards the margin in age, pale brownish orange (6B-C5-6). Stipe 20-35 $\times 2-10 \mathrm{~mm}$, central, initially terete, becoming compressed or cleft in age, cylindrical above an enlarged base, tough, pliant, hollow, non-insititious; surface dull, dry, pubescent to subvelutinous, apex brownish orange (6B-C5-6), base brown to dark brown (6-7E-F4-7). Odor and taste indistinct. 


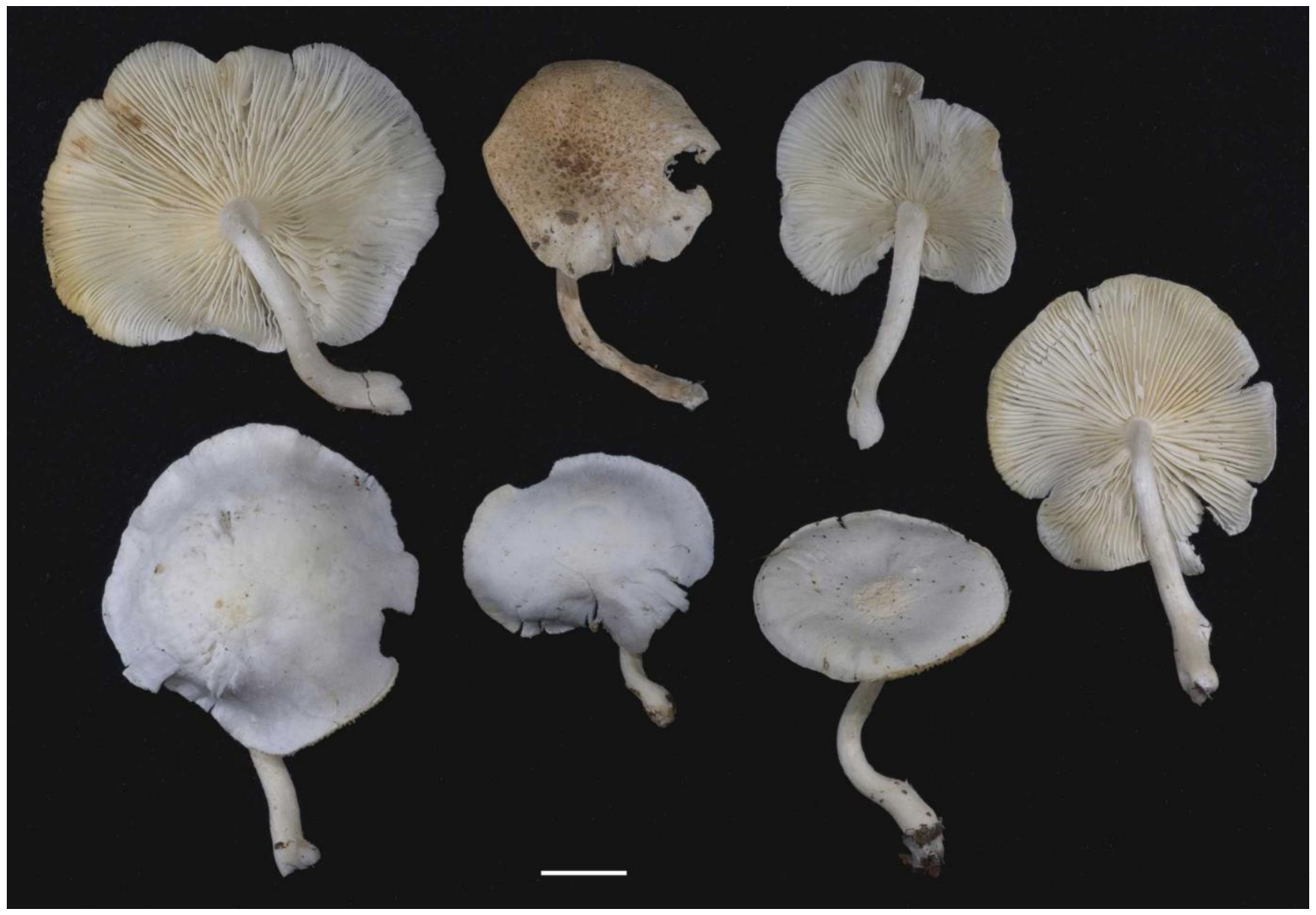

Fig. 2 - Basidiomes of Ripartitella brasiliensis $($ DED 8323). Scale bar $=10 \mathrm{~mm}$

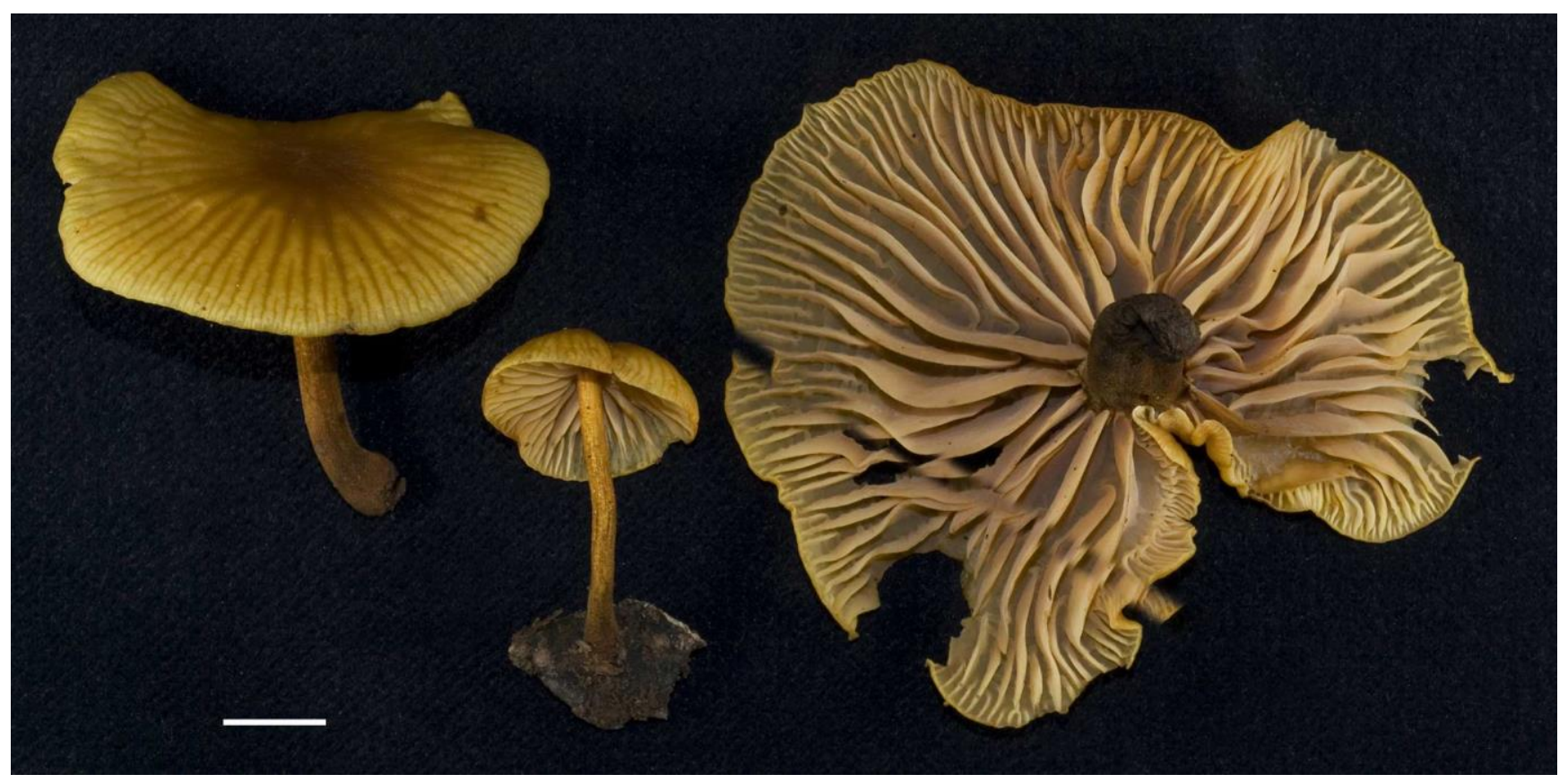

Fig. 3 - Basidiomes of Heimiomyces tenuipes (BAP 640). Scale bar $=10 \mathrm{~mm}$ 
Basidiospores 7.5-9.5 × 4.2-5 $\mu \mathrm{m}\left[\mathrm{x}_{\mathrm{m}}=8.42 \pm 0.63 \times 4.67 \pm 0.27 \mu \mathrm{m}, \mathrm{Q}=1.6-2.0, \mathrm{Q}_{\mathrm{m}}=1.8 \pm\right.$ $0.08, \mathrm{n}=25, \mathrm{~s}=1]$, ellipsoid, smooth, hyaline, amyloid, thin-walled. Basidia 38-42 $\times 8-9.5 \mu \mathrm{m}$ with sterigmata up to $9.5 \mu \mathrm{m}$ long, clavate, 4 -spored. Basidioles broadly clavate. Pleurocystidia-like cells interspersed amongst basidioles, arising from deeper in the subhymenium and not projecting, 40-60 $\times$ 3.8-6.5 $\mu \mathrm{m}$, narrowly fusoid. Lamellar edge heteromerous, fertile. Cheilocystidia common, $22-48 \times 3-$ $7 \mu \mathrm{m}$, irregularly cylindrical, often with a few apical lobes or knobs, hyaline, inamyloid, a few thinwalled, mostly with walls $0.5-1.5 \mu \mathrm{m}$ thick. Pileipellis a cutis of loosely interwoven hyphae with scattered pileocystidia; hyphae 1.5-5 $\mu \mathrm{m}$ diam, cylindrical, branched, hyaline to pale yellow, inamyloid, pale red in 3\% KOH, non-incrusted, weakly gelatinous. Pileocystidia 30-55 x 4-5.5 $\mu \mathrm{m}$, cylindrical, seldom lobed, hyaline to pale yellow, faintly red in $3 \% \mathrm{KOH}$, thick-walled $(-2 \mu \mathrm{m})$. Pileus trama bilayered: upper layer of loosely interwoven narrow hyphae 1.5-2.5 $\mu \mathrm{m}$ diam, cylindrical, branched, hyaline, inamyloid, thin-walled, in a gelatinous matrix; lower layer more compact, hyphae (3-)5-20 $\mu \mathrm{m}$ diam, short-celled, hyaline, inamyloid, gelatinous, with walls 0.5-2 mm thick. Lamellar trama of subparallel hyphae $1.5-8 \mu \mathrm{m}$ diam, cylindrical to irregular in outline, hyaline, inamyloid, nongelatinous, thin-walled or with walls $0.5-1 \mu \mathrm{m}$ thick. Stipitipellis a trichodermium of erect caulocystidia; cortical hyphae 4-8 $\mu \mathrm{m}$ diam, cylindrical, hyaline to pale yellow, inamyloid, pale red in $3 \% \mathrm{KOH}$, non-gelatinous, with walls up to $0.5 \mathrm{~mm}$ thick; medullary hyphae $3-18 \mu \mathrm{m}$ diam, cylindrical, hyaline, inamyloid, thin-walled or with walls up to $2 \mu \mathrm{m}$ thick. Caulocystidia (32-)50-170 $\times 5-10 \mu \mathrm{m}$, wavy-cylindrical, obtuse, lacking projections or rarely apically lobed, orangish yellow, inamyloid, pale red in 3\% $\mathrm{KOH}$, walls $1-2.5 \mu \mathrm{m}$ thick. Clamp connections common in all tissues.

Habitat and known distribution - Solitary to gregarious on decaying logs in secondary upland forest. Africa (Kenya, Príncipe, South Africa, Tanzania, Uganda), North America, Caribbean region, South America, Southeast Asia.

Material examined - AFRICA. Príncipe, along trail to Roça Pico Papagaio, N01³7.182', E07 23.474', 21 April 2008, coll. by D.E. Desjardin and B.A. Perry, BAP 640 (MF100953, SFSU).

Notes - Heimiomyces tenuipes is a morphologically variable, pantropical species, accepted by many in the genus Xeromphalina. Unpublished molecular data indicate a small group of species determined as belonging to the morpho-genus Heimiomyces (type: H. rheicolor (Berk.) Singer, a synonym of $H$. tenuipes) form a well-supported clade sister to taxa commonly accepted in Xeromphalina, and following Horak (1979), we recognize Heimiomyces as a distinct genus. The Príncipe specimen matches nicely material from Africa reported by Pegler (1977). Heimiomyces neovelutipes (Hongo) E. Horak, described from Papua New Guinea, differs subtly in forming a trichodermium pileipellis with more numerous and narrower pileocystidia, and cheilocystidia and caulocystidia with numerous knob-like outgrowths (Horak 1979).

Pairwise comparisons of aligned, overlapping ITS sequences of the Príncipe specimen of Heimiomyces tenuipes with the top ten BLAST results indicate closest similarity (98.4\%) with a sequence determined as Xeromphalina sp. (AB509965) from Japan, and 85.9-89.3\% similarity with two sequences of Heimiomyces neovelutipes (KT120056 - Nigeria; KM975407 - New Zealand).

Arrhenia cystidiata Desjardin \& B.A. Perry, sp. nov.

MycoBank: MB 821157; Facesoffungi number: FoF03729

Fig. 5a-c

Holotype - AFRICA. São Tomé, along main road (EN1) on north side of island, west of Ria Luisa at $33 \mathrm{~km}$ marker, N00¹9.606', E06 30.667', 18 April 2008, coll. by D.E. Desjardin, DED 8266 (SFSU)

Etymology - cystidiata $=$ with cystidia, referring to the lamellar edge composed exclusively of broadly clavate to sphaeropedunculate cystidia.

Diagnosis - Pileus 2-3 mm diam, hoof-shaped in side view, ovoid to chordate or fan-shaped in face view; surface dull, dry, tomentose to felted, pale grey to greyish brown (6D2-3). Context $0.5 \mathrm{~mm}$ 
thick, fragile, concolorous. Lamellae adnexed to point of attachment to substrate, subdistant (5-12) with 1-2 series of lamellulae, broad (1 mm), pale greyish brown (6D2) with white, granulose edges. Stipe absent; attached eccentrically to nearly laterally from pileus to the substrate.

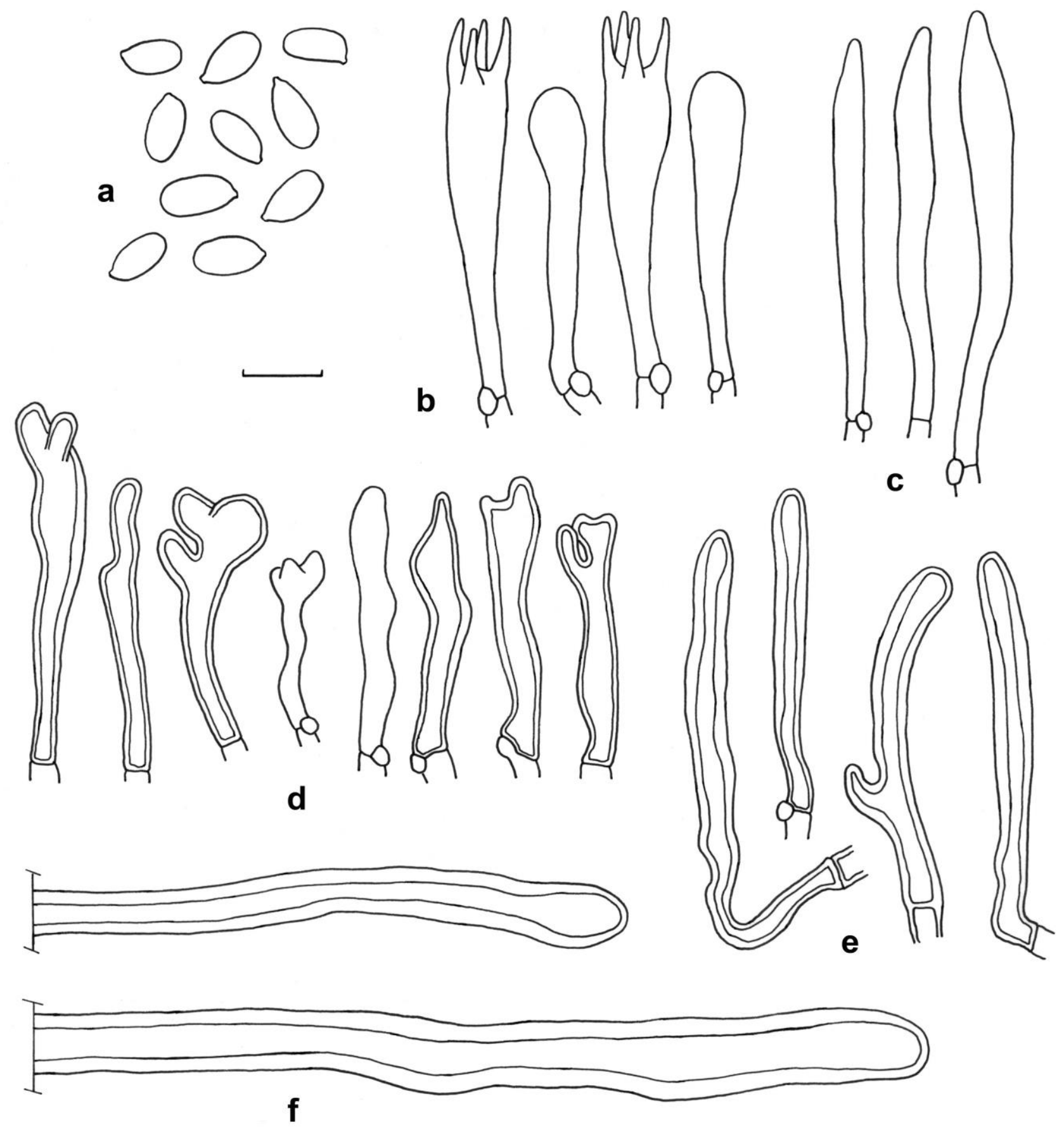

Fig. 4 - Micromorphological features of Heimiomyces tenuipes (BAP 640). a. Basidiospores. b. Basidia and basidioles. c. Pleurocystidia-like cells. d. Cheilocystidia. e. Pileocystidia. f. Caulocystidia. Scale bar $=10 \mu \mathrm{m}$ 
Basidiospores 6.8-8 × 3.8-4.8 $\mu \mathrm{m}\left[\mathrm{x}_{\mathrm{m}}=7.3 \pm 0.48 \times 4.2 \pm 0.25 \mu \mathrm{m}, \mathrm{Q}=1.6-2.0, \mathrm{Q}_{\mathrm{m}}=1.73 \pm\right.$ $0.11, \mathrm{n}=20, \mathrm{~s}=1$ ], lacrymoid, smooth, hyaline, inamyloid, thin-walled. Basidia 17.5-19 $\times$ 5.5-6.5 $\mu \mathrm{m}$, clavate, 4-spored, clamped. Basidioles clavate. Pleurocystidia absent. Cheilocystidia abundant, lamellar edge sterile; 19-30 × 9.5-16 $\mu \mathrm{m}$, broadly clavate to sphaeropedunculate, lacking apical projections, hyaline, thin-walled. Pileipellis a cutis of radially arranged to loosely interwoven hyphae 4-10 $\mu \mathrm{m}$ diam, cylindrical, non-inflated, smooth or incrusted with pale grey pigments, nondiverticulate, non-gelatinous, hyaline, inamyloid, thin-walled; not a Rameales-structure, not an astrostromelloid-structure; terminal cells cylindrical, obtuse; some hyphae with glassy-reflective contents. Pileus trama interwoven; lamellar trama subregular to slightly interwoven; hyphae 3.5-8 $\mu \mathrm{m}$ diam, smooth, hyaline or with greyish brown contents, inamyloid, non-gelatinous, thin-walled. Clamp connections present.

Habitat and known distribution - Gregarious, scattered on very rotten wood in coastal cacaobanana grove with secondary forest canopy. Africa (São Tomé).

Material examined - AFRICA. São Tomé, along main road (EN1) on north side of island, west of Ria Luisa at $33 \mathrm{~km}$ marker, N00¹9.606', E06 30.667', 18 April 2008, coll. by D.E. Desjardin, DED 8266 (Holotype, nLSU-MF100992, ITS-MF100954, SFSU).

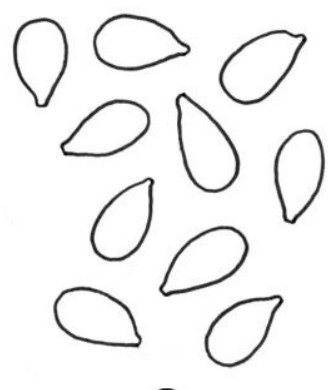

a

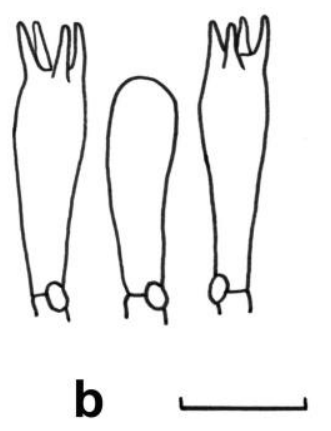

b

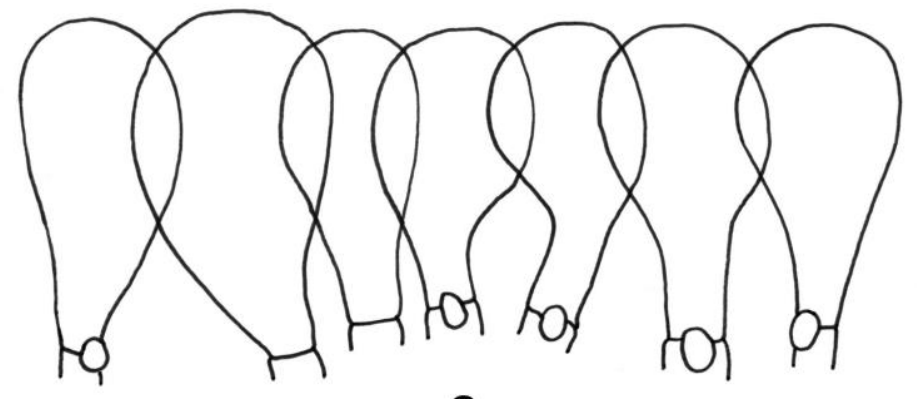

C

Fig. 5 - Micromorphological features of Arrhenia cystidiata (Holotype, DED 8266). a. Basidiospores. b. Basidia and basidiole. c. Cheilocystidia. Scale bar $=10 \mu \mathrm{m}$

Notes - Arrhenia cystidiata is distinguished by very small, pleurotoid basidiomes with pale greyish brown, tomentose-felted pileus, distant greyish brown lamellae, no stipe, hyaline, inamyloid basidiospores with mean $7.3 \times 4.2 \mu \mathrm{m}$, no pleurocystidia, broadly clavate to sphaeropedunculate cheilocystidia 9.5-16 $\mu \mathrm{m}$ diam, a cutis-type pileipellis with non-diverticulate, non-gelatinous hyphae and undifferentiated terminal cells, and growth on very rotten wood. Although the molecular data (see below) suggest placement in Arrhenia, morphologically the species is more similar to members of Marasmiellus, Sect. Marasmiellus, Subsect. Marasmiellus sensu Singer (1973), where it shows some affinities to M. goossensiae (Beeli) Pegler and M. purpureoalbus (Petch) Singer. The latter two species differ, however, in forming larger basidiomes (pileus 10-20 mm diam) with purplish brown pigments, diverticulate cheilocystidia, and Rameales-structure pileipelli (Pegler 1977, 1986). Marasmiellus epochnous (Berk. \& M.A. Curtis) Singer, another small taxon (pileus 2-6 mm diam), differs in forming a tiny stipe (0.5-3 mm long), diverticulate cheilocystidia, and Rameales-structure pileipellis (Singer 1973, Pegler 1986). The small grey-brown basidiomes with cutis-type pileipellis of the new species are also reminiscent of Resupinatus, however, Resupinatus species have gelatinous tissues and astrostromelloid- or Rameales-structure pileipelli.

Arrhenia cystidiata is unusual in the genus, which is comprised mainly of bryophilous species 
with poorly-developed hymenophores that lack cheilocystidia (Redhead 1984, Redhead et al. 2002). However, wood-rotting species with clavate cheilocystidia are known, e.g., A. epichysium (Pers.) Redhead, Lutzoni, Moncalvo \& Vilgalys, although the latter species forms much larger, centrally stipitate basidiomes. Arrhenia cystidiata is most similar to A. stercoraria (Barrasa, Esteve-Rav. \& Sánchez) Redhead, Lutzoni, Moncalvo \& Vilgalys, but the latter forms cyphelloid basidiomes with a pseudostipe, grows on dung, and because it lacks lamellae has no cheilocystidia (Barrasa et al. 1998).

Pairwise comparisons of aligned, overlapping nLSU sequences of Arrhenia cystidiata with the top five BLAST results of taxa with $100 \%$ sequence coverage, indicate $97.5 \%$ similarity to Arrhenia auriscalpium (DQ071732) and 97.2\% similarity to Arrhenia griseopallida (as Phaeotellus griseopallidus, U66436). Pairwise comparisons of aligned, overlapping ITS sequences of Arrhenia cystidiata with the top ten BLAST results of taxa with at least $60 \%$ sequence coverage, indicate only 82.4-83.3\% similarity to two Arrhenia lobata sequences (U66429, GU234033). Although Arrhenia cystidiata belongs in the Hygrophoraceae, subfamily Lichenomphalioideae sensu Lodge et al. (2013) and is only distantly related to gymnopoid fungi, it is treated here because of its resemblance to flabelliform Marasmiellus species.

Pleurocollybia imbricata T.J. Baroni, Lodge \& Linder, Mycotaxon 103: 355. 2008.

Figs $67 \mathrm{a}-\mathrm{d}$

Facesoffungi number: FoF03730

Pileus 10-22 mm broad, spathulate to flabelliform, plano-convex in profile, margin lobed or cleft, incurved; surface canescent, hygrophanous, brownish grey (6C3) to brownish orange (6C4-5), fading with moisture loss to nearly white, lacking lilac, purple, green or olive shades. Context thin, very fragile, white. Lamellae adnexed to point of attachment, close with 2-3 series of lamellulae, narrow (up to $1 \mathrm{~mm}$ ), greyish orange (6B3) to pale brownish orange (6C4). Stipe absent; whitetomentose at lateral point of attachment; with numerous white rhizomorphs.

Basidiospores 2.8-3.5 $\times 2.2-2.8 \mu \mathrm{m}\left[\mathrm{x}_{\mathrm{m}}=3.1 \pm 0.24 \times 2.5 \pm 0.16 \mu \mathrm{m}, \mathrm{Q}=1.2-1.35, \mathrm{Q}_{\mathrm{m}}=1.25\right.$ $\pm 0.0, \mathrm{n}=20, \mathrm{~s}=1]$, subglobose to ovoid, smooth, hyaline, inamyloid, thin-walled. Basidia 14-17 $\times 4$ $5 \mu \mathrm{m}$, clavate, 4-spored, rarely 2-spored, clamped. Basidioles clavate. Lamellar edge partially fertile. Pleurocystidia absent. Cheilocystidia 20-24 $\times 2.2-3.5 \mu \mathrm{m}$, irregularly cylindrical to flexuous, subcapitate or strangulate, hyaline, thin-walled. Lamellar trama hyphae subparallel, $2.5-9 \mu \mathrm{m}$ diam, cylindrical or inflated up to $12.5 \mu \mathrm{m}$, smooth or roughened, hyaline, non-gelatinous. Pileipellis a cutis of repent, subparallel to interwoven hyphae $2-3.5 \mu \mathrm{m}$ diam, cylindrical, non-diverticulate, hyaline to pale yellow in $3 \% \mathrm{KOH}$, pigment intraparietal and not soluble in $\mathrm{KOH}$, non-gelatinous, giving rise to scattered pileocystidia, 6.5-15 $\times 2-3.5 \mu \mathrm{m}$, cylindrical, as intercalary outgrowths. Pileus trama hyphae 2.5-6.5 $\mu \mathrm{m}$ diam, cylindrical or irregular in outline, hyaline, non-gelatinous, thin-walled or with walls up to $0.5 \mathrm{~mm}$ thick. Clamp connections only at the base of basidia, absent in other tissues.

Habit and known distribution -Densely gregarious, imbricate, on soil over very rotten wood in primary forest. Africa (São Tomé), Belize.

Specimen examined - AFRICA. São Tomé, Parque Nacional Obo, on trail to Lagoa Amelia, between N00 17.112', E06 35.967' and N00 16.922', E06 36.062', 14 April 2008, coll. by D. E. Desjardin, DED 8232 (MF100955, SFSU).

Notes - Distinctive features of Pleurocollybia imbricata include: a spathulate-lobed, pale brownish grey to brownish orange, hygrophanous pileus; close, brownish orange lamellae; no stipe but with a white-tomentose, lateral attachment point with white rhizomorphs; small, smooth basidiospores with mean $3.1 \times 2.5 \mu \mathrm{m}$; irregularly cylindrical, subcapitate cheilocystidia 2.2-3.5 $\mu \mathrm{m}$ diam; a cutistype pileipellis of hyphae 2-3.5 $\mu \mathrm{m}$ diam with yellow parietal pigments; clamp connections present only at the base of basidia; and growth in soil over very rotten wood. Overall basidiome morphology is reminiscent in the field of a species of Pyrrhoglossum, for which it was initially confused, but the latter form rusty brown, verrucose basidiospores. 


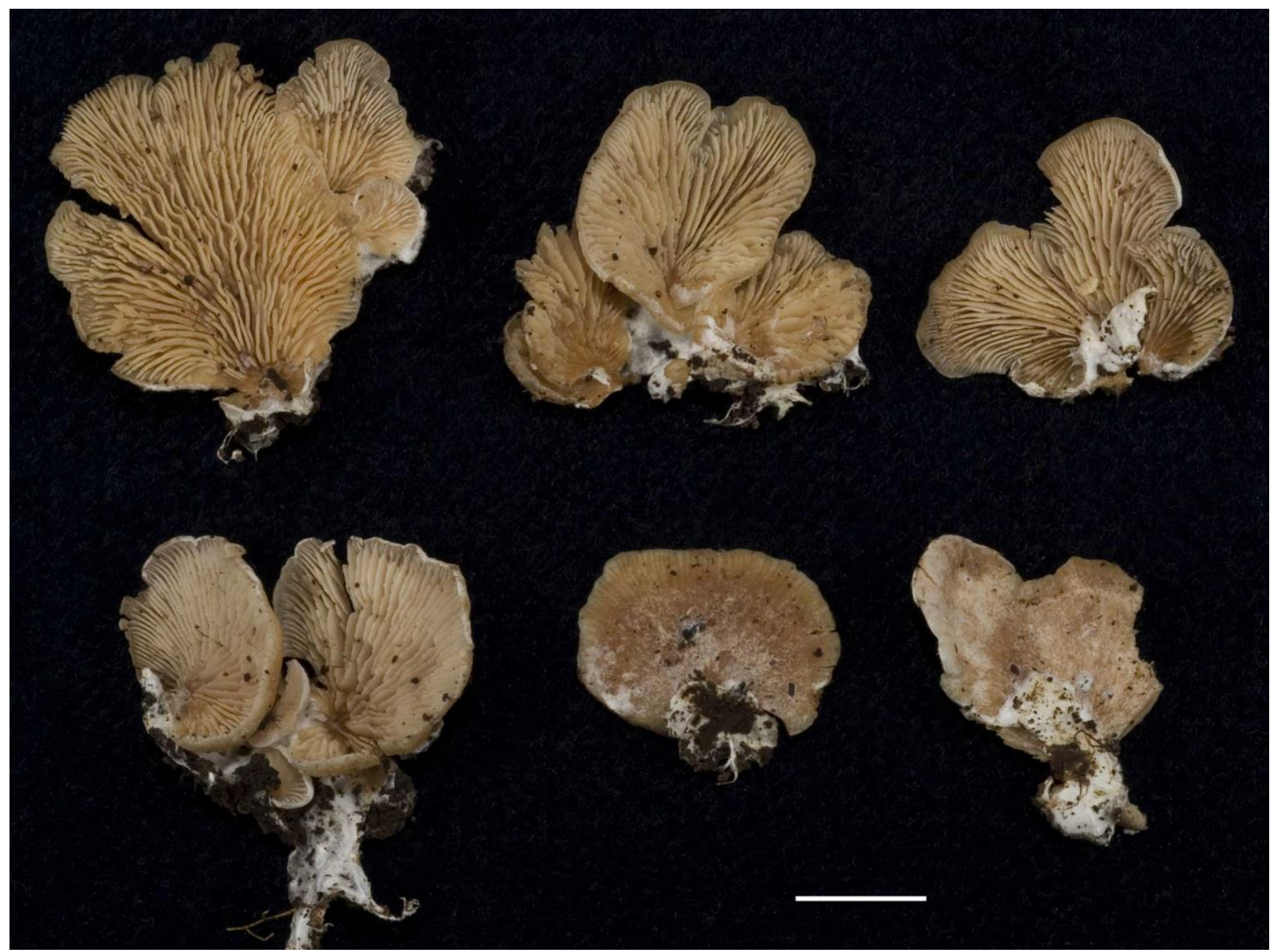

Fig. 6 - Basidiomes of Pleurocollybia imbricata (DED 8232). Scale bar $=10 \mathrm{~mm}$

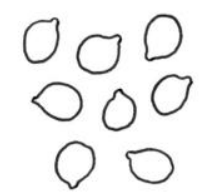

a

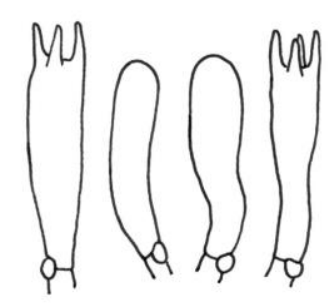

b
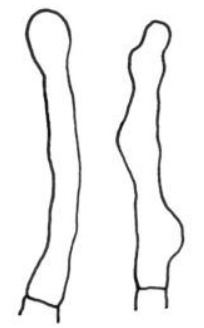

C
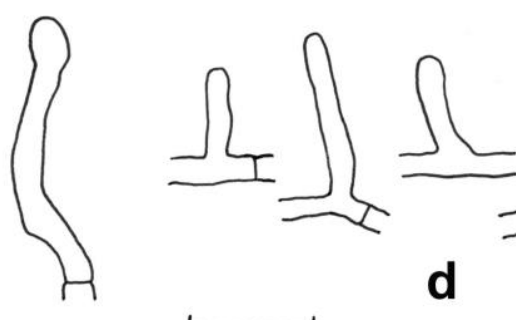

d

Fig. 7 - Micromorphological features of Pleurocollybia imbricata (DED 8232). a. Basidiospores. b. Basidia and basidioles. c. Cheilocystidia. d. Pileocystidia. Scale bar $=10 \mu \mathrm{m}$

The São Tomé specimen is composed of basidiomes in the small end of the size range for Pleurocollybia imbricata, a species described recently from Belize (Baroni et al. 2008). Other differences include less crowded lamellae, unbranched and less contorted cheilocystidia, and the presence of clamp connections at the base of basidia. Pairwise comparisons of aligned, overlapping 
ITS sequences of DED 8232 with the top ten BLAST results indicate $99 \%$ similarity with the holotype specimen of $P$. imbricata (HM105568).

Pleurocollybia praemultifolia (Murrill) Singer, Mycologia 39: 80. 1947.

Basionym: Gymnopus praemultifolius Murrill, Proc. Fla. Acad. Sci. 7 (2/3): 109. 1945 [1944].

= Collybia praemultifolia (Murrill) Murrill, Proc. Fla. Acad. Sci. 7 (2/3): 127. 1945 [1944].

Potential heterotypic synonyms: refer to Pegler (1983).

Facesoffungi number: FoF03731

Pileus $45 \mathrm{~mm}$ diam, asymmetrically plano-convex with a low broad umbo, margin undulate, lobed, decurved, split in age, non-striate; surface dull, moist, hygrophanous, canescent, disc brown (67E5-6; "chestnut brown") to light brown (6D4-5; "hazel"), fading to pale greyish orange (5B3) to dingy buff with moisture loss; drying cream-brown. Context 1-1.5 mm thick, soft, watery greyish orange. Lamellae shallowly adnexed to adnate, extremely crowded with 5 series of truncate lamellulae, narrow (1-1.5 mm), dingy beige to orangish white (5A2); drying cream. Stipe $23 \times 3 \mathrm{~mm}$, strongly

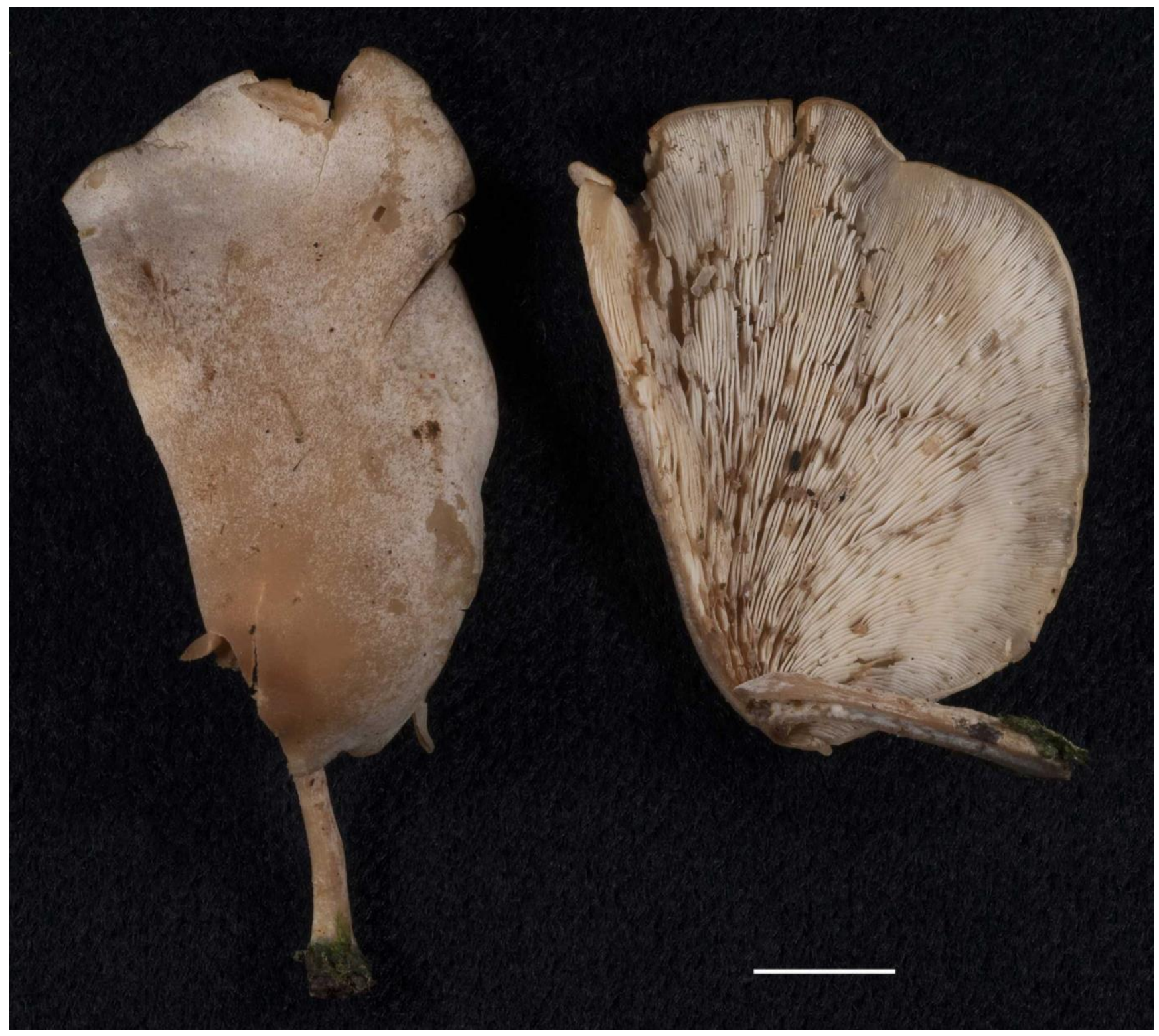

Fig. 8 - Basidiomes of Pleurocollybia praemultifolia (DED 8238). Scale bar $=10 \mathrm{~mm}$ 
eccentric, curved, terete, cylindrical, hollow, tough, non-insititious; surface dull, dry, longitudinally fibrous, light brown 6D4-5) to greyish orange (5B3) overall. Odor not distinctive; taste not observed.

Basidiospores 3.5-4.2 $\times 2.5-3.0 \mu \mathrm{m}\left[\mathrm{x}_{\mathrm{m}}=3.7 \pm 0.21 \times 2.8 \pm 0.21 \mu \mathrm{m}, \mathrm{Q}=1.21-1.45, \mathrm{Q}_{\mathrm{m}}=1.35\right.$ $\pm 0.06, \mathrm{n}=20, \mathrm{~s}=1$ ], ovoid to ellipsoid, smooth, hyaline, inamyloid, non-dextrinoid, thin-walled. Basidia 12-15 × 4-5 $\mu \mathrm{m}$, clavate, 4-spored, unclamped. Basidioles clavate. Pleurocystidia absent. Cheilocystidia absent; lamellar edge fertile. Pileipellis a cutis of radially arranged, interwoven hyphae forming a tissue layer several cells thick; hyphae 2-6.5 $\mu \mathrm{m}$ diam, irregularly cylindrical, smooth or with scattered finger-like or knob-like diverticula, hyaline, inamyloid, non-incrusted, non-gelatinous, thin-walled; terminal cells repent or erect, undifferentiated. Pileus trama interwoven; hyphae 4-10 $\mu \mathrm{m}$ diam, cylindrical, branched, hyaline, inamyloid, non-incrusted, non-gelatinous, thin-walled to thickwalled $(-1 \mu \mathrm{m})$. Lamellar trama regular; hyphae 2.5-12 (-20) $\mu \mathrm{m}$ diam, cylindrical to inflated, hyaline, inamyloid, non-gelatinous, thin-walled. Stipitipellis a cutis; cortical hyphae $2-4 \mu \mathrm{m}$ diam, cylindrical or irregular in outline, smooth or with a few scattered knobs, hyaline, inamyloid, non-incrusted, nongelatinous, thin-walled; medullary hyphae 5-16 $\mu \mathrm{m}$ diam, cylindrical, hyaline, inamyloid, nongelatinous, with walls 0.5-1.5 $\mu \mathrm{m}$ thick. Caulocystidia absent. Clamp connections absent in all tissues.
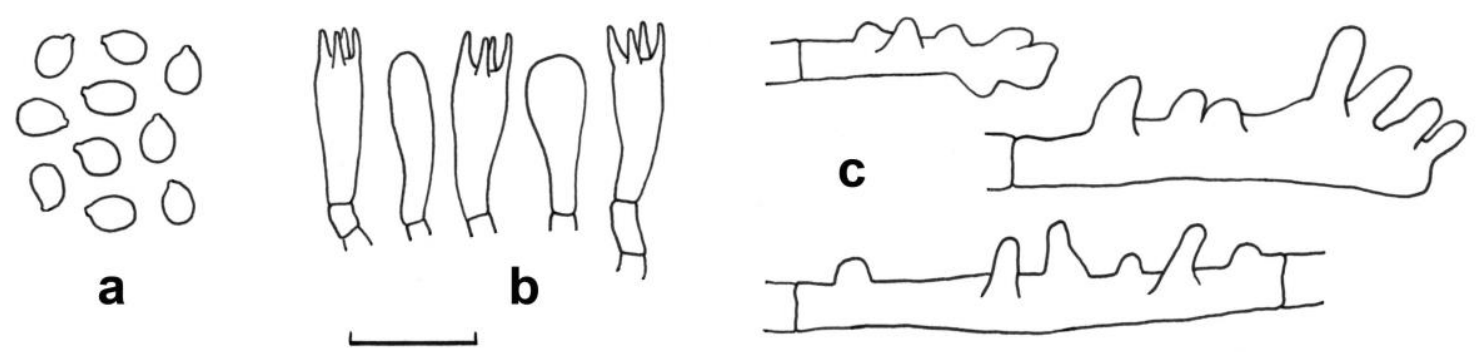

Fig. 9 - Micromorphological features of Pleurocollybia praemultifolia (DED 8238). a. Basidiospores. b. Basidia and basidioles. c. Pileipellis hyphae and terminal cells. Scale bar $=10 \mu \mathrm{m}$

Habitat and known distribution - Solitary on a standing dead tree in primary forest. Africa (Príncipe), Caribbean region (Dominica, Guadeloupe, Martinique, Trinidad), North America (Florida), South America (Bolivia).

Material examined - AFRICA. Príncipe, Parque Nacional Obo, trail to Lagoa Amelia, between N00 ${ }^{\circ} 17.112^{\prime}, \mathrm{E}^{\circ} 6^{\circ} 35.967^{\prime}$ and N00 16.922', E06 36.062', 14 April 2008, coll. by D.E. Desjardin, DED 8238 (MF100956, SFSU).

Notes - Pleurocollybia praemultifolia is distinguished by a light brown, hygrophanous, planoconvex pileus, extremely crowded, narrow, orangish white lamellae, a strongly eccentric, greyish orange stipe, very small, inamyloid (non-dextrinoid) basidiospores with mean $3.7 \times 2.8 \mu \mathrm{m}$, no hymenial cystidia or caulocystidia, a cutis-type pileipellis and stipitipellis with smooth or weakly diverticulate, non-dextrinoid hyphae, no clamp connections, and growth on dead wood. The Príncipe specimen matches quite nicely the material reported from the Caribbean region (type locality Florida) and South America (Singer 1970, Pegler 1983).

Pegler (1977) reported Pleurocollybia brunescens (Earle) Singer from East Africa and accepted $P$. praemultifolia as a synonym. He later reported both $P$. brunescens and $P$. praemultifolia from the Lesser Antilles (Pegler 1983), accepting them as distinct species, with P. brunescens differing in forming lamellae that dry dark brown, hence the specific epithet. He explicitly stated that "the two species are readily separable in the field." Interestingly, Pegler never mentioned dried dark brown lamellae in the African material he collected, and we have not seen this feature in our material. Accordingly, we recognize the African material as representing P. praemultifolia. 
Pairwise comparisons of aligned, overlapping ITS sequences of Pleurocollybia praemultifolia with the top ten BLAST results indicate closest similarity (87.7-90.3\%) with two sequences determined as Pleurocollybia sp. (KY559342 - Argentina; KP311477 - Australia).

Callistosporium elegans Desjardin \& B.A. Perry, sp. nov.

Figs 10, 11a-d

MycoBank: MB821158; Facesoffungi number: FoF03732

Holotype - AFRICA. São Tomé, Parque Nacional Obo, trail to Lagoa Amelia, between N00 ${ }^{\circ} 16.922^{\prime}, \mathrm{E}^{\circ} 6^{\circ} 36.062^{\prime}$ and N00 ${ }^{\circ} 17.112^{\prime}, \mathrm{E}^{\circ} 6^{\circ} 35.957^{\prime}, 14$ April 2008, coll. by D.E. Desjardin and B.A. Perry, BAP 617 (SFSU).

Etymology - elegans - elegant.

Diagnosis - Pileus 10-20 mm diam, hemispherical to convex, centrally depressed, margin at first inrolled, becoming decurved, non-striate; surface dull, moist to dry, minutely pruinose, dark purplish brown or violet brown (9-11F5-8), hygrophanous, becoming brown with moisture loss. Context 1-2 mm thick, soft, grey. Lamellae adnate, close with 1-2 series of lamellulae, often forked near pileus margin, moderately broad (2-3 mm), purplish brown to violet brown (9-11E6-7). Stipe 20-30 × 2.5-4 $\mathrm{mm}$, central, terete, cylindrical, hollow; surface dull, dry, felted, greyish brown (7C-D3-4) with violet tones, base with white tomentum.

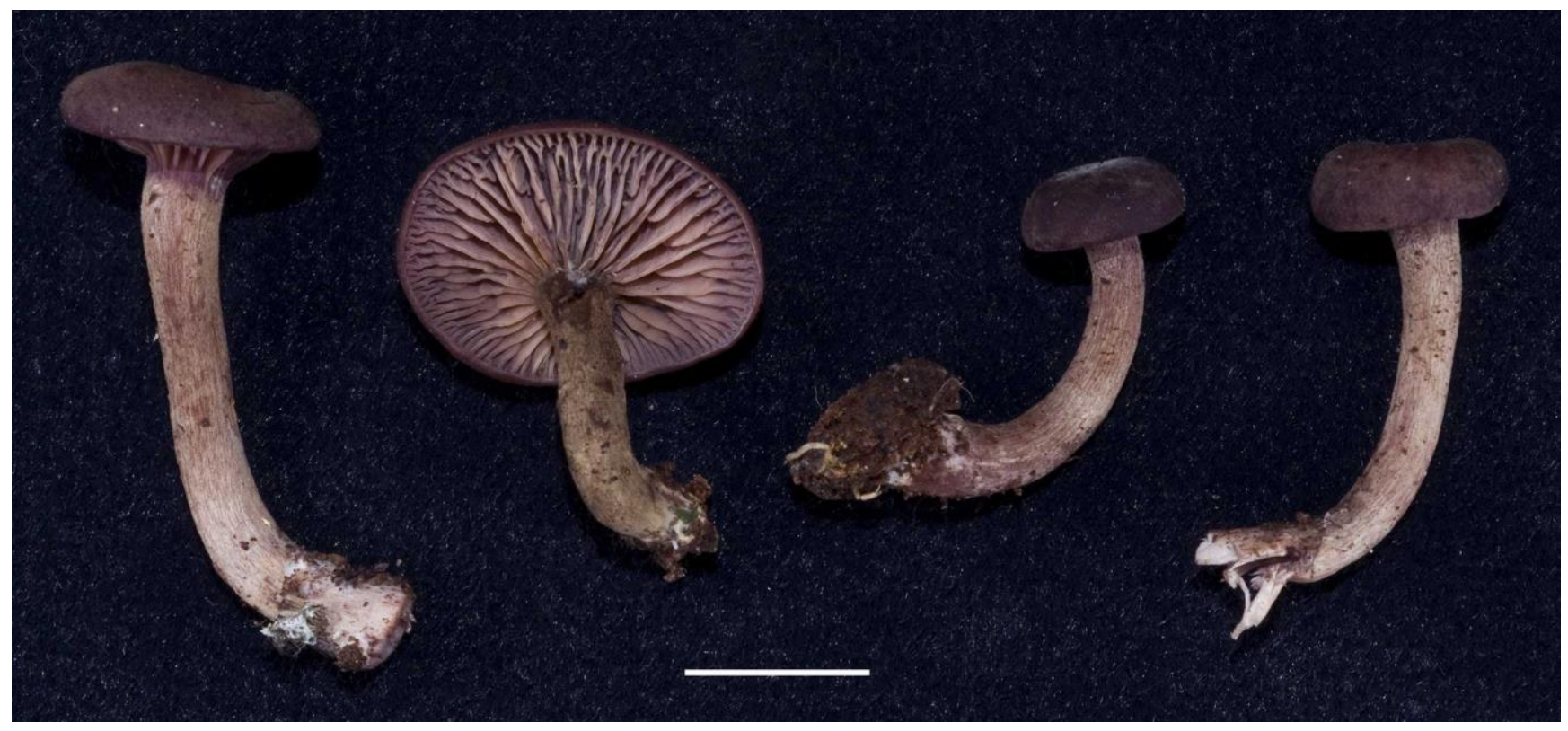

Fig. 10 - Basidiomes of Callistosporium elegans (Holotype, BAP 617). Scale bar = $10 \mathrm{~mm}$

Basidiospores 4.5-5.5 × 3.0-3.5 $\mu \mathrm{m}\left[\mathrm{x}_{\mathrm{m}}=4.8 \pm 0.32 \times 3.2 \pm 0.16 \mu \mathrm{m}, \mathrm{Q}=1.4-1.7, \mathrm{Q}_{\mathrm{m}}=1.5 \pm\right.$ $0.12, \mathrm{n}=20, \mathrm{~s}=1$ ], ellipsoid to subovoid, smooth, hyaline or some with purple contents (necropigments), inamyloid, thin-walled. Basidia 22-26 × 5.7-6.5 $\mu \mathrm{m}$, clavate, 4-spored, hyaline or with purple globular contents, unclamped. Basidioles clavate. Pleurocystidia absent. Lamellar edge sterile. Cheilocystidia 20-24 × 2.2-4 $\mu \mathrm{m}$, cylindrical to subclavate, apex sometimes subcapitate, up to $6.5 \mu \mathrm{m}$ diam, hyaline or with purple globular contents, thin-walled. Pileipellis a cutis of interwoven hyphae 4-11 $\mu \mathrm{m}$ diam, cylindrical, brown (pigments intraparietal), non-incrusted, non-gelatinous, thick-walled; terminal cells erect to repent, cylindrical or narrowed toward apex, obtuse, similar to cheilocystidia, 2.5-5 $\mu \mathrm{m}$ diam. Pileus trama interwoven; hyphae 4-11 $\mu \mathrm{m}$ diam, cylindrical, hyaline, non-gelatinous, thin-walled. Lamellar tama regular; hyphae 3-10 $\mu \mathrm{m}$ diam, cylindrical or inflated, hyaline or with purplish brown contents, non-incrusted, non-gelatinous, thin-walled. Stipitipellis a 
cutis with erect caulocystidia; cortical hyphae $2.5-8 \mu \mathrm{m}$ diam, cylindrical, pale brown to yellowish brown, pigment intraparietal, some with brown globular contents, inamyloid, thin-walled; medullary hyphae 4-16 $\mu \mathrm{m}$ diam, cylindrical to inflated, hyaline, inamyloid, thin-walled. Caulocystidia clustered, $12-30 \times 4.5-12.5 \mu \mathrm{m}$, irregularly cylindrical to clavate, sometimes geniculate or intercalary, hyaline, inamyloid, thin-walled. Clamp connections absent in all tissues. Tomé).

Habitat and known distribution - Scattered on decaying logs in upland forest. Africa (São

Material examined - AFRICA. São Tomé, Parque Nacional Obo, trail to Lagoa Amelia, between N00 $16.922^{\prime}, \mathrm{E} 06^{\circ} 36.062^{\prime}$ and N00 17.112', E06 35.957', 14 April 2008, coll. by D.E. Desjardin and B.A. Perry, BAP 617 (Holotype, MF100991, SFSU).

Notes - Callistosporium elegans is characterized by small, violet-brown basidiomes with forked, violet brown lamellae, inamyloid basidiospores with mean $4.8 \times 3.2 \mu \mathrm{m}$, a sterile lamellar edge composed of cylindrical-subcapitate cheilocystidia, a cutis-type pileipellis with scattered erect terminal cells, clustered, irregularly cylindrical caulocystidia, no clamp connections, basidiospores and hymenial cells with purple necropigments, and growth on decayed logs. Of the vinaceous to purpleviolet pigmented species of Callistosporium, $C$. elegans is most phenetically similar to $C$. vinosobrunneum Desjardin \& Hemmes, described from native kipukas in the Hawaiian Islands, and $C$. amazonicum Singer, described from Brazil. Callistosporium vinosobrunneum differs in forming more reddish brown basidiomes with pellucid-striate pileus, a dark reddish brown stipe, and larger basidiospores with mean $7.1 \times 5.6 \mu \mathrm{m}$ (Desjardin and Hemmes 2011). Callistosporium amazonicum forms a pellucid-striate pileus, pinkish grey lamellae, a smaller and more gracile stipe $(14-17 \times 1.5-2.5$ $\mathrm{mm}$ ), and smaller basidiospores in the range 3-4.5 × 1.7-3.5 $\mu \mathrm{m}$ (Singer 1977).
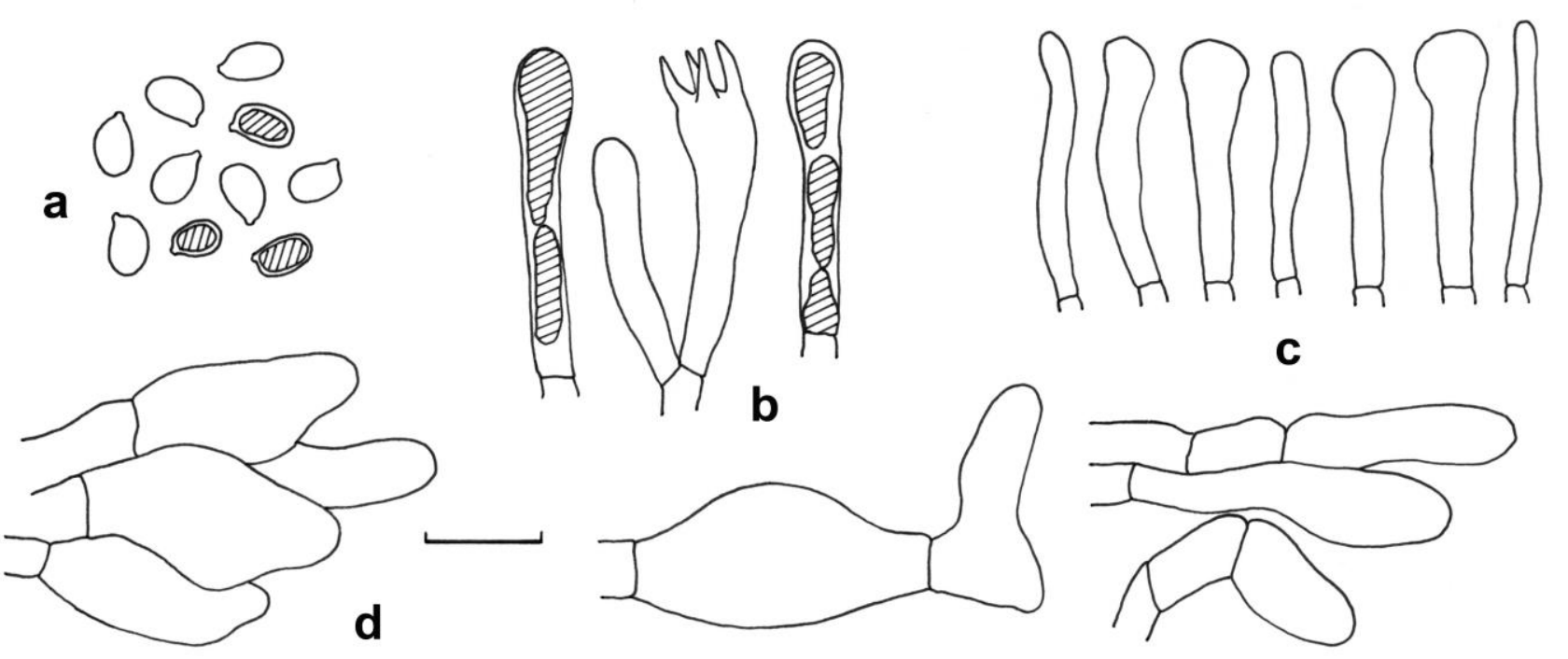

Fig. 11 - Micromorphological features of Callistosporium elegans (Holotype, BAP 617). a. Basidiospores. b. Basidium and basidioles. c. Cheilocystidia. d. Caulocystidia. Scale bar $=10 \mu \mathrm{m}$

Pairwise comparison of aligned, overlapping regions of the ITS sequence of the holotype material with the top 10 BLAST hits, indicate closest similarity to Callistosporium graminicolor Lennox (87.6\%; DQ484065) and an undetermined Callistosporium collection from Tennessee, USA (85.0\%; KUO58492). It should be noted however that few Callistosporium sequences are currently available in public databases. 
Cyptotrama asprata (Berk.) Redhead \& Ginns, Can. J. Bot. 58(6): 731. 1980.

Fig. 12

Basionym: Agaricus aspratus Berk., London J. Bot. 6: 481. 1847.

= Lepiota asprata (Berk.) Sacc., Syll. Fung. (Abellini) 5: 48.1887.

= Mastocephalus aspratus (Berk.) Kuntze, Revis. Gen. Pl. (Leipzig) 2: 859. 1891.

= Armillaria aspratus (Berk.) Petch, Ann. R. Bot. Gdns. Peradeniya 4(6): 386. 1910.

= Xerula asprata (Berk.) Aberdeen, Kew Bull. 16(1): 129. 1962.

= Xerulina asprata (Berk.) Pegler, Kew Bull. 27(1): 196. 1972.

Possible heterotypic synonyms: refer to Pegler (1977, 1986), Redhead and Ginns (1980).

Facesoffungi number: FoF03733

For a description of African material refer to Pegler (1977).

Habitat and known distribution - Solitary to scattered on decaying wood in primary and secondary forests. Old World tropics and the Pacific.

Material examined - AFRICA. Príncipe, Roça Pico Papagaio, N01 37.182', E07²3.474', 21 April 2008, coll. by B.A. Perry and D.E. Desjardin, DED 8294 (MF100957, SFSU). São Tomé, Macambrara, radio antenna area, N00 16.557', E06 36.326', elev. 1300 m, 11 April 2008, coll. by B.A. Perry, DED 8204 (MF100958, SFSU); along road to Bombain, N00¹6.615', E06³8.942', elev. 400 m, 26 April 2008, coll. by D.E. Desjardin, DED 8336 (MF100959, SFSU).

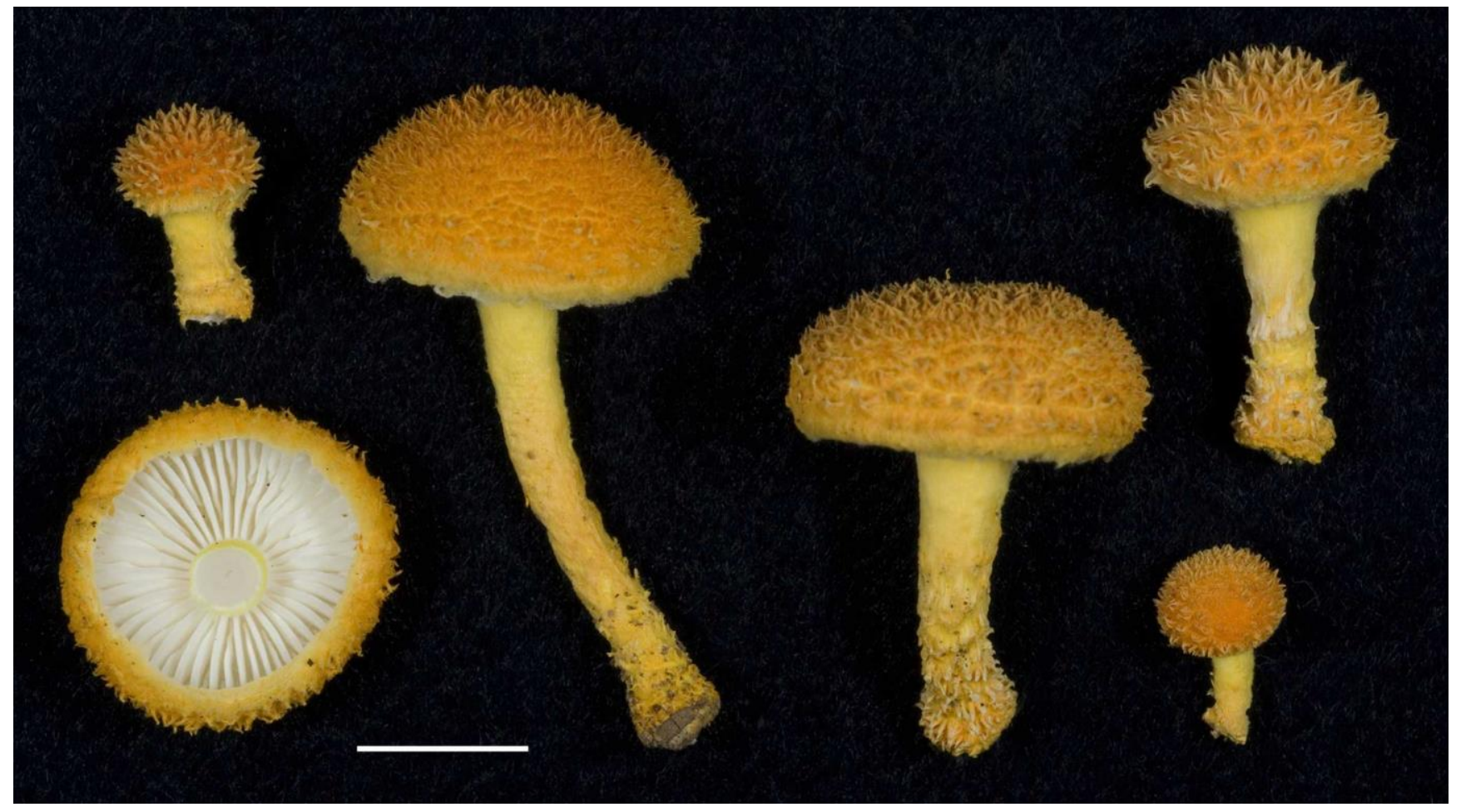

Fig. 12 - Basidiomes of Cyptotrama asprata (DED 8336). Scale bar $=10 \mathrm{~mm}$

Notes - The material of Cyptotrama asprata from São Tomé and Príncipe matches quite nicely that reported from Africa (East Africa, Kenya, South Africa) by Pegler (1977; as Xerulina asprata), and the topotypical material from Sri Lanka described by Pegler (1986; as X. asprata). The pileus is initially deep orange (5-6A7-8) and covered with pyramidal furfuraceous squamules, then fades to pale orange (5A4-5), yellow (4A5-8) and eventually yellowish white to cream (4A2-3) on the margin with a squamulose disc and granulose margin. A recent treatment of Cyptotrama from Asia that used DNA sequences to aid in species recognition (Qin \& Yang 2016), distinguished $C$. asprata from $C$. chrysopepla (Berk. \& M.A. Curtis) Singer, the latter commonly accepted as a synonym of the former, 
as follows: $C$. asprata has subacute hymenial cystidia, an epithelium-type pileipellis, and thin-walled cells of the stipe squamules, whereas $C$. chrysopepla has attenuate hymenial cystidia, a hymenidermtype pileipellis, and thick-walled cells of the stipe squamules. Based on material of $C$. asprata that we have studied from throughout the Old World tropics, the hymenial cystidia are often obtuse but never subcapitate as in $C$. chrysopepla, and the cells of the stipe squamules are never thin-walled. Rather, they are usually solid (which may appear thin-walled) with only a thin line of lumen to thick-walled $(1-4 \mu \mathrm{m})$.

Pairwise comparisons of aligned, overlapping ITS sequences of São Tomé specimens of Cyptotrama asprata with the top ten BLAST results indicate closest similarity (97.2-99\%) to specimens of $C$. asprata from China (KR607174, KR607179, KR607189, KR607192), Korea (KF668296, KF668317) and Martinique (KM588682).

Tricholomopsis aurea (Beeli) Desjardin \& B.A. Perry, comb. nov.

Figs 13, 14a-d

Basionym: Marasmius aureus Beeli, Bull. Soc. R. Bot. Belg. 60(2): 155.1928.

= Collybia aurea (Beeli) Pegler, Kew Bull. 21(3): 516. 1968.

Holotype - AFRICA. Democratic Republic of Congo, Eala, in groups on dead wood in an inundated forest, May 1923, M. Goossens-Fontana 149 (BR 31303-69).

MycoBank: MB821170; Facesoffungi number: FoF03734

Pileus 7-33 mm diam, convex to broadly convex, expanding to plano-convex, shallowly depressed or umbilicate in age; margin decurved, even, not striate, sometimes splitting; surface dull, moist, glabrous, hygrophanous, golden to orangish yellow (4-5A-B6-8), fading with moisture loss to yellow (4A4-5) or light yellow (3A3-4). Context $1 \mathrm{~mm}$ thick, yellow, soft. Lamellae adnate, sometimes with a short decurrent tooth, crowded with 3-5 series of lamellulae, narrow (1-2 mm), deep yellow (4A7-8) to deep orangish yellow (4B7-8). Stipe 10-50 $\times 2-5 \mathrm{~mm}$, central to slightly eccentric, terete or cleft, cylindrical or with a flared apex and narrowed base, hollow, non-insititious; surface dull, dry, mostly glabrous, very apex with minute white pruinae, base with appressed white tomentum, orangish yellow (4-5A-B6-8). Odor mild. Taste mild or faintly like bleach.

Basidiospores 5-6 $(-6.5) \times 4.5-5.2 \mu \mathrm{m}\left[\mathrm{x}_{\mathrm{mr}}=5.5-5.6 \times 4.8 \mu \mathrm{m}, \mathrm{x}_{\mathrm{mm}}=5.5 \pm 0.07 \times 4.8 \pm 0.06\right.$ $\left.\mu \mathrm{m}, \mathrm{Q}=1.1-1.3, \mathrm{Q}_{\mathrm{mr}}=1.13-1.17, \mathrm{Q}_{\mathrm{mm}}=1.15 \pm 0.03, \mathrm{n}=10-20, \mathrm{~s}=2\right]$, subglobose to ovoid or broadly ellipsoid, smooth, hyaline, inamyloid, thin-walled. Basidia 20-25 × 5.5-6.5 $\mu$ m, clavate, 2spored and 4-spored, with sterigmata up to $5.5 \mu \mathrm{m}$ long, hyaline or with yellow amorphous globular contents. Basidioles clavate, hyaline, sometimes with yellow contents. Pleurocystidia absent. Lamellar edge sterile. Cheilocystidia 36-52 × 6-9.5 (-12) $\mu \mathrm{m}$, subcylindrical to clavate, broadly obtuse, hyaline, inamyloid, thin-walled. Pileipellis a cutis of repent, radially arranged, weakly interwoven hyphae 3-10 $\mu \mathrm{m}$ diam, cylindrical, smooth, non-incrusted or with hyaline annular incrustations, non-diverticulate, hyaline to pale yellow, inamyloid, non-gelatinous, thin-walled. Pileus trama interwoven; hyphae 5-13 $(-16) \mu \mathrm{m}$ diam, cylindrical to inflated, smooth, hyaline to pale yellow, inamyloid, non-gelatinous, thinwalled. Lamellar trama subparallel; hyphae $2.5-8 \mu \mathrm{m}$, cylindrical or inflated up to $12 \mu \mathrm{m}$ diam, hyaline to pale yellow, inamyloid, non-gelatinous, thin-walled; with scattered yellow oleiferous hyphae. Stipitipellis a cutis; cortical hyphae 3-7 $\mu \mathrm{m}$ diam, cylindrical, smooth, hyaline to yellow, inamyloid, non-gelatinous, thin-walled; medullary hyphae similar but 3-10 $\mu \mathrm{m}$ diam, cylindrical or inflated. Caulocystidia scattered or clustered on stipe apex, 43-64 $\times 5.5-8 \mu \mathrm{m}$, irregularly cylindrical to clavate, hyaline, thin-walled. Clamp connections present.

Habitat and known distribution - Scattered to gregarious on rotten wood in primary forest. Pantropical; Africa (DR Congo, Kenya, São Tomé, Tanzania, Uganda, Zaire), Caribbean (Guadeloupe, Martinique, Trinidad).

Material examined - AFRICA. São Tomé, Macambrara, radio antenna area, $1300 \mathrm{~m}$ elev., N00¹6.557', E06 36.326', 25 April 2008, coll. by D.E. Desjardin, DED 8327 (nLSU-MF100993, 


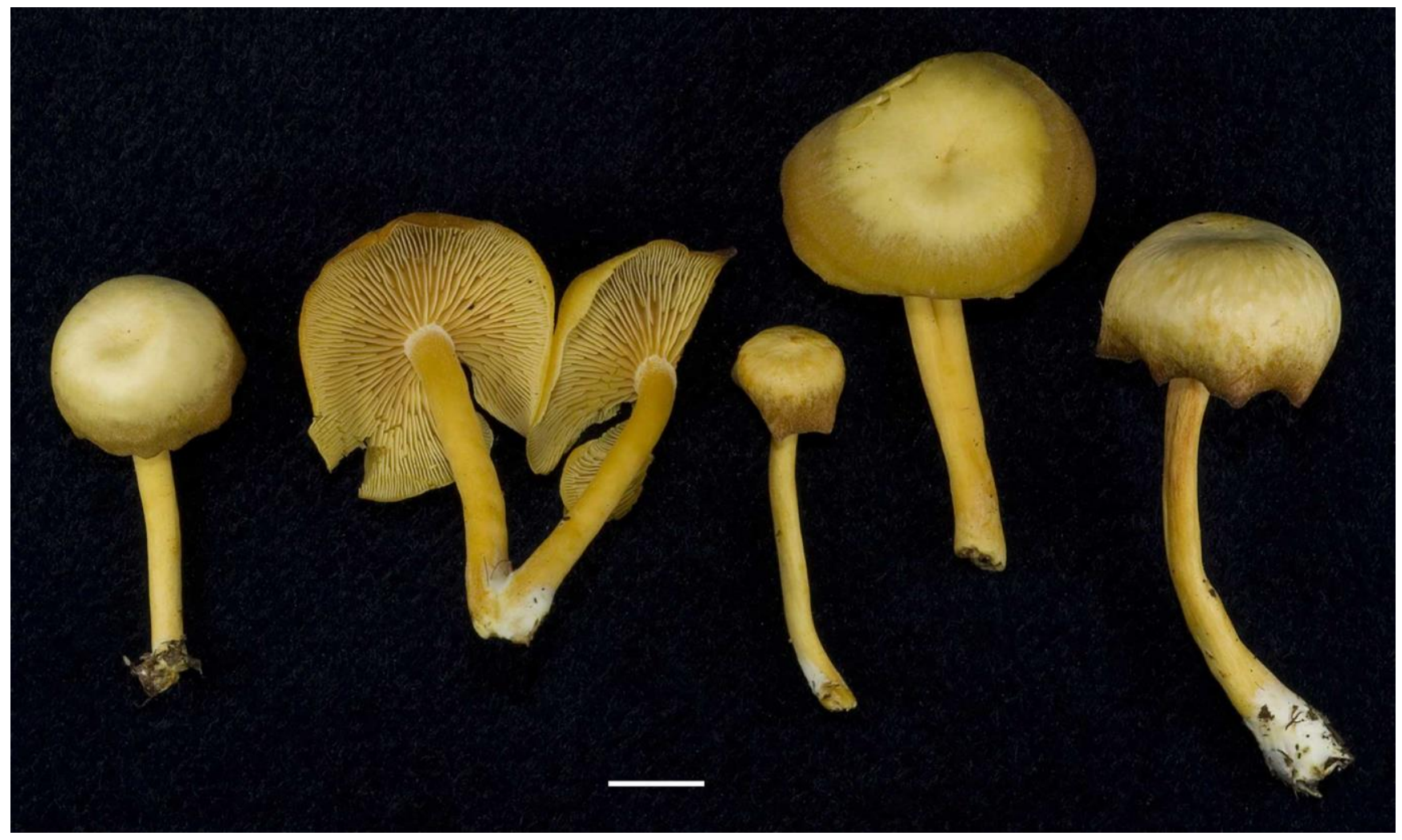

Fig. 13 - Basidiomes of Tricholomopsis aurea $($ DED 8327). Scale bar $=10 \mathrm{~mm}$

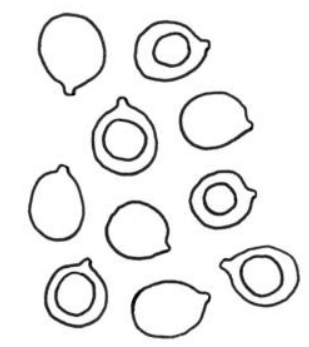

a

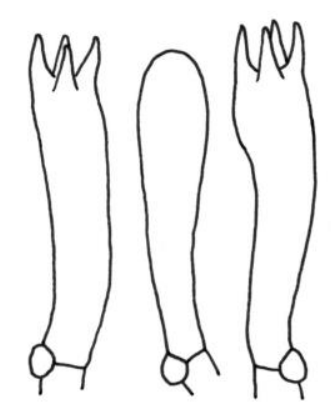

b
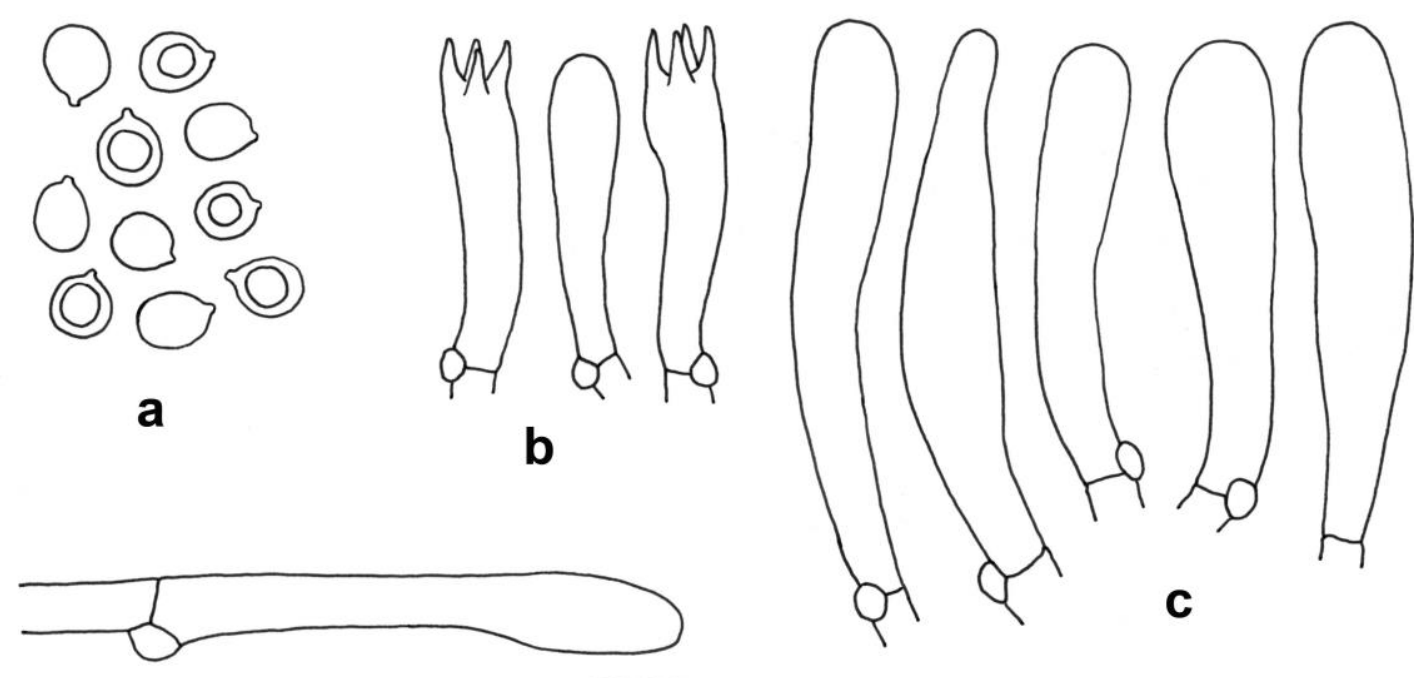

C
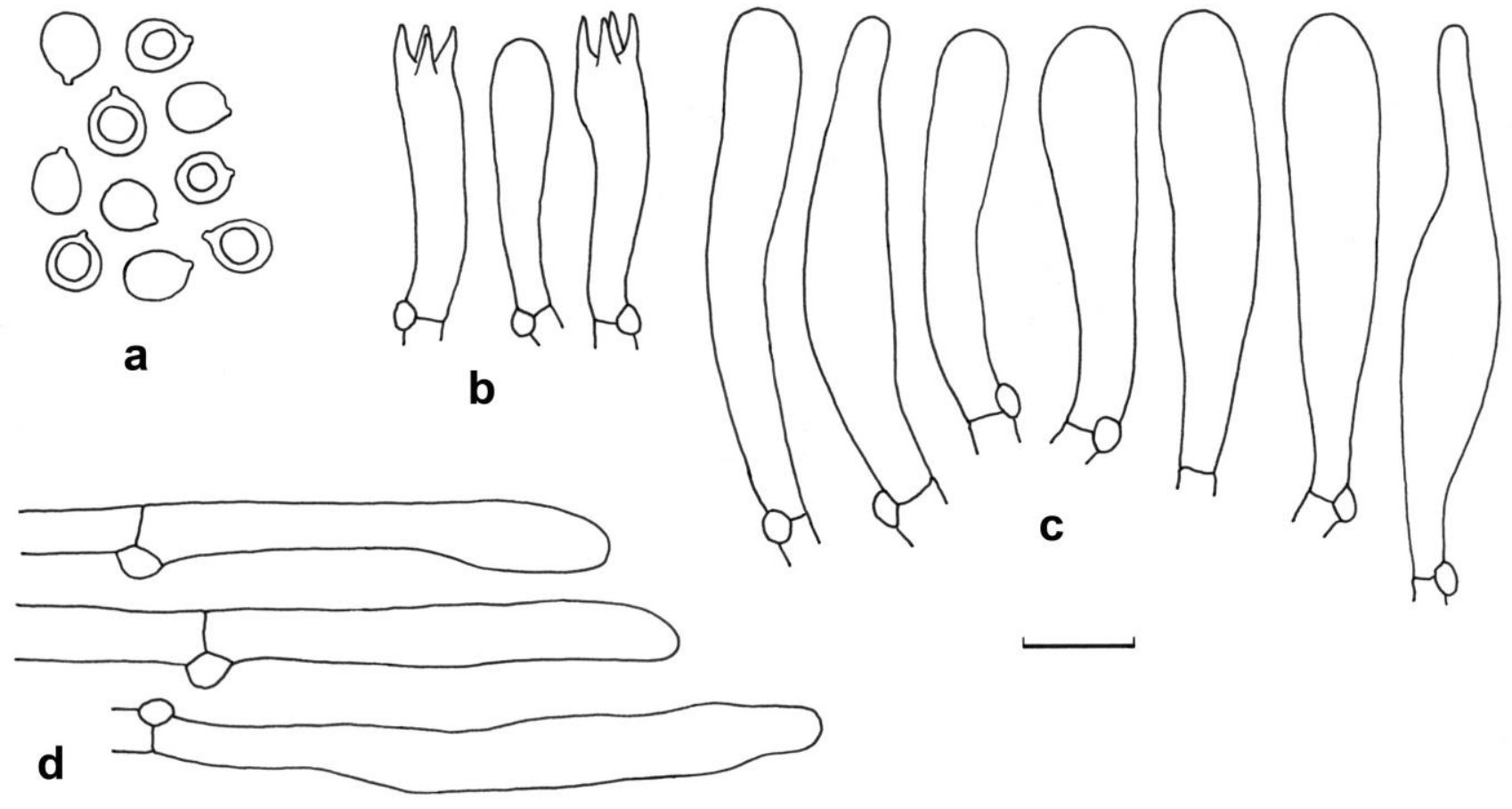

Fig. 14 - Micromorphological features of Tricholomopsis aurea (DED 8327, BAP 618). a. Basidiospores. b. Basidia and basidiole. c. Cheilocystidia. d. Caulocystidia. Scale bar $=10 \mu \mathrm{m}$ 
ITS-MF100960, SFSU); Parque Nacional Obo, along trail from Bom Succeso to Lagoa Amelia,

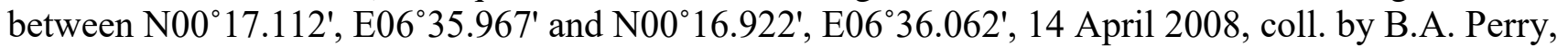
BAP 618 (nLSU-MF100994, ITS-MF100961, SFSU).

Notes - Marasmius aureus was described originally from Eala, DR Congo, and the material from São Tomé matches quite nicely with that reported in the protologue (Beeli 1928). Pegler (1968) transferred the species to Collybia, but the latter genus is now restricted to species allied with $C$. tuberosa (Bull.) P. Kumm., which form small, white basidiomes that arise from sclerotia. The micromorphology of this golden species is more similar to the genus Tricholomopsis, as first suggested by Dennis (1970: 27), with subglobose, inamyloid basidiospores, large, clavate cheilocystidia, and a cutis-type pileipellis. Moncalvo et al. (2002) were the first to show a sister relationship between Collybia aurea and Tricholomopsis rutilans, based on nLSU sequences of New World specimens. Their nLSU sequence of $C$. aurea (AF261403) was from a specimen collected in Puerto Rico (RV.PR98/27; DUKE), which has 99.5-99.8\% sequence similarity to the two São Tomé specimens cited above. Pairwise comparisons of aligned, overlapping ITS sequences of $C$. aurea with the top ten BLAST results indicate $96.8-99.2 \%$ similarity to "uncultured fungus" sequences, and 91.1-91.6\% similarity to Tricholomopsis sp. (KP012806). The "uncultured fungus" sequence with $99.2 \%$ similarity (KU2012-31) was from material isolated from a decayed stump of Anthosthema aubryanum (Euphorbiaceae) in Gabon, a substrate and region likely to host $C$. aurea. Pairwise comparisons of aligned, overlapping nLSU sequences of $C$. aurea with the top ten BLAST results indicate 95.2-95.6\% similarity with sequences of Tricholomopsis decora (Fr.) Singer and T. rutilans (Schaeff.) Singer. Rather than retain $C$. aurea in Collybia where it surely does not belong, given that it shows closer molecular and morphological similarity to Tricholomopsis than to other known genera, and lacking substantial supportive data to erect a new genus for $C$. aurea, we formally transfer the taxon as Tricholomopsis aurea.

Trogia infundibuliformis Berk. \& Broome, J. Linn. Soc., Bot. 14(73): 45. 1873 (1875).

Potential heterotypic synonyms: refer to Corner (1966), Pegler (1986)

Figs 15, 16a-c

Facesoffungi number: FoF03735

Pileus 15-70 mm diam, infundibuliform, perforate, striate to sulcate; surface moist to dry, dull, glabrous, hygrophanous, faintly radially streaked, pale greyish red (7-8B3) with a hint of violet, with slightly darker streaks. Context $<1 \mathrm{~mm}$ thick, rubbery-pliant, concolorous with pileus surface. Lamellae long-decurrent, distant to remote with 2-3 series of lamellulae, narrow $(0.5-1.5 \mathrm{~mm})$, not intervenose, not forked, dingy buff to pale greyish red (7-8B3). Stipe 15-40 $\times 2-5 \mathrm{~mm}$, central to eccentric, terete, seldom longitudinally cleft, centrally cylindrical with a flared apex and subbulbous base, tough, pliant, hollow, subinsititious; surface dull, dry, glabrous, greyish red (8C3) or darker. Odor pleasant.

Basidiospores 8-9.6 × 4.5-5.4 $\mu \mathrm{m}\left[\mathrm{x}_{\mathrm{m}}=8.71 \pm 0.53 \times 4.96 \pm 0.29 \mu \mathrm{m}, \mathrm{Q}=1.6-1.9, \mathrm{Q}_{\mathrm{m}}=1.76 \pm\right.$ $0.05, \mathrm{n}=12, \mathrm{~s}=1]$, ellipsoid, smooth, hyaline, inamyloid, thin-walled. Basidia 32-38 $\times 7-8.5 \mu \mathrm{m}$, clavate, 4-spored. Basidioles clavate. Pleurocystidia absent. Lamellar edge fertile. Cheilocystidia clustered, inconspicuous, 19-32 × 4.8-8 $\mu \mathrm{m}$, basidiole-like, cylindrical to clavate, hyaline, thin-walled. Pileipellis a cutis of repent hyphae with a few, erect, cylindrical to irregularly clavate outgrowths 3-15 $\times 2.5-5 \mu \mathrm{m}$; hyphae 2.5-5 $\mu \mathrm{m}$ diam, cylindrical, hyaline, inamyloid, non-incrusted, non-gelatinous. Pileus trama and lamellar trama sarcodimitic; hyphae 2.2-5 $\mu \mathrm{m}$ diam, cylindrical, branched, and 8-24 $\mu \mathrm{m}$ diam, fusiform, hyaline, inamyloid, non-gelatinous, thin- to thick-walled. Stipitipellis like the pileipellis, with scattered outgrowths; medullary hyphae sarcodimitic, with cylindrical cells $2.5-5 \mu \mathrm{m}$ diam, and fusiform cells 5-24 $\mu \mathrm{m}$ diam, hyaline, inamyloid, non-gelatinous, thin-walled or with walls up to $2 \mu \mathrm{m}$ thick. Caulocystidia absent. Clamp connections present. 
Habitat and known distribution - Scattered to gregarious on wood in secondary forest. Africa (Príncipe, Uganda, Zaire), Malaysia, Sri Lanka, Thailand.

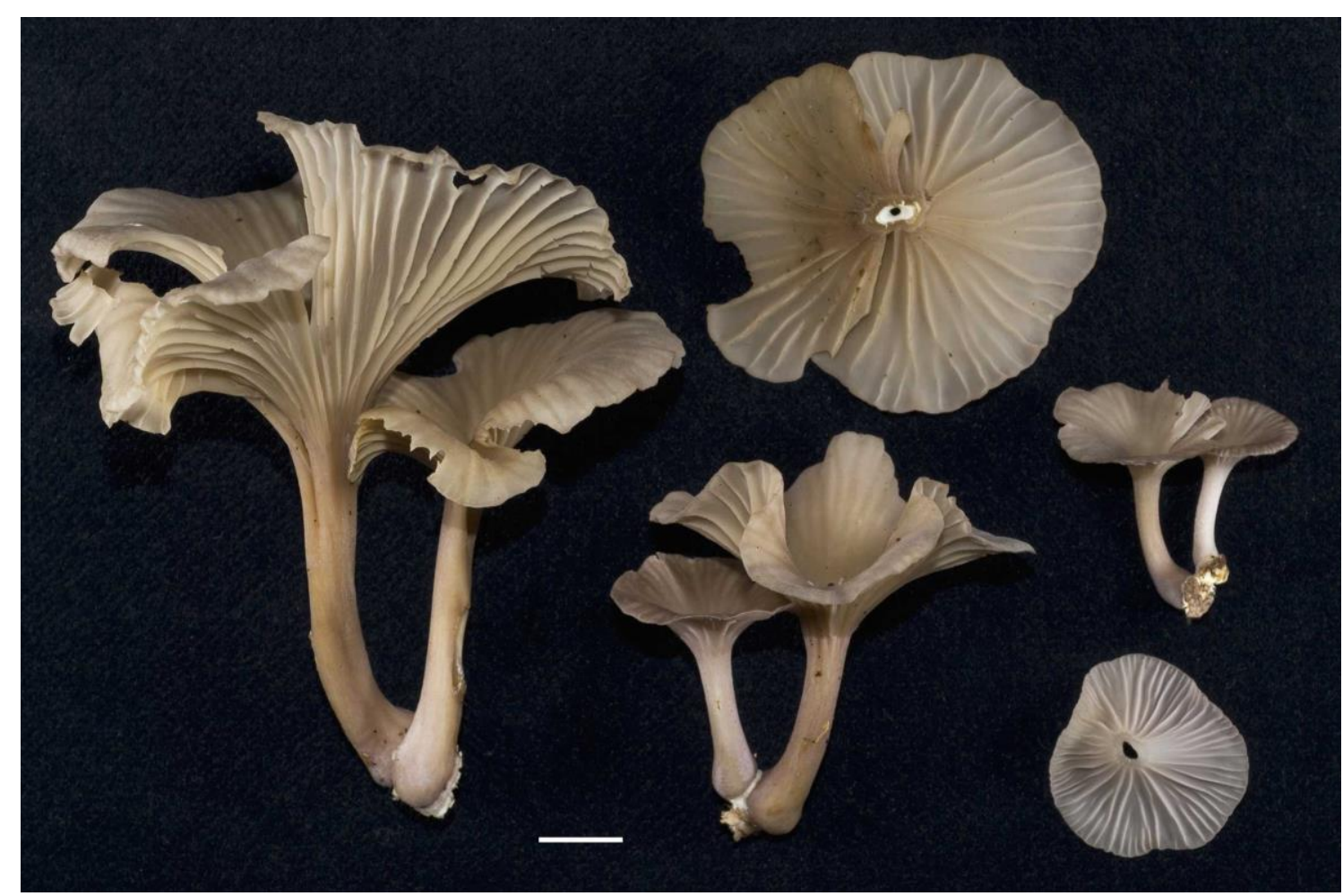

Fig. 15 - Basidiomes of Trogia infundibuliformis (DED 8286). Scale bar $=10 \mathrm{~mm}$

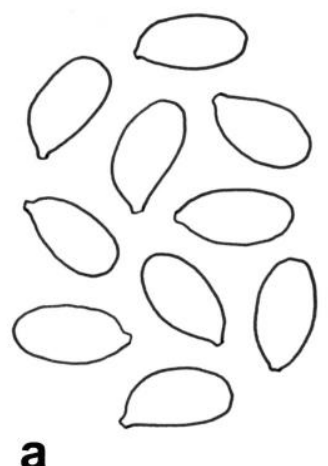

b
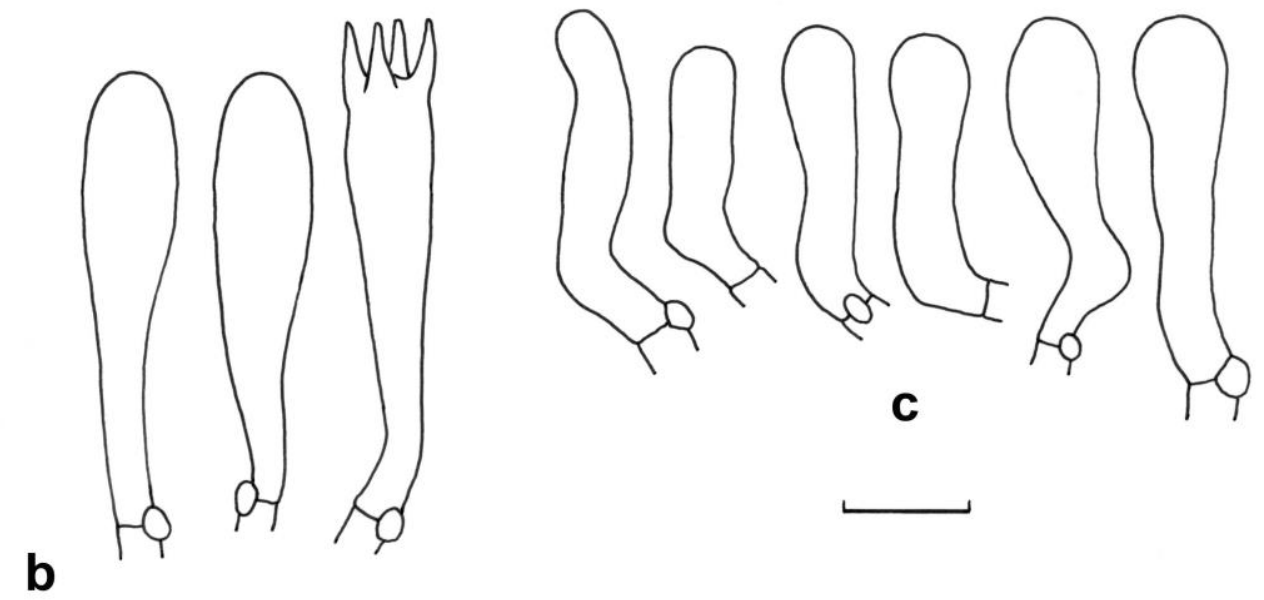

Fig. 16 - Micromorphological features of Trogia infundibuliformis (DED 8286). a. Basidiospores. b. Basidium and basidioles. c. Cheilocystidia. Scale bar $=10 \mu \mathrm{m}$

Material examined - AFRICA. Príncipe, Roça Pico Papagaio, N01 37.182', E07²3.474', 21 April 2008, coll. by D.E. Desjardin, DED 8286 (SFSU).

Notes - Trogia infundibuliformis, described from Sri Lanka, is paleotopical in distribution, and easily recognized by the large, deeply infundibuliform, rubbery-pliant basidiomes with pale greyish red 
to pinkish violet, perforate pileus, very narrow, deeply decurrent lamellae, basidiospores in the range (6.3-) 7-9.6 × 4.5-6 $\mu \mathrm{m}$, sarcodimitic tissues, inconspicuous cheilocystidia, and lacks pleurocystidia, pileocystidia and caulocystidia. The Príncipe material matches nicely that reported from Africa (Pegler 1977), Sri Lanka (Pegler 1986) and tropical Asia (Corner 1966), but has basidiospores at the larger end of the range. Although the type species of the genus Trogia Fr. (Cantharellus aplorutis Mont. = Trogia montagnei Fr.) from India is poorly known, T. infundibuliformis is one of the species most phenetically similar to the protologue of Trogia, representing what we recognize as the core morphotype for the genus. Repeated attempts to obtain quality DNA sequences from DED 8286 were unsuccessful.

Trogia anthidepas (Berk. \& Broome) Corner, Monogr. Cantharelloid Fungi: 195. 1966.

Basionym: Agaricus anthidepas Berk. \& Broome, J. Linn. Soc., Bot. 11(56): 527. 1871

Figs $17,18 \mathrm{a}-\mathrm{f}$

= Omphalia anthidepas (Berk. \& Broome) Sacc., Syll. Fung. (Abellini) 5: 325. 1887.

= Hydropus anthidepas (Berk. \& Broome) Singer, Fl. Neotrop. Monogr. 32: 53. 1982.

Potential heterotypic synonyms: refer to Corner (1966), Pegler (1986).

Facesoffungi number: FoF03736

Pileus 35-50 mm diam, convex, becoming plane-depressed to shallowly umbilicate, pellucidstriate, margin decurved to straight; surface dull, dry, glabrous, hygrophanous, yellowish brown (5E45) to light yellowish brown (5D5-6) with olive tones, with darker radial streaks. Context $\leq 1 \mathrm{~mm}$ thick, rubbery-pliant, pale yellowish olive. Lamellae decurrent to adnate with a decurrent tooth, distant with 3-4 series of lamellulae, broad (2-3 mm), strongly intervenose to reticulate at maturity, pale yellowish white (4A2) to greyish yellow (4B4-5). Stipe 25-35 × 3-5 mm, central, terete, cylindrical above a subbulbous base, tough, pliant, hollow, subinsititious; surface dull, dry, glabrous, apex off-white, greyish yellow (4B4-5) at the base.

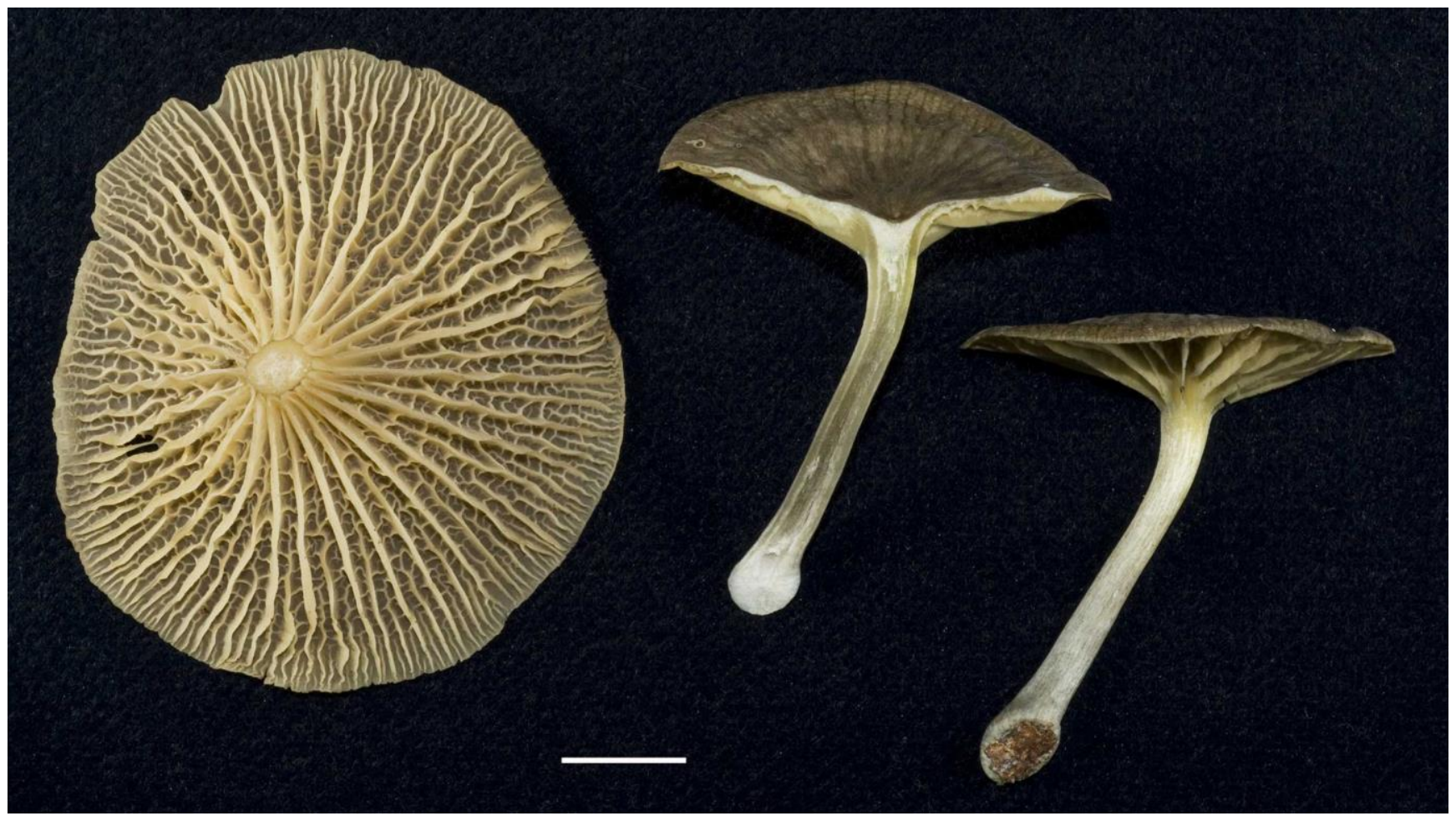

Fig. 17 - Basidiomes of Trogia anthidepas (DED 8291). Scale bar $=10 \mathrm{~mm}$ 
Basidiospores 7-8.3 × 4.2-4.8 $\mu \mathrm{m}\left[\mathrm{x}_{\mathrm{m}}=7.68 \pm 0.42 \times 4.41 \pm 0.2 \mu \mathrm{m}, \mathrm{Q}=1.6-1.8, \mathrm{Q}_{\mathrm{m}}=1.74 \pm\right.$ $0.07, \mathrm{n}=20, \mathrm{~s}=1]$, ellipsoid, smooth, hyaline, inamyloid. Basidia 30-36 $\times 6.5-7 \mu \mathrm{m}$, clavate, 2spored and 4-spored. Basidioles clavate. Pleurocystidia inconspicuous, scattered, often collapsed, 37$54 \times 5-7 \mu \mathrm{m}$, cylindrical to clavate, arising from just below the subhymenium, not projecting above basidia, with hyaline (apex) to greyish brown (base) walls. Lamellar edge fertile. Cheilocystidia clustered, scattered, 24-52 $\times 6.5-8 \mu \mathrm{m}$, cylindrical to clavate, hyaline, thin-walled. Pileipellis a cutis of radially arranged hyphae $3-5 \mu \mathrm{m}$ diam, cylindrical, non-diverticulate, giving rise to scattered, clustered or solitary pileocystidia $25-50 \times 7-11 \mu \mathrm{m}$, cylindrical, clavate or ventricose, similar to the cheilocystidia but with brown contents. Pileus trama and lamellar trama sarcodimitic; hyphae 3-5 $\mu \mathrm{m}$ diam, cylindrical, and 5-18 $\mu \mathrm{m}$ diam, fusiform, hyaline, inamyloid, thin-walled, non-gelatinous. Stipe cortical hyphae 2-8 $\mu \mathrm{m}$ diam, parallel, cylindrical, hyaline, inamyloid, non-gelatinous, thin- to thickwalled; medullary hyphae sarcodimitic, with long fusiform cells up to $20 \mu \mathrm{m}$ diam and shorter cylindrical hyphae 2-5 $\mu \mathrm{m}$ diam. Caulocystidia abundant, clustered, 19-40 $\times 5-7 \mu \mathrm{m}$, subcylindrical to clavate or irregular in outline, hyaline or with brown contents, thin-walled. Clamp connections present.

Habitat and known distribution - Solitary on woody debris in secondary forest. Africa (Príncipe), Malaysia, Singapore, Sri Lanka,

Material examined - AFRICA. Príncipe, Roça Pico Papagaio, N01³7.182', E07²3.474', 21 April 2008, coll. by D.E. Desjardin, DED 8291 (SFSU).

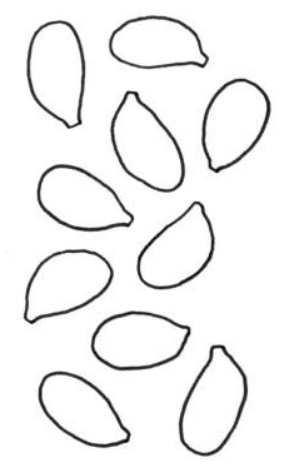

a
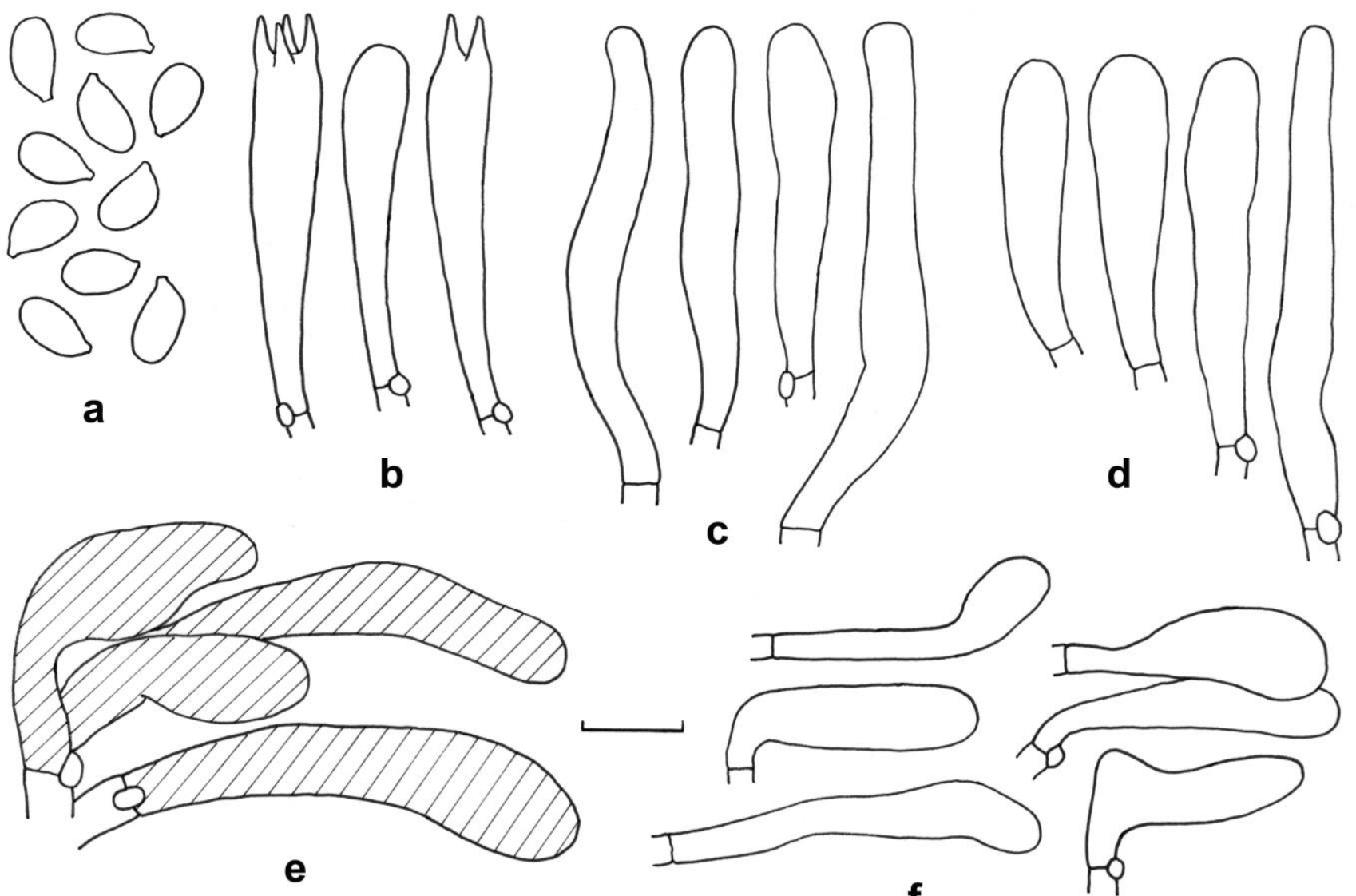

Fig. 18 - Micromorphological features of Trogia anthidepas (DED 8291). a. Basidiospores. b. Basidia and basidiole. c. Pleurocystidia. d. Cheilocystidia. e. Pileocystidia. f. Caulocystidia. Scale bar $=10 \mu \mathrm{m}$ 
Notes - Trogia anthidepas was described originally from Sri Lanka. It is variable in size and coloration and has been described independently at least four times (see synonymy reported by Pegler 1986). The Príncipe specimen matches nicely the Malaysian material reported by Corner (1966), differing subtly in a few features. Our material forms basidiospores at the shorter end of the range, and has very inconspicuous pleurocystidia. In comparison Corner (1966) reported the basidiospores as 7$10 \times 4-5.5 \mu \mathrm{m}$, and the species as lacking pleurocystidia. Pegler (1986) recognizes the species as belonging to the genus Hydropus, and reported the basidiospores with mean $8 \times 4.7 \mu \mathrm{m}$, and no pleurocystidia. Repeated attempts to obtain quality DNA sequences from DED 8291 were unsuccessful.

Trogia aff. brevipes Corner, Gdns' Bull., Singapore, Suppl. 2: 20. 1991.

Figs 19, 20a-e

Facesoffungi number: FoF03737

Pileus 12-22 mm diam, convex, umbilicate becoming plane-umbilicate, margin decurved, striate; surface dull, dry, glabrous, radially streaked, yellowish brown (5E6-8) with a hint of olive, with darker streaks, in age becoming dark yellowish brown (5-6F6-8) overall. Context $<1 \mathrm{~mm}$ thick, pliant,

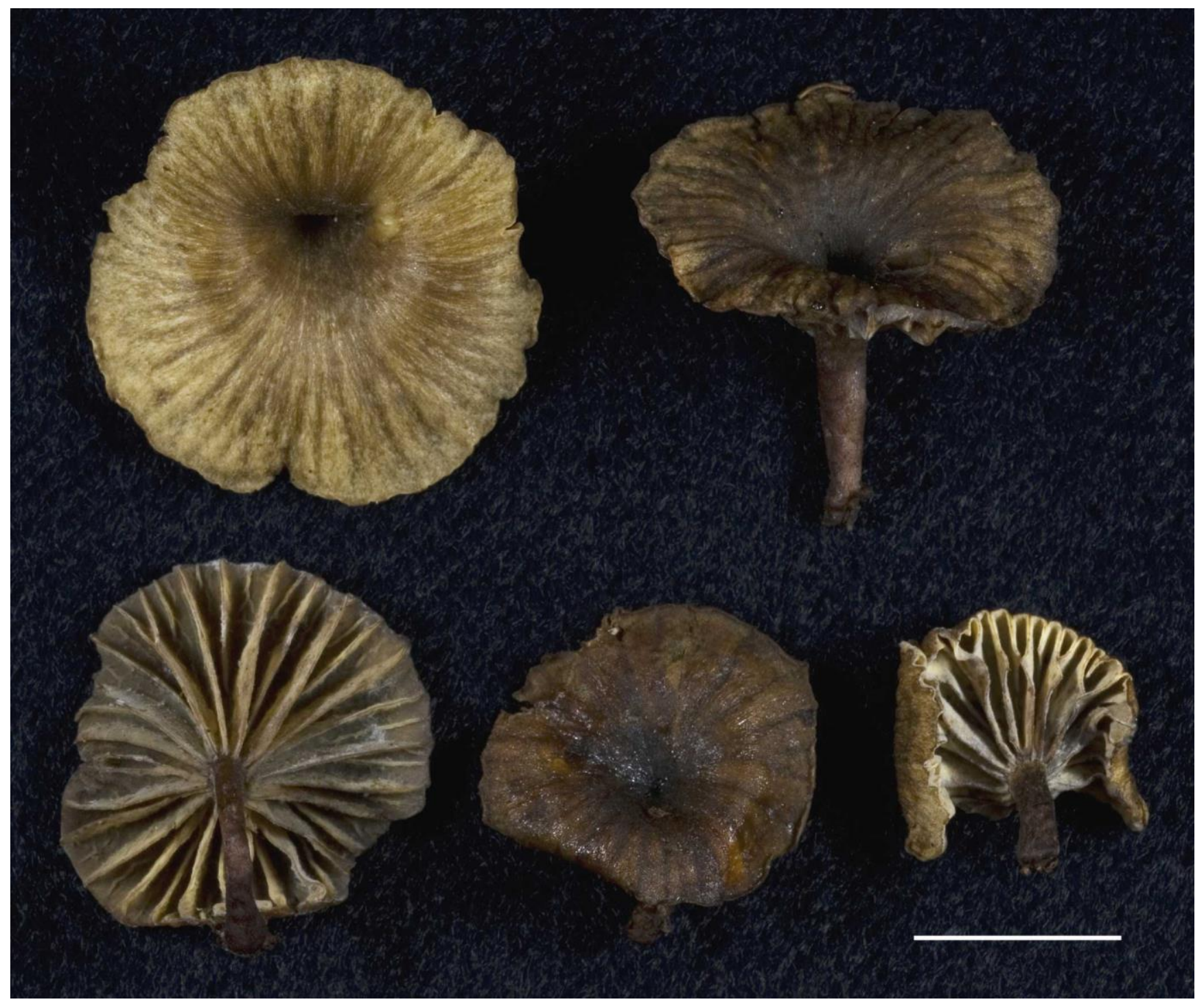

Fig. 19 - Basidiomes of Trogia aff. brevipes (DED 8241). Scale bar $=10 \mathrm{~mm}$ 
concolorous with pileus surface. Lamellae decurrent, subdistant (16-23) with 1-2 series of lamellulae, brown (1-3 mm), yellowish brown (5D6-8). Stipe 7-10 × 1-3 mm, central to eccentric, cylindrical or slightly narrowed downward, curved, tough, hollow, subinsititious; surface dull, dry, glabrous, yellowish brown (5D6-8) to dark yellowish brown (5-6F6-8). Basidiomes entirely yellowish brown with a hint of olive in age.

Basidiospores 7.4-9 × 4.5-5.5 $\mu \mathrm{m}\left[\mathrm{x}_{\mathrm{m}}=7.85 \pm 0.39 \times 4.82 \pm 0.34 \mu \mathrm{m}, \mathrm{Q}=1.5-1.8, \mathrm{Q}_{\mathrm{m}}=1.63 \pm\right.$ $0.07, \mathrm{n}=20, \mathrm{~s}=1$ ], ellipsoid, smooth, inamyloid, thin-walled. Basidia 32-40 $\times 7-8 \mu \mathrm{m}$, clavate, 4spored. Basidioles clavate. Pleurocystidia absent. Lamellar edge fertile. Cheilocystidia scattered, 35$43 \times 6-9 \mu \mathrm{m}$, subcylindrical to clavate or subventricose, hyaline, thin-walled. Pileipellis a cutis with scattered pileocystidia; hyphae 2.5-5 $\mu \mathrm{m}$ diam, cylindrical, non-diverticulate, hyaline or with brown contents, inamyloid, non-incrusted, non-gelatinous; pileocystidia 35-56 × 8-13.5 $\mu \mathrm{m}$, subcylindrical to clavate or ventricose, walls hyaline to brown, with brown contents, inamyloid, thin- to thick-walled. Pileus trama and lamellar trama sarcodimitic; hyphae 2.5-5 $\mu \mathrm{m}$ diam, cylindrical, and 5-16 mm diam, fusiform, hyaline, inamyloid, non-gelatinous. Stipe cortical hyphae 2.5-10 $\mu \mathrm{m}$ diam, cylindrical, parallel, hyaline to pale brown, inamyloid, thin-walled; medullary hyphae sarcodimitic, with cylindrical cells $2.5-10 \mu \mathrm{m}$ diam and fusiform cells up to $25 \mu \mathrm{m}$ diam, hyaline, inamyloid, nongelatinous, thin-walled. Caulocystidia scattered to clustered, 25-65 $\times 6.5-13 \mu \mathrm{m}$, subcylindrical to clavate, ventricose or irregular in outline, yellowish brown, thin-walled. Clamp connections present.

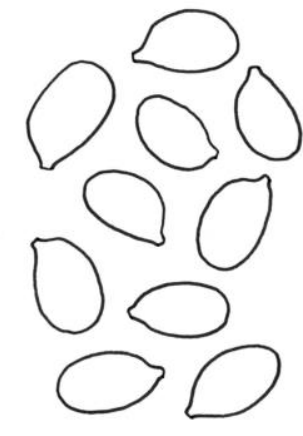

a

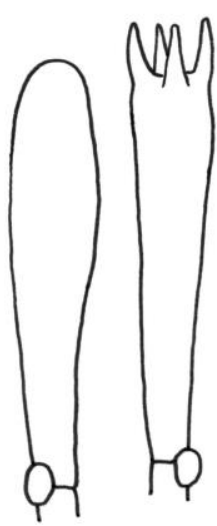

b
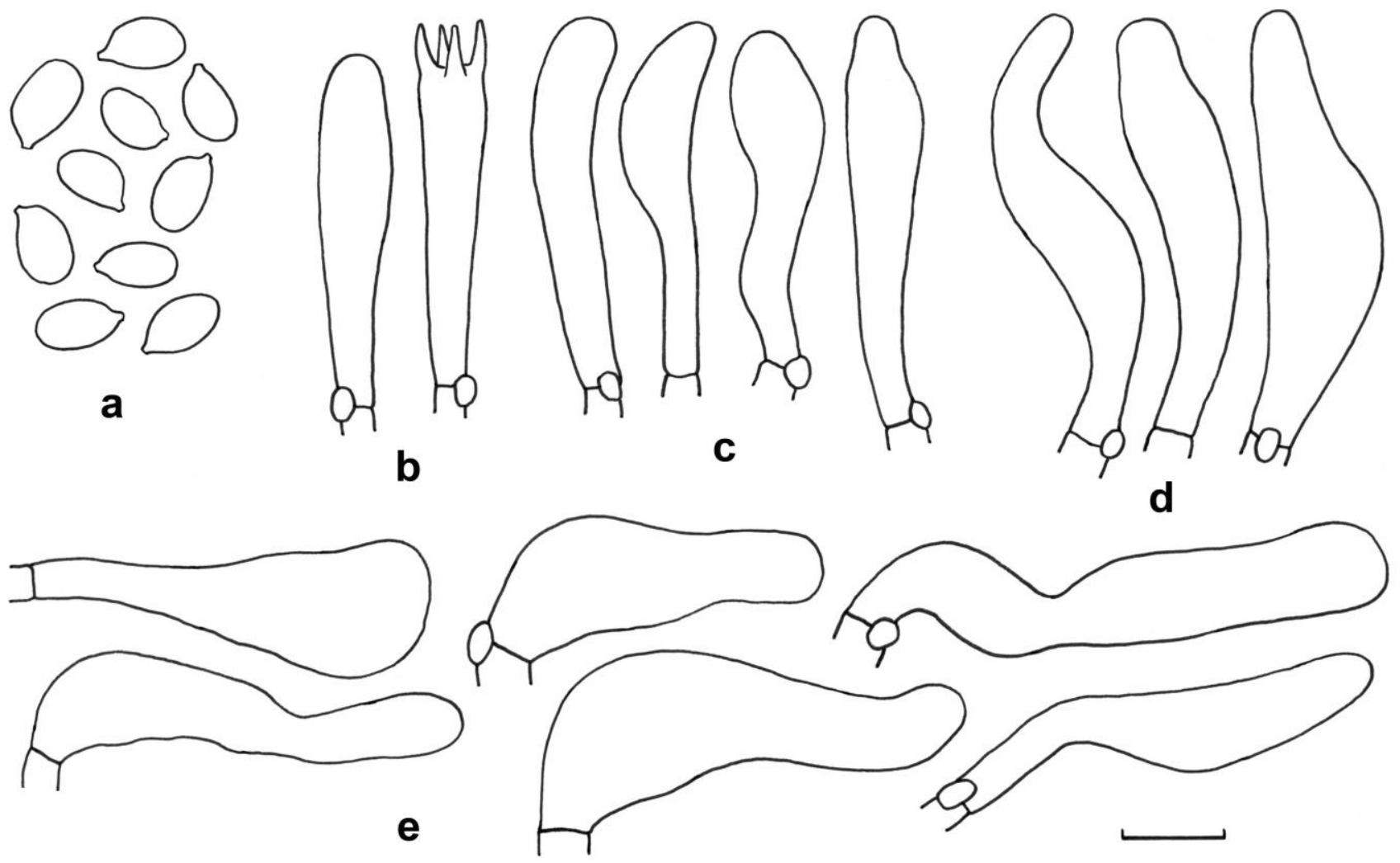

Fig. 20 - Micromorphological features of Trogia aff. brevipes (DED 8241). a. Basidiospores. b. Basidium and basidiole. c. Cheilocystidia. d. Pileocystidia. e. Caulocystidia. Scale bar $=10 \mu \mathrm{m}$

Habitat and known distribution - Scattered on woody debris in primary forest. Africa (São Tomé), Borneo.

Material examined - AFRICA. São Tomé, Parque Nacional Obo, on trail to Lagoa Amelia, 
between ${ }^{0} 00^{\circ} 17.112^{\prime}$, E06 35.967' and N00 16.922', E06 36.062', 14 April 2008, coll. by D.E. Desjardin, DED 8241 (SFSU).

Notes - Trogia aff. brevipes is characterized by rather small, yellowish-olivaceous brown basidiomes with deeply umbilicate-striate pileus, subdistant, broad lamellae, a short glabrous stipe, basidiospores with mean $7.8 \times 4.8 \mu \mathrm{m}$, subcylindrical to clavate cystidia on lamellae edges, pileipellis and stipitipellis, no pleurocystidia, sarcodimitic tissues, and growth on woody debris. Trogia brevipes, described from Borneo, is indistinguishable micromorphologically but differs subtly in forming more obviously pruinose pileus and stipe surfaces, and has narrower and more crowded lamellae. A side-byside comparison with Trogia aff. furcata reveals nearly indistinguishable micromorphology, but the latter forms paler basidiomes lacking olive tones, and has a forked to venose-reticulate hymenophore at maturity. Repeated attempts to obtain quality DNA sequences from DED 8241 were unsuccessful.

Trogia aff. furcata Corner, Monogr. Cantharelloid Fungi: 210. 1966.

Figs $21,22 \mathrm{a}-\mathrm{c}$

Facesoffungi number: FoF03738

Pileus 10-18 mm diam, broadly convex-umbilicate to shallowly infundibuliform, margin striate, wavy, often lobed; surface dull, dry, glabrous, radially streaked, disc and streaks yellowish brown (5E5-6), elsewhere pale greyish yellow (4B3-5) to cream-buff, in age darkening overall to dark yellowish brown (5F4-8). Context $<1 \mathrm{~mm}$ thick, pliant, pale greyish yellow (4B3). Lamellae decurrent, close to subdistant with 2-3 series of lamellulae, often forked or anastomosing, venose-reticulate in age, narrow $(0.5-1 \mathrm{~mm})$, nearly white when young, becoming dingy pale yellowish grey in age. Stipe 15-30 × 1-3 mm, central to eccentric, terete or compressed, tough, hollow, subinsititious; surface dull, dry, glabrous; apex greyish yellow (4B3-4), base dark brown to black. Odor strongly fungal.

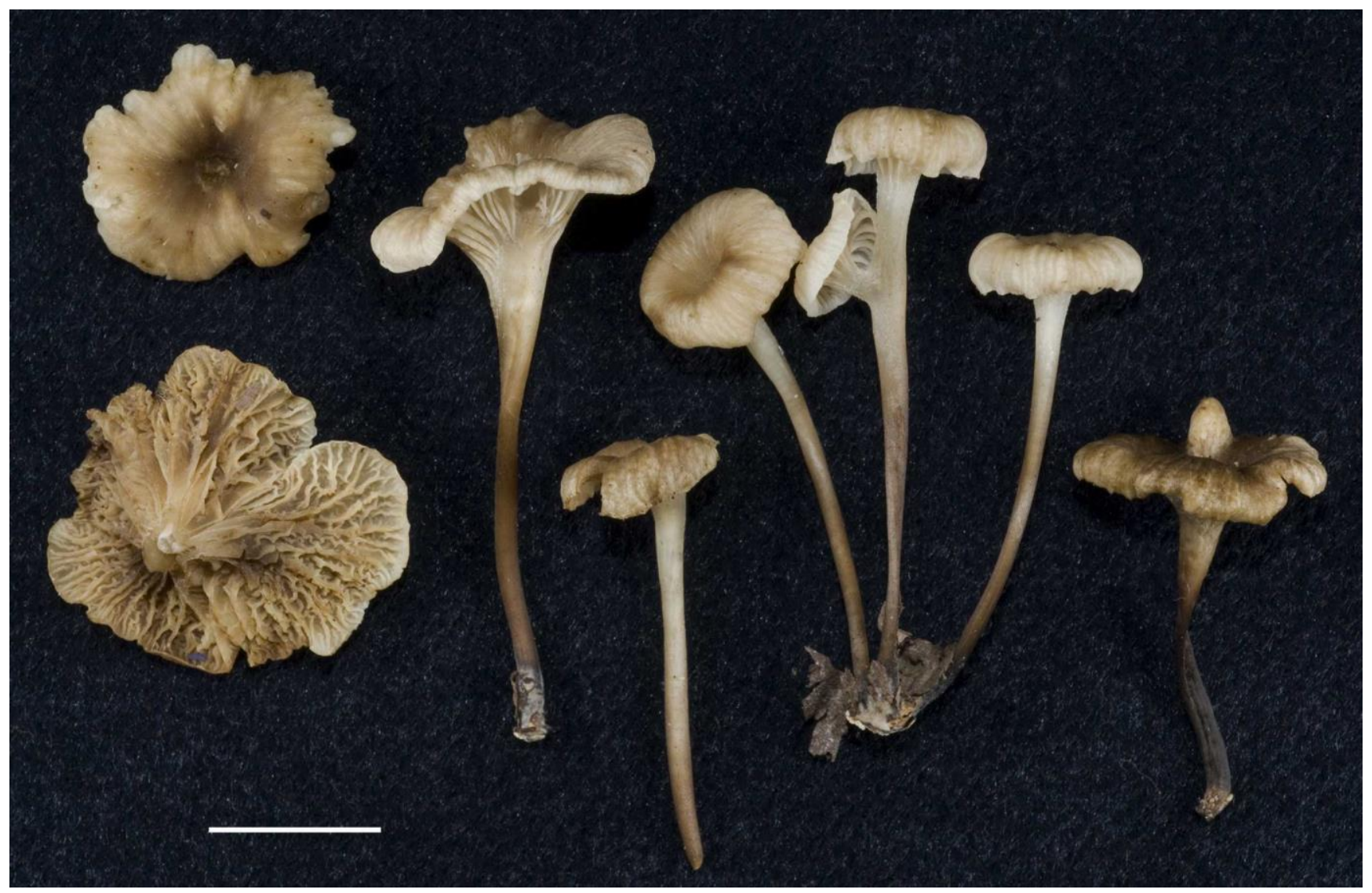

Fig. 21 - Basidiomes of Trogia aff. furcata (DED 8260). Scale bar $=10 \mathrm{~mm}$ 
Basidiospores 7.4-8.5 × 4.2-5.5 $\mu \mathrm{m}\left[\mathrm{x}_{\mathrm{m}}=8.05 \pm 0.4 \times 5.14 \pm 0.33 \mu \mathrm{m}, \mathrm{Q}=1.5-1.7, \mathrm{Q}_{\mathrm{m}}=1.57 \pm\right.$ $0.08, \mathrm{n}=20, \mathrm{~s}=1]$, ellipsoid, smooth, hyaline, inamyloid. Basidia 25-38 $\times 7-8 \mu \mathrm{m}$, clavate, 4-spored with sterigmata up to $8 \mu \mathrm{m}$ long, many 2 -spored with sterigmata up to $12 \mu \mathrm{m}$ long, few 1- or 3-spored. Basidioles clavate. Pleurocystidia absent. Lamellar edge sterile near the margin of pileus, fertile elsewhere. Cheilocystidia 22-36 (-52) $\times 4-9.5 \mu \mathrm{m}$, irregularly cylindrical to subclavate or ventricose, hyaline. Pileipellis a cutis of repent hyphae 3-8 $\mathrm{m}$ diam, cylindrical, non-diverticulate, hyaline to yellow, non-incrusted, non-gelatinous; pileocystidia absent or few, similar to the cheilocystidia. Hypodermium absent. Pileus trama and Lamellar trama sarcodimitic; hyphae 2.5-5 $\mu \mathrm{m}$ diam, cylindrical, and 5-13 $\mu \mathrm{m}$ diam, fusiform, hyaline, inamyloid, non-gelatinous. Stipe cortical hyphae 2.5-8 $\mu \mathrm{m}$ diam, cylindrical, hyaline, inamyloid, non-gelatinous; medullary hyphae sarcodimitic, with cylindrical hyphae 2.5-5 $\mu \mathrm{m}$ diam, and fusiform hyphae 5-16 $\mu \mathrm{m}$ diam, hyaline, inamyloid, thinwalled. Caulocystidia few, scattered or clustered, similar to the cheilocystidia. Clamp connections present.

Habitat and known distribution - Gregarious on rotten wood in coastal secondary forest. Africa (São Tomé), Brunei.

Material examined - AFRICA. São Tomé, Shipwreck Cove, along EN-1 on north side of the island at $18 \mathrm{~km}$ marker, N00²3.687', E06 36.302', 17 April 2008, coll. by D.E. Desjardin. DED 8260 (MF100962, SFSU).

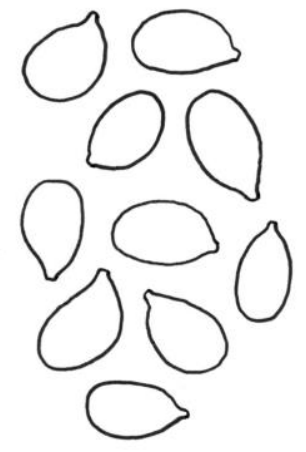

a

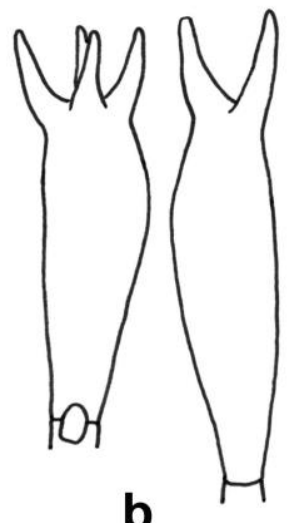

b
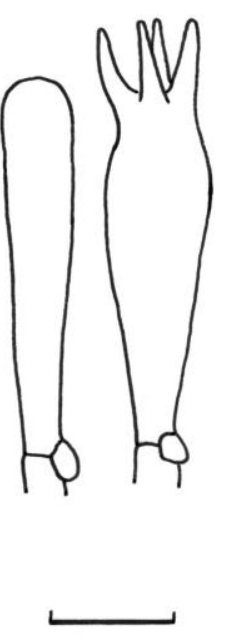
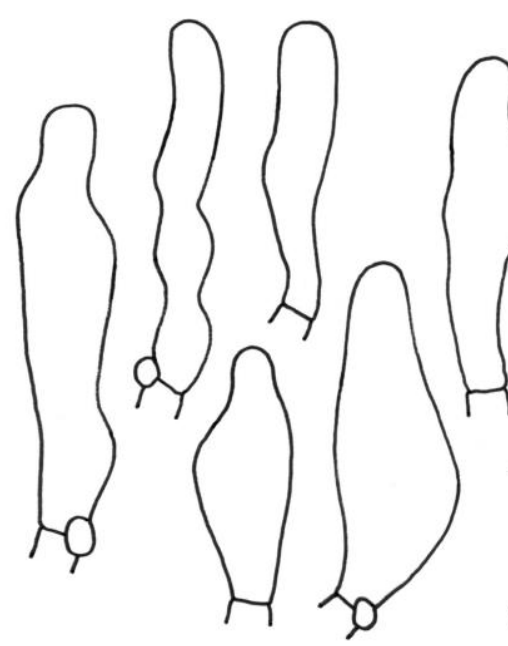

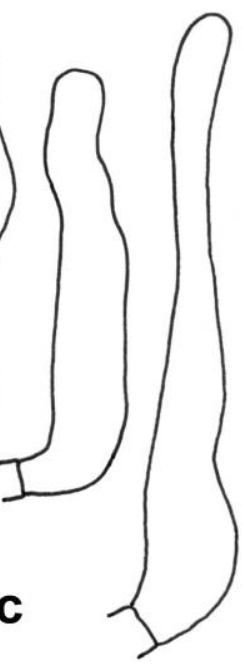

Fig. 22 - Micromorphological features of Trogia aff. furcata (DED 8260). a. Basidiospores. b. Basidia and basidiole. c. Cheilocystidia. Scale bar $=10 \mu \mathrm{m}$

Notes - Trogia aff. furcata is characterized by small, shallowly infundibuliform basidiomes with yellowish brown, streaked pileus, long decurrent, forked to venose-reticulate lamellae, a tough brown stipe, inamyloid basidiospores with mean $8 \times 5.1 \mu \mathrm{m}$, scattered cylindrical to subclavate cheilocystidia, no pleurocystidia, sarcodimitic tissues, sparse pileocystidia and caulocystidia, and growth on rotten wood. It differs slightly from T. furcata, described from Brunei, which forms darker fuscous pileus, a shorter stipe $(8-14 \mathrm{~mm})$, and larger, weakly amyloid basidiospores $(8-10.5 \times 6.5-8.5 \mu \mathrm{m})$ (Corner 1966). Both taxa form 2- and 4-spored basidia and have cells on the lamellar sides described by Corner as "cystidia ... like sterile basidia with a sterigma-like process 7-16 $\mu \mathrm{m}$ long." The latter are aborted 1spored basidia. Trogia mellea Corner is a similar honey-yellow species with inamyloid basidiospores 
in the range 7-9.5 $\times 4.5-5.5 \mu \mathrm{m}$, but differs in forming basidiomes with more yellow pigments, less venose-reticulate lamellae, and pileipellis and stipitipellis with more numerous cystidia (Corner 1966, 1991).

Pairwise comparisons of aligned, overlapping ITS sequences of $T$. aff. furcata with the top ten BLAST results indicate closest similarity (89.5-90.5\%) to uncultured Tricholomataceae sequences, and $87.9-89.3 \%$ similarity to Porotheleum fimbriatum (Pers.) Fr., a poroid resupinate taxon.

Mycetinis ignobilis (Berk. \& Broome) Desjardin \& B.A. Perry, comb. nov.

Figs 23, 24a-e Basionym: Marasmius ignobilis Berk. \& Broome, J. Linn. Soc., Bot. 14(73): 40. 1873 (1875).

= Marasmius ignobilis (Berk. \& Broome) Pegler, Kew Bull., Addit. Ser. 6: 124. 1977. (Superfluous combination)

= Marasmiellus ignobilis (Berk. \& Broome) Singer, Beih. Nova Hedwigia 44: 264. 1973.

Potential heterotypic synonyms: refer to Pegler (1986).

MycoBank: MB822662; Facesoffungi number: FoF03739

Type: Sri Lanka (Ceylon), 'south of the island', on dead wood, Nov. 1868, Thwaites 683 p.p. (K).

Pileus 4-17 mm diam, convex to plano-convex; margin decurved, short-sulcate to rugulosestriate; surface dull, dry, glabrous, pale orangish white (5A2-3) to greyish orange (5B3-4) when young, white in age. Context $<0.5 \mathrm{~mm}$ thick, soft, white. Lamellae horizontal, adnate, distant with 1-2 series of lamellulae, broad (1-2 mm), white with a hint of pale orangish white. Stipe $1-3 \times 0.5 \mathrm{~mm}$, strongly eccentric to nearly lateral, terete, cylindrical, curved, tough, solid, insititious; surface dull, dry, minutely pruinose, white to pale orangish white (5A2-3). Odor and taste strongly of garlic.

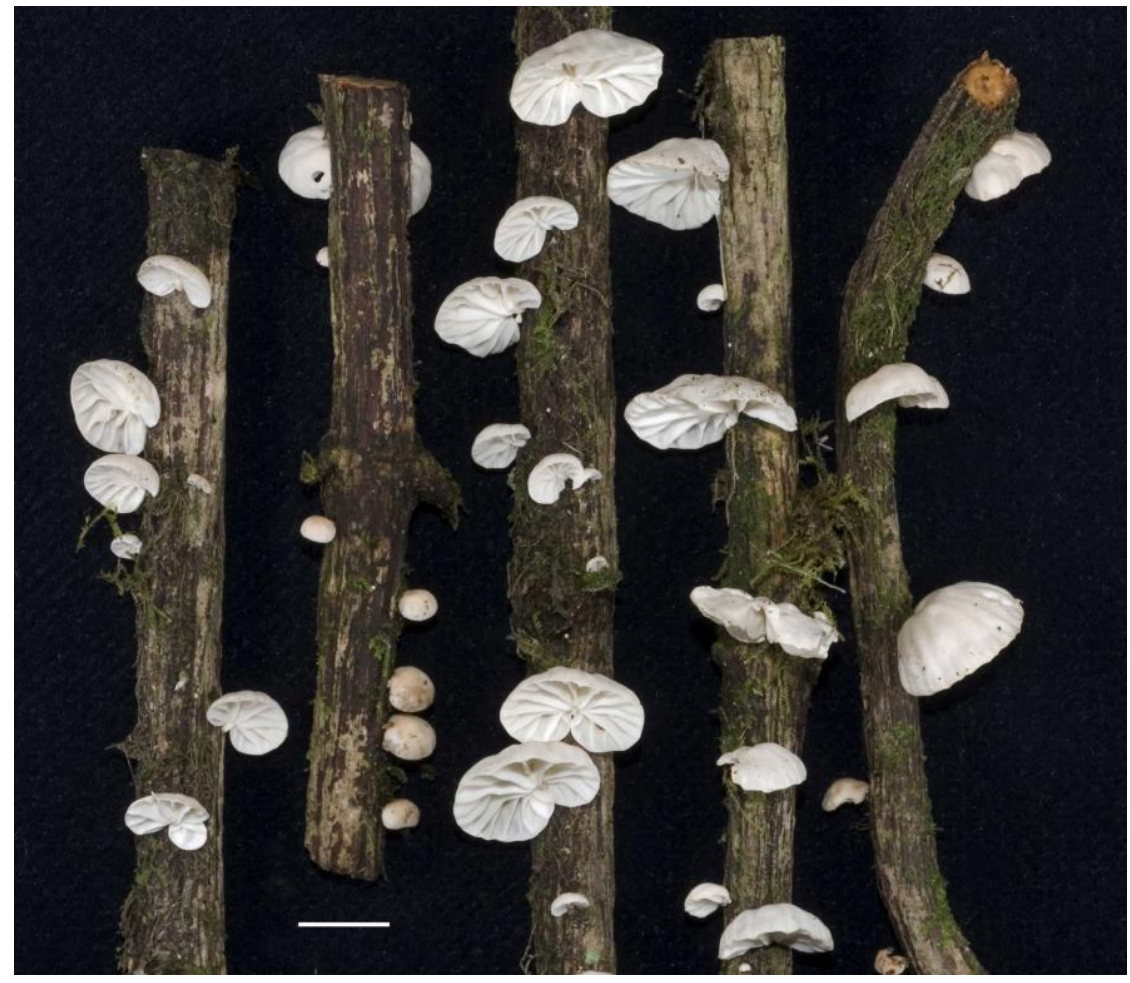

Fig. 23 - Basidiomes of Mycetinus ignobilis (DED 8207). Scale bar $=10 \mathrm{~mm}$

Basidiospores 8-9 $\times 4.8-5.8 \mu \mathrm{m}\left[\mathrm{x}_{\mathrm{m}}=8.43 \pm 0.40 \times 5.23 \pm 0.36 \mu \mathrm{m}, \mathrm{Q}=1.5-1.7, \mathrm{Q}_{\mathrm{m}}=1.61 \pm\right.$ 0.09, $\mathrm{n}=20, \mathrm{~s}=1]$, ellipsoid to pip-shaped, smooth, hyaline, inamyloid, thin-walled. Basidia $28-32 \times$ 8-9 $\mu \mathrm{m}$, clavate, 4-spored. Basidioles subclavate to fusoid. Pleurocystidia absent. Lamellar edge 
mostly sterile. Cheilocystidia abundant, 22-32 ×9.5-16 $\mu \mathrm{m}$, clavate, with numerous finger-like apical projections 3-7 $\times 2.5-5 \mu \mathrm{m}$, hyaline, inamyloid, thin-walled. Pileipellis a cutis, a poorly-developed Rameales-structure; hyphae 3.5-6.5 $\mu \mathrm{m}$ diam, cylindrical to irregular in outline, with scattered branchlets or broad knob-like diverticula, hyaline, inamyloid, non-incrusted, non-gelatinous; terminal cells versiform, repent to erect, broadly clavate, subangular to irregular in outline with a few broad diverticula, 6.5-16 $\mu \mathrm{m}$ diam. Pileus trama loosely interwoven; hyphae 3-6.5 $\mu \mathrm{m}$ diam, cylindrical, hyaline, inamyloid, thin-walled; lamellar trama regular, hyphae similar. Stipe cortical hyphae 2.5-7 $\mu \mathrm{m}$ diam, cylindrical or irregular in outline, smooth or with scattered diverticula, a poorly-developed Rameales-structure, hyaline, inamyloid, non-gelatinous, thin-walled; stipe medullary hyphae similar but non-diverticulate. Caulocystidia abundant, $16-40 \times 5.5-9.5 \mu \mathrm{m}$, clavate to irregular in outline,

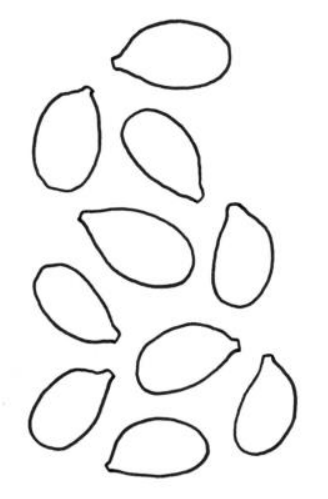

a

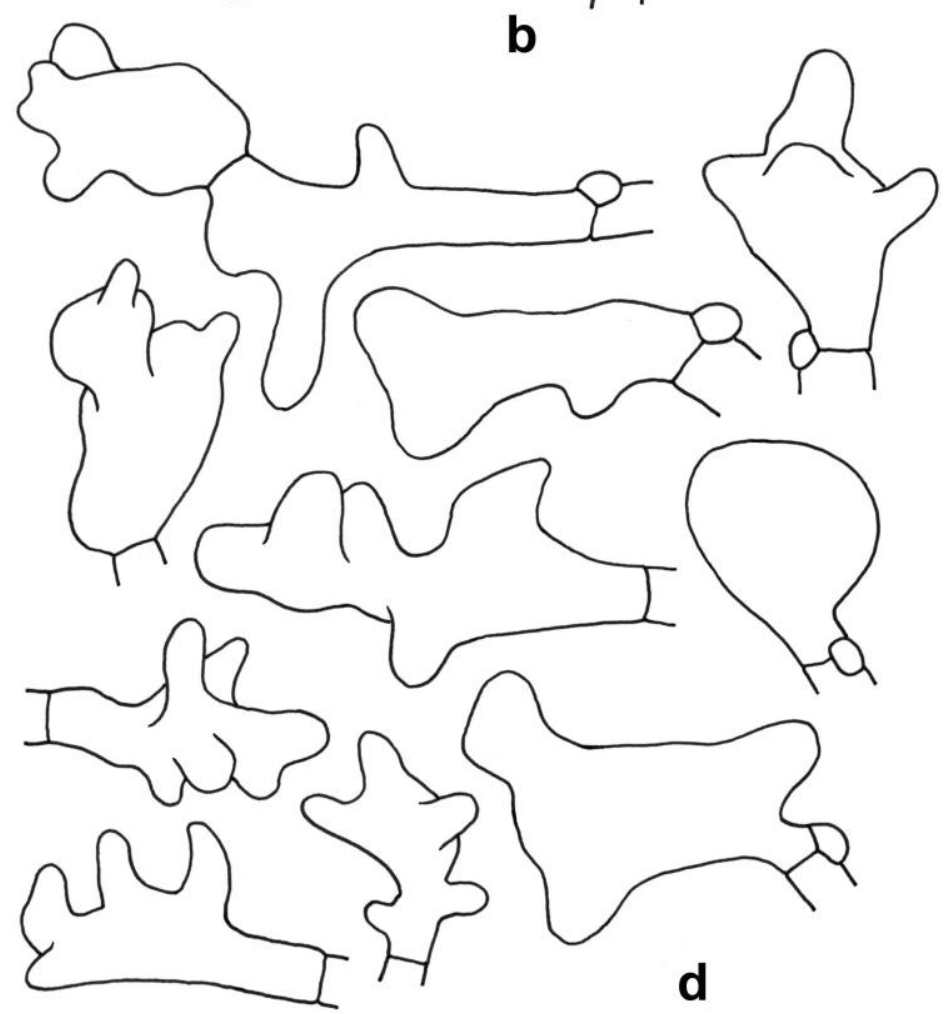

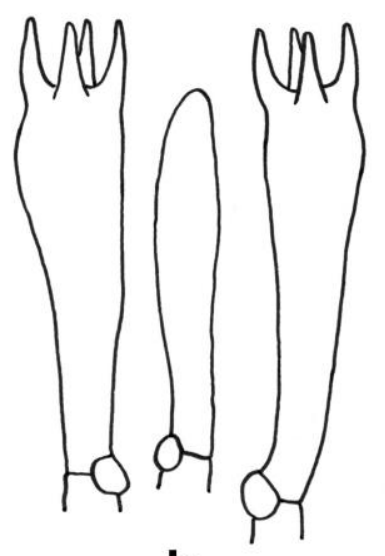

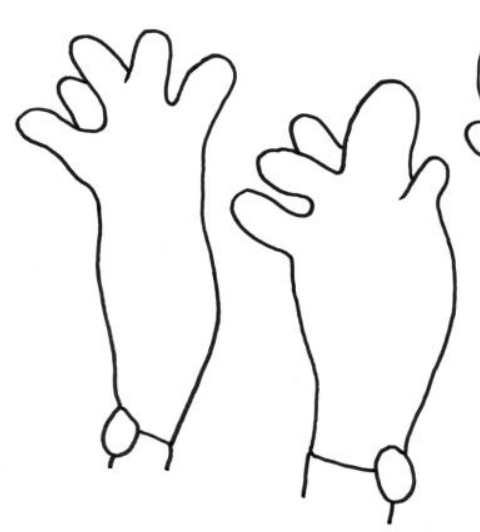

C
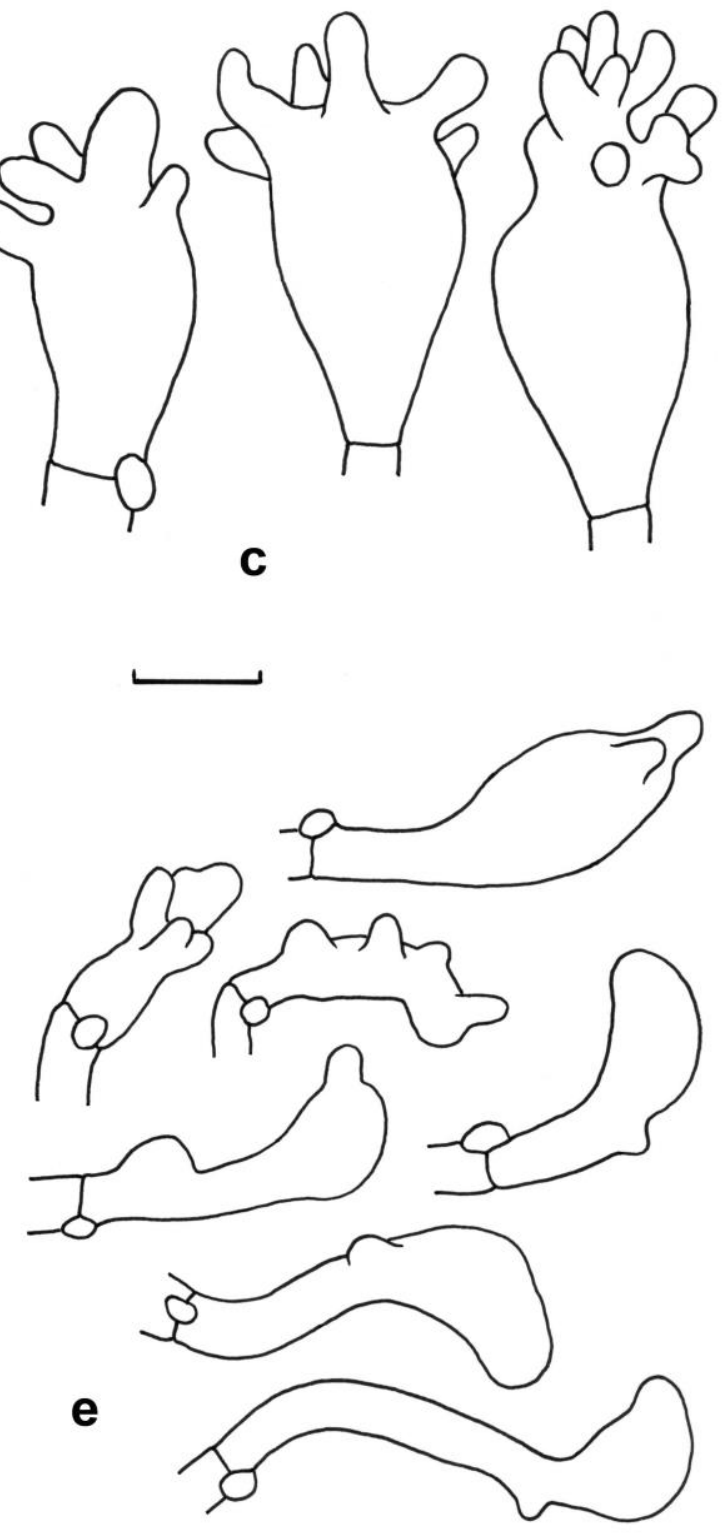

Fig. 24 - Micromorphological features of Mycetinus ignobilis (DED 8207). a. Basidiospores. b. Basidia and basidiole. c. Cheilocystidia. d. Pileipellis terminal cells. e. Caulocystidia. Scale bar $=10$ $\mu \mathrm{m}$ 
smooth or with a few knob-like diverticula, hyaline, inamyloid, thin-walled. Clamp connections present.

Habitat and known distribution - Gregarious on undetermined dicotyledonous twigs in primary forest. Africa (Kenya, São Tomé, Tanzania, Uganda), Indonesia (Bali, Java), Mexico, Sri Lanka.

Material examined - AFRICA. São Tomé, Macambrara, radio antenna area, $1300 \mathrm{~m}$ elev., N00 $16.557^{\prime}$, E06 $36.326^{\prime}, 11$ April 2008, coll. by B.A. Perry and D.E. Desjardin, DED 8207 (MF100963, SFSU).

Notes - Mycetinus ignobilis, described originally from Sri Lanka, is characterized by small, pleurotoid basidiomes with pale brown to orangish white pileus that fades to white, distant lamellae, a strongly eccentric to nearly lateral, pruinose white stipe, a poorly-developed Rameales-structure on pileipellis and stipitipellis, broad, clavate cheilocystidia with apical projections, and growth on woody debris. In the field, it is easily recognized by the strong garlic odor and taste. The São Tomé specimen differs slightly from the material reported from Sri Lanka (Pegler 1986), Africa (Pegler 1977) and Indonesia (Retnowati 2011) in forming a less well-developed Rameales-structure on the pileus and stipe, and has a paler pileus. Basidiospore size has been reported in a wide range: $6.5-8.5 \times 4.3-6 \mu \mathrm{m}$ $\left(\mathrm{x}_{\mathrm{m}}=7.5 \times 4.7 \mu \mathrm{m}\right)$ from Africa (Pegler 1977); 9.5-12.2 $\times$ 4.5-6.5 $\mu \mathrm{m}$ from Mexico (Singer 1973); 8.0-8.8 $\times 3.2-4.8 \mu \mathrm{m}$ from Indonesia (Retnowati 2011); and 7.5-10 $\times$ 4.5-5.5 $\mu \mathrm{m}\left(\mathrm{x}_{\mathrm{m}}=9.2 \times 5 \mu \mathrm{m}\right)$ from Sri Lanka (Pegler 1986). The São Tomé specimen falls nicely in the range reported for topotypical material with basidiospores $8-9 \times 4.8-5.8 \mu \mathrm{m}\left(\mathrm{x}_{\mathrm{m}}=8.4 \times 5.2 \mu \mathrm{m}\right)$, and the basidiomes match nicely with those figured in a color plate of Marasmius alliarius Petch (synonym of $M$. ignobilis) from Sri Lanka (Plate 2, Fig. 12; Petch 1948).

Pairwise comparisons of aligned, overlapping ITS sequences of Mycetinis ignobilis with the top ten BLAST results indicate closest similarity (96.1-97\%) to six sequences of Marasmius scorodonius (Fr.) Fr. (= Mycetinis scorodonius (Fr.) A.W. Wilson \& Desjardin), a species that shares the garlic odor, but forms centrally stipitate basidiomes with a hymeniform pileipellis of clavate cells and an absence of caulocystidia. Our ITS phylogeny (Fig. 1) places M. ignobilis on a long branch in a clade with other Mycetinis species with $87 \%$ BS and 1.0 PP support. Most other members of Mycetinis (e.g., M. alliaceus (Jacq.) Earle ex A.W. Wilson \& Desjardin, M. applanatipes (Desjardin) A.W. Wilson \& Desjardin, M. copelandii (Peck), A.W. Wilson \& Desjardin, M. querceus (Britzelm.) Antonín \& Noordel., M. salalis (Desjardin \& Rdhead) Redhead), also share the garlic odor, which may be a synapomorphy of the lineage.

Marasmius palmivorus Sharples, Malay. Agric. Journal 16(9-10): 345.1928.

Figs 25, 26a-d

Type: not designated in protologue; no original material located.

Facesoffungi number: FoF03740

Pileus 7-45 $\mathrm{mm}$ diam, hemispherical to convex, expanding to plano-convex, in age depressed to subumbilicate; margin initially smooth, soon striate to sulcate or rugulose-striate, sometimes wavy or cleft; surface dull, moist to dry, glabrous to felted or radially appressed-fibrillose, subhygrophanous; when young white to cream (4A2-3) or more commonly pinkish buff (6-7A2-3) to orange (5A5-6), in age retaining pink or orange tones on the disc, fading elsewhere to white, sometimes with small, orange to brownish orange (6C4-5) or cinnamon (6D6) spots or splotches. Context $<1 \mathrm{~mm}$ thick, soft, pliant, white. Lamellae horizontal, adnate, distant with 1-3 series of lamellulae, often intervenose in age, rarely forked, broad (2-4 mm), white, sometimes discoloring pink to orangish red. Stipe 2-10 ($25) \times$ 0.5-1.5 mm, central to eccentric, terete, cylindrical, base often enlarged, curved, solid, tough, subinsititious or arising from a pad of appressed white to pale orange mycelium; surface dull, dry, glabrous or minutely silky-pruinose, at first white overall, base darkening in age to greyish red (7B3$4)$, reddish orange (7-8B6-7) or reddish brown (8F5); often with fan-like white mycelium over substrate. Odor not distinctive. 


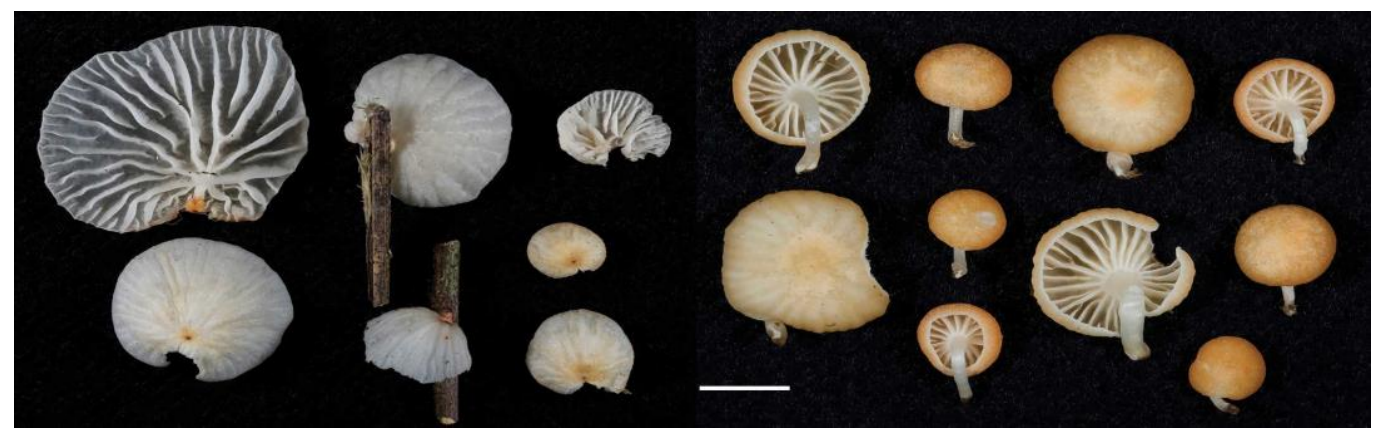

Fig. 25 - Basidiomes of Marasmius palmivorus (DED 8281-left; DED 8337-right). Scale bar = 10 $\mathrm{mm}$

Basidiospores (8-) 8.5-11 × 4.5-5.5 $\mu \mathrm{m}\left[\mathrm{x}_{\mathrm{mr}}=9.0-10.2 \times 4.9-5.1 \mu \mathrm{m}, \mathrm{x}_{\mathrm{mm}}=9.7 \pm 0.4 \times 5.0 \pm\right.$ $\left.0.1 \mu \mathrm{m}, \mathrm{Q}=1.7-2.3, \mathrm{Q}_{\mathrm{mr}}=1.9-2.0, \mathrm{Q}_{\mathrm{mm}}=1.94 \pm 0.1, \mathrm{n}=7-20, \mathrm{~s}=6\right]$, ellipsoid, smooth, hyaline, inamyloid, thin-walled. Basidia 25-34 × 6.5-10 $\mu \mathrm{m}$, clavate, 4-spored. Basidioles clavate, subfusoid cells absent. Pleurocystidia absent. Lamellar edge mostly sterile. Cheilocystidia 17.5-24 × 8-12 $\mu \mathrm{m}$, clavate with numerous apical setulae, similar to Siccus-type broom cells, hyaline, inamyloid, thinwalled; setulae 1.5-3.5 × 1-3.2 $\mu \mathrm{m}$, irregularly cylindrical or knob-like, sometimes forked, obtuse to acute, hyaline. Pileipellis a cutis of loosely interwoven, repent hyphae, not a hymeniform layer, not a Rameales-structure; hyphae 4.5-12 $\mu \mathrm{m}$ diam, cylindrical, non-diverticulate, smooth or incrusted with annular to helical hyaline or yellow pigments; walls hyaline, inamyloid, non-dextrinoid, nongelatinous; thin-walled; terminal cells undifferentiated, cylindrical. Pileus trama interwoven, lamellar trama regular; hyphae 3-15 $\mu \mathrm{m}$ diam, cylindrical or inflated, smooth, hyaline, inamyloid, nondextrinoid, non-gelatinous, thin-walled or with walls up to $1 \mu \mathrm{m}$ thick. Stipe cortical hyphae 3-6.5 $\mu \mathrm{m}$ diam, cylindrical, parallel, non-diverticulate, smooth, hyaline, inamyloid, non-dextrinoid, non-

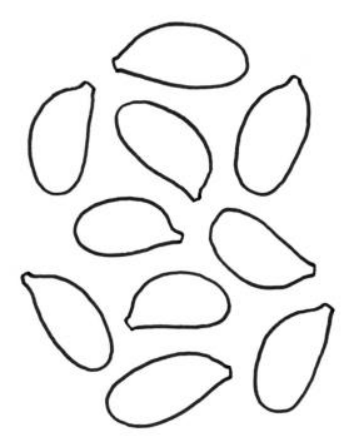

a
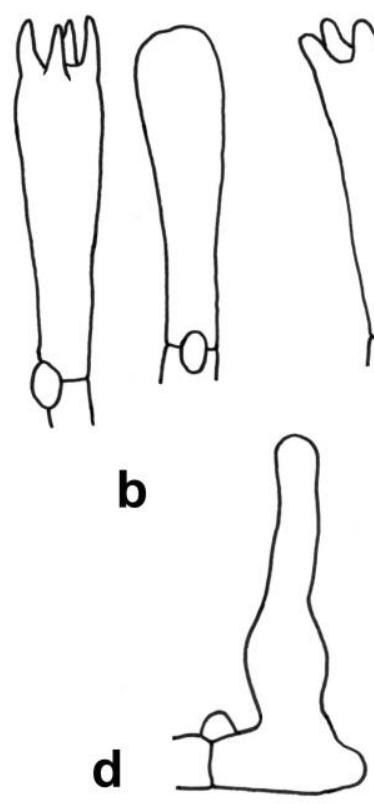
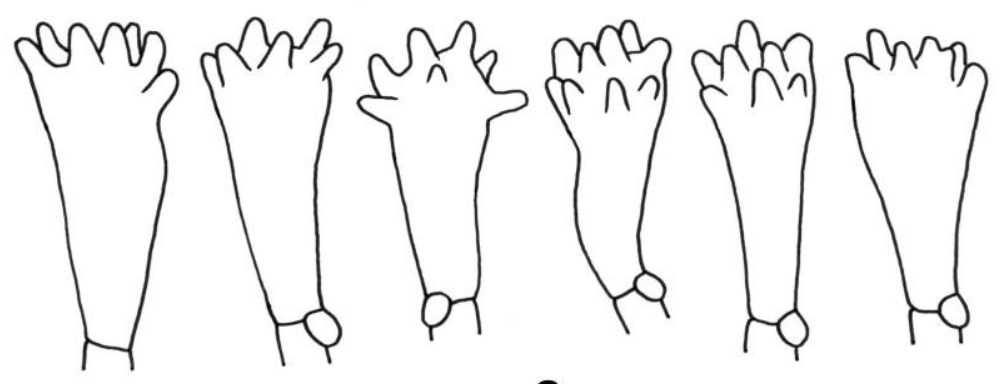

C
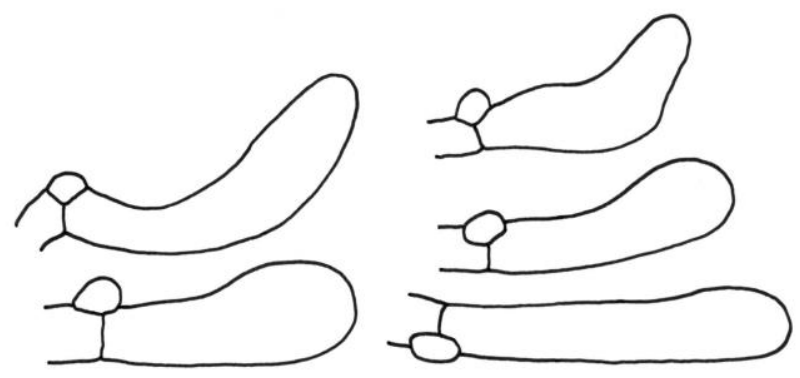

Fig. 26 - Micromorphological features of Marasmius palmivorus (DED 8219, BAP 628). a. Basidiospores. b. Basidium and basidiole. c. Cheilocystidia. d. Caulocystidia. Scale bar $=10 \mu \mathrm{m}$ 
gelatinous, thin-walled; medullary hyphae similar but many fusoid, up to $22 \mu \mathrm{m}$ diam, some with walls up to $1 \mu \mathrm{m}$ thick. Caulocystidia scattered, 25-32 $\times 5.5-9 \mu \mathrm{m}$, cylindrical to clavate or fusoid, nondiverticulate, hyaline, thin-walled. Clamp connections present.

Habitat and known distribution - Gregarious on rotten coconut palm wood or fruits, on leaves and stems of banana, or on undetermined woody debris in coastal coconut groves and banana-cacao groves. Africa (São Tomé), Hawaiian Islands, Indonesia (Java), Malaysia.

Material examined - AFRICA. São Tomé, along main road (EN1) on north side of island, west of Ria Luisa at $33 \mathrm{~km}$ marker, N0¹9.606', E06³0.667', 18 April 2008, coll. by B.A. Perry, BAP 628 (MF100964, SFSU); same location, 26 April 2006, coll. by D.E. Desjardin (material lost); São Tomé, along main road (EN1) on north side of island at $18.25 \mathrm{~km}$ marker, N0 23.687', E06 36.302', 17 April 2008, coll. by D.E. Desjardin and B.A. Perry, BAP 625 (MF100965, SFSU); São Tomé, along main road (EN2) on south side of island, N0 ${ }^{\circ} 12.126^{\prime}, \mathrm{E}^{\circ} 6^{\circ} 42.362^{\prime}, 13$ April 2008, coll. by D.E. Desjardin, DED 8219 (MF100966, SFSU); São Tomé, along road to Bombain, N0¹6.615', E06³8.942', elev. 400 m, 26 April 2008, coll. by D.E. Desjardin, DED 8337 (MF100967, SFSU). Príncipe, along road to Roça Pico Papagaio, N01 38.538', E07²3.890', elev. 250 m, 21 April 2008, coll. by D.E. Desjardin, DED 8281 (MF100968, SFSU); same location and date, coll. by D.E. Desjardin and B.A. Perry, BAP 641(MF100969, SFSU).

Notes - Marasmius palmivorus is characterized by small to moderate-sized basidiomes with a pink to orange, striate, plano-convex pileus that fades to white in age, distant, occasionally intervenose, white lamellae, a central to eccentric, white stipe that becomes reddish orange to reddish brown at the base in age, basidiospores with mean $9.7 \times 5 \mu \mathrm{m}$, clavate cheilocystidia with apical setulae, a cutistype pileipellis of non-diverticulate hyphae, non-dextrinoid tissues, clavate, thin-walled caulocystidia, and growth on monocotyledonous debris. It was described originally from material causing "bud rot" of palms in Malaysia, and the protologue provided extensive details of the disease, ecology and basidiome morphology of the species (Sharples 1928). Our African material is indistinguishable from that reported in the protologue. Sharples (1928) reported obtaining pure cultures of M. palmivorus from basidiomes growing on African oil palms (Elaeis guineensis), dwarf and tall coconuts (Cocos nucifera), and on a variety of bananas. Subsequent studies have confirmed the pathogenic nature of the species on these host plants (Turner 1981, Almaliky et al. 2011). Hemmes and Desjardin (2002) tentatively recognized the species as belonging in Marasmiellus, reporting the taxon from coconut palms on Hawaii island. Wilson and Desjardin (2005) were the first to include the species (as Marasmiellus palmivorus comb. prov.) in a phylogenetic analysis of marasmioid and gymnopoid taxa, based on a nLSU sequence of the Hawaiian material (AY639434). Subsequently, Pong et al. (2012) provided nLSU sequences of six specimens of $M$. palmivorus from the type locality in Malaysia (JQ654219-JQ654224) that matched the Hawaiian material with 99.7\% similarity, and the authors recently deposited in GenBank numerous ITS sequences of their Malaysian specimens. We obtained ITS sequences from six specimens of $M$. palmivorus from São Tomé and Príncipe that showed 99.7$100 \%$ similarity to each other, and $99.3-99.7 \%$ similarity to 10 sequences from Malaysia, confirming the conspecificity of our African material with that from Malaysia.

The generic placement of Marasmius palmivorus is problematical. Morphologically, $M$. palmivorus is more similar to Marasmiellus than to Marasmius sensu stricto. As currently delimited, Marasmius species form a hymeniform pileipellis of broom cells or clavate, non-setulose cells and have dextrinoid tissues, whereas Marasmiellus species have cutis-type pileipelli and non-dextrinoid tissues, as seen in $M$. palmivorus. The phylogenetic analysis of gymnopoid and marasmioid fungi by Wilson and Desjardin (2005) placed M. palmivorus as sister to Crinipellis (but with only $0.54 \mathrm{PP}$ support) and together were sister to Marasmius species in a well-supported Marasmiaceae clade (1.0 PP). Pairwise comparisons of aligned, overlapping nLSU sequences of Marasmius palmivorus with the top 250 BLAST results indicate $97.5-98.3 \%$ similarity to 25 different species of Marasmius, 
suggesting placement in the Marasmiaceae. Indeed, our ITS sequences of M. palmivorus are so divergent from those of members of the Omphalotaceae (Fig. 1) that they are unalignable. Until further analyses with molecular sequences from multiple gene regions are performed to clarify the generic placement of this taxon, we conservatively retain the taxon in Marasmius.

Marasmius palmivorus is most phenetically similar to a complex of Marasmiellus species and forms that are reportedly pathogenic on a range of economically important monocots, including banana, palms, sugar cane and corn (Singer 1973). Within this group of taxa, it is difficult to distinguish M. palmivorus from Marasmiellus troyanus (Murrill) Dennis, Ma. semiustus (Berk. \& M.A. Curtis) Singer and Ma. inoderma (Berk.) Singer. Marasmiellus troyanus differs in forming a pure white pileus when young, lacks intervenose lamellae at maturity, and has slightly smaller basidiospores (mean $9 \times 5 \mu \mathrm{m}$ ). Marasmiellus semiustus and Ma. inoderma differ primarily in forming a Rameales-structure on the pileus and stipe surfaces; other macro- and micromorphological features span a range of variation overlapping that of Ma. troyanus and M. palmivorus.

Campanella burkei Desjardin \& B.A. Perry, sp. nov.

Figs 27, 28a-b

MycoBank: MB821159; Facesoffungi number: FoF03741

Holotype - AFRICA. Príncipe, Bom Bom Island Resort area, along trail to top of island, 20 April 2008, coll. by D.E. Desjardin and B.A. Perry, BAP 632 (SFSU).

Etymology - named in honor of Coleman P. Burke who has supported this project since its inception.

Diagnosis - Pileus 7-16 mm diam, broadly convex to plano-convex with a shallow central depression, sulcate, rugulose-reticulate between sulcae; surface dull, dry to moist, glabrous, hygrophanous, white. Context very thin, pliant, white. Lamellae adnate to subdecurrent, distant (9-13) with $0-1$ series of lamellulae, sometimes forked, intervenose, thru-lamellae relatively broad (1-2 mm), white with concolorous edges, not discoloring in age. Stipe 7-12 $\times 0.5-1 \mathrm{~mm}$, central, terete, cylindrical or gradually narrowed downward, tough, pliant, solid, insititious; surface dull, dry, minutely white-pruinose, glabrescent, apex white, base greyish brown to dark greyish brown (6F3-4). Odor slightly musty, pungent.

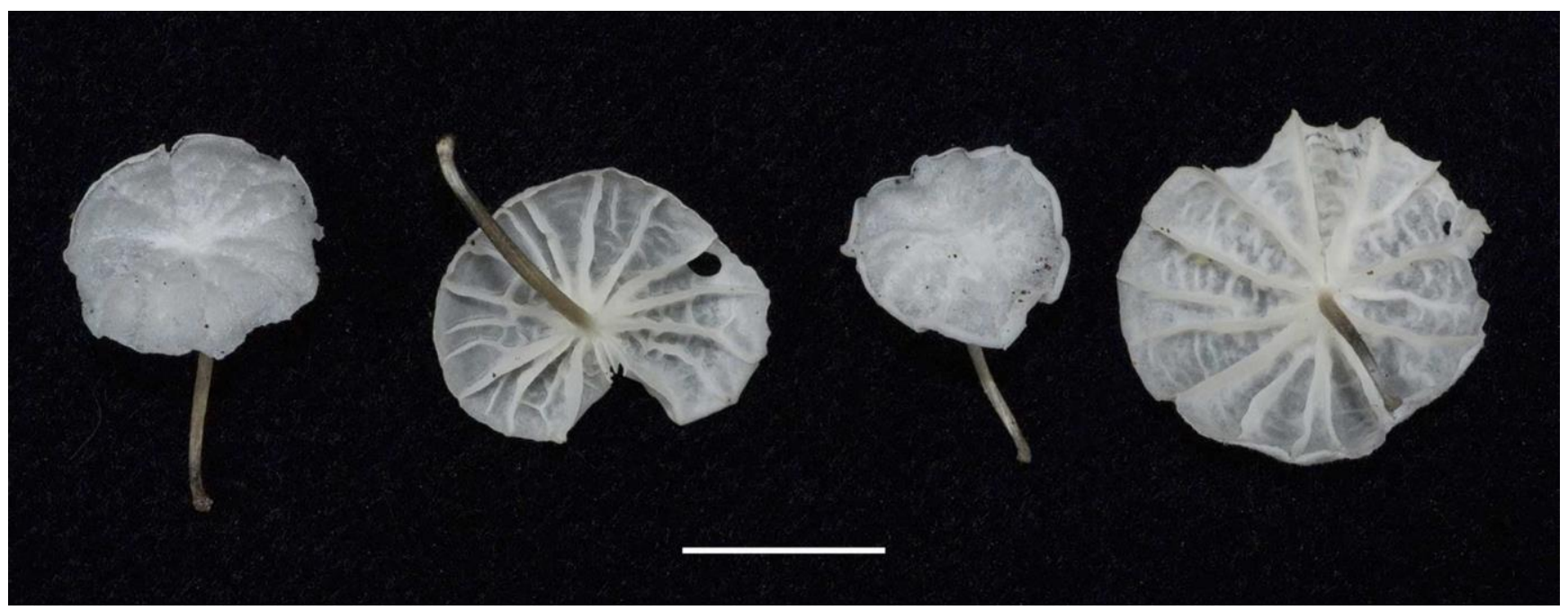

Fig. 27 - Basidiomes of Campanella burkei (Holotype, BAP 632). Scale bar = $10 \mathrm{~mm}$

Basidiospores 14.5-18.5 (-22) × 5.2-6.5 (-7.5) $\mu \mathrm{m}\left[\mathrm{x}_{\mathrm{m}}=16.2 \pm 1.18 \times 6.2 \pm 0.76 \mu \mathrm{m}, \mathrm{Q}=2.0\right.$ $\left.2.9, \mathrm{Q}_{\mathrm{m}}=2.66 \pm 0.17, \mathrm{n}=20, \mathrm{~s}=1\right]$, elongate-ellipsoid to subfusoid, smooth, hyaline, inamyloid, thinwalled. Basidia 28-36 × 7.7-9.5 $\mu \mathrm{m}$, clavate, 2-spored, clamped. Basidioles clavate. Pleurocystidia 
absent. Cheilocystidia absent. Pileipellis a loosely interwoven cutis; hyphae 4-12 (-20) $\mu \mathrm{m}$ diam, cylindrical to slightly inflated, non-diverticulate or with scattered, small, finger-like diverticula, smooth or hyaline-incrusted, hyaline, inamyloid, non-gelatinous, thin-walled; pileocystidia and sclerocystidia (setae) absent. Pileus trama interwoven; hyphae as in pileipellis. Lamellar trama regular to slightly interwoven; hyphae 2-5 $\mu \mathrm{m}$ diam, cylindrical, hyaline, inamyloid, non-gelatinous, thinwalled. Stipitipellis a cutis with scattered caulocystidia; cortical hyphae 4-8 $\mu \mathrm{m}$ diam, repent, parallel, cylindrical, non-diverticulate or with scattered finger-like diverticula, hyaline (stipe apex) to pale brown (stipe base), inamyloid, non-gelatinous, thin-walled; medullary hyphae 4-16 $\mu \mathrm{m}$ diam, cylindrical to inflated, hyaline, otherwise similar to cortical hyphae. Caulocystidia absent or as repent to geniculate terminal cells, cylindrical, obtuse, hyaline, thin-walled. Clamp connections present.

Habitat and known distribution - Scattered to gregarious on bark at the base of a standing dicotyledonous tree in coastal forest. Africa (Príncipe).

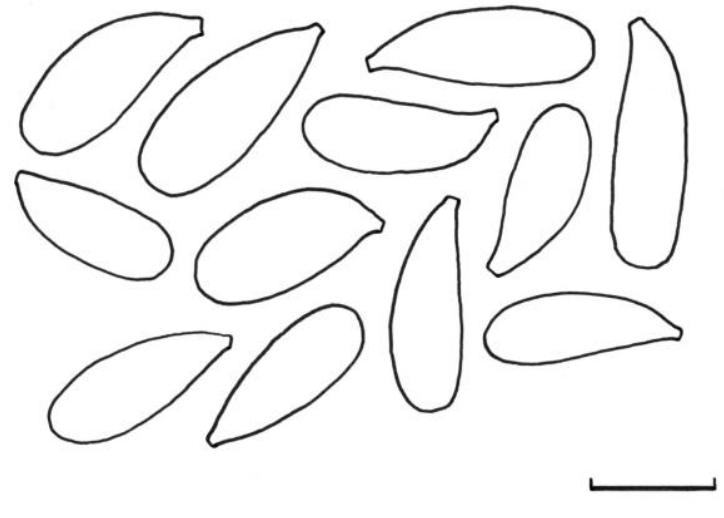

$\mathbf{a}$
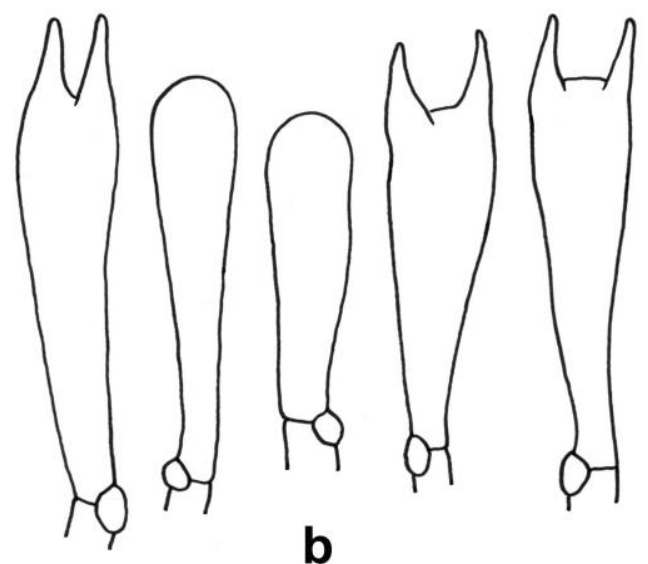

Fig. 28 - Micromorphological features of Campanella burkei (Holotype, BAP 632). a. Basidiospores. b. Basidia and basidioles. Scale bar $=10 \mu \mathrm{m}$

Material examined - AFRICA. Príncipe, Bom Bom Island Resort area, along trail to top of island, 20 April 2008, coll. by D.E. Desjardin and B.A. Perry, BAP 632 (Holotype, MF100970, SFSU).

Notes - Campanella v.s. Tetrapyrgos v.s. Marasmiellus Sect. Candidi - Wilson and Desjardin (2005) provided nLSU sequence data that showed that Marasmiellus candidus (Fr.) Singer, type species of Marasmiellus Sect. Candidi Singer, was not closely related to the type species of Marasmiellus, M. juniperinus Murrill, but rather was sister to several species of Tetrapyrgos (1.0 PP, 99\% BS support) in a clade sister to all other gymnopoid fungi. Subsequently, Mata et al. (2007) confirmed the distant relationship of $M$. candidus to $M$. juniperinus with ITS sequence data, but suggested that $M$. candidus was sister to Mycetinis. In a taxonomic revision of Tetrapyrgos supported with ITS sequence data, Honan et al. (2015) reported M. candidus as sister to Campanella (0.92 PP support), but embedded within Tetrapyrgos. They acknowledged the difficulty in distinguishing species of Campanella from Tetrapyrgos, and suggested that they may represent a single genus (Campanella has nomenclatural priority), but hesitated to accept the synonymy until the type species of both genera were clearly circumscribed with morphological and molecular data. They encouraged further studies incorporating a broad sampling of Campanella species and members of Marasmiellus Sect. Candidi. Singer (1973) accepted four species in Sect. Candidi, and additional taxa were added later (Singer 1989, Desjardin et al. 1992, Antonín et al. 2010). Our ITS data set (Fig. 1) contains four species of Tetrapyrgos, two of Campanella, four of Marasmiellus, and the new species from Príncipe. 
All 11 species belong to a well-supported clade (100\% BS, $1.0 \mathrm{PP})$ whose position relative to other gymnopoid fungi was variable depending on the analysis. The new species from Príncipe is sister to $M$. candidus. Because $M$. candidus clearly does not belong in the genus Marasmiellus (if one accepts that genus as distinct from Gymnopus), the question arises to which genus does the new species belong? Rather than describe the new taxon in Marasmiellus, we have chosen to accept it in Campanella, the oldest available name for all taxa in the Campanella/Tetrapyrgos/Marasmiellus Sect. Candidi clade. Addressing nomenclatural transfers of additional members of Sect. Candidi is beyond the scope of this paper.

Distinctive features of Campanella burkei include a rugulose-sulcate, white pileus, distant, intervenose white lamellae, an insititious, greyish brown stipe, basidiospores with mean $16.2 \times 6.2 \mu \mathrm{m}$ and $\mathrm{Q}_{\mathrm{m}}=2.66$, 2-spored basidia, no cheilocystidia or pleurocystidia, non-diverticulate or sparsely diverticulate pileipellis and stipitipellis hyphae, and growth on bark of an undetermined dicotyledonous tree. Campanella burkei shows some similarities to M. candidus, M. pacificus Desjardin, and M. coilobasis (Berk.) Singer. Marasmiellus candidus differs in forming distinctive filiform to sublageniform pileocystidia, cheilocystidia and caulocystidia, shorter and narrower basidiospores $(11.5-15 \times 3.5-5.5 \mu \mathrm{m})$, 4-spored basidia, and older basidiomes discolor pinkish (Desjardin 1987, Antonín \& Noordeloos 2010). Marasmiellus pacificus forms narrower basidiospores (mean width $5.0 \mu \mathrm{m} ; \mathrm{Q}_{\mathrm{m}}=3.2$ ), predominantly 4-spored basidia, conspicuous ventricose-rostrate pileocystidia and cheilocystidia, and grows on leaf bases and stalks of red ginger (Desjardin et al. 1992). Marasmiellus coilobasis, known from Brazil and Bolivia, has been reported to have all or nearly all basidia 2-spored as in $M$. burkei, with basidiospores in the same size range, but the former species forms a disc at the base of the subinsititious white stipe, and has ventricose to subcylindrical pleurocystidia up to $100 \mu \mathrm{m}$ long (Singer 1973).

Pairwise comparisons of aligned, overlapping ITS sequences of Campanella burke $i$ with the top ten BLAST results indicate closest similarity (93.2-95.3\%) to six specimens of $M$. candidus (KJ906507-Pakistan; EF175513, EF175514, EF175515-California; DQ480088-unknown, HM240532-British Columbia).

Lactocollybia variicystis D.A. Reid \& Eicker, Mycotaxon 66: 159. 1998.

Figs 29, 30a-f

Facesoffungi number: FoF03742

Pileus 8-22 mm diam, broadly convex to plano-convex, sometimes with a low, broad umbo; margin pellucid-striate, undulating; surface moist, glabrous, white overall or with a pale yellowish brown (2-3B4-5) disc. Context up to $1 \mathrm{~mm}$ thick, soft, white. Lamellae ascending-adnate with a short decurrent tooth, close to subdistant with 2-3 series of lamellulae, broad (1-2.5 mm), rarely forked at margin, white with concolorous edges, developing yellowish brown stains where bruised. Stipe 5-12 $\times$ 1-2 mm, central to eccentric, tough, pliant, hollow, non-insititious, base with scant white mycelium; surface dull, dry, minutely pruinose, white when young, becoming yellowish brown (2-3C-D5-6) in age. Odor cruciferous; taste mildly bitter.

Basidiospores 7.4-9.6 × 5.1-6.4 $\mu \mathrm{m}\left[\mathrm{x}_{\mathrm{m}}=8.5 \pm 0.63 \times 5.7 \pm 0.39 \mu \mathrm{m}, \mathrm{Q}=1.4-1.7, \mathrm{Q}_{\mathrm{m}}=1.48 \pm\right.$ $0.05, \mathrm{n}=12, \mathrm{~s}=1]$, ellipsoid to broadly amygdaliform, smooth, hyaline, inamyloid, thin-walled. Basidia 24-28 $\times 6.5-8 \mu \mathrm{m}$, clavate, 4-spored. Basidioles cylindrical to subclavate. Pleurocystidia scattered, similar to the cheilocystidia, versiform, majority cylindrical-capitate. Cheilocystidia abundant, scattered along a fertile lamellar edge; 48-75 $\times 6.5-14.5 \mu \mathrm{m}$, versiform, narrowly cylindrical to fusoid, ventricose or lageniform, sometimes capitate, hyaline, inamyloid, thin-walled. Chrysocystidia-like gloeocystidia common on lamellar sides, less common on lamellar edges, 88-136 $\times 11-18 \mu \mathrm{m}$, clavate to fusoid-ventricose, obtuse, arising from the lamellar trama as terminal cells of the gloeosystem, contents yellow to golden, refractive. Pileipellis a cutis of radially arranged hyphae 2.5-5 $\mu \mathrm{m}$ diam, cylindrical, hyaline, inamyloid, non-gelatinous, thin-walled, interspersed with 
elements of the gloeosystem, the latter as fusoid intercalary swellings 9-24 $\mu \mathrm{m}$ diam, narrowing at both ends to 2.5-4 $\mu \mathrm{m}$ diam, with refractive, yellow to golden contents; terminal cells as gloeocystidia $>100 \times 9.5-18(-23) \mu \mathrm{m}$, versiform, fusoid-ventricose to clavate, repent, with refractive, yellow to golden contents. Pileus trama loosely interwoven; hyphae 2.5-20 $\mu \mathrm{m}$ diam, cylindrical to inflated, hyaline, inamyloid, non-gelatinous, thin-walled. lamellar trama subparallel; hyphae 3.5-18 $\mu \mathrm{m}$ diam, cylindrical, hyaline, inamyloid, non-gelatinous, thin-walled; with interspersed hyaline to yellow gloeohyphae. Stipitipellis a cutis of parallel, repent hyphae giving rise to caulocystidia; hyphae 2.5-8 $\mu \mathrm{m}$ diam, cylindrical, smooth, hyaline, inamyloid, non-gelatinous, thin-walled; overlaying a gloeosystem as in the pileipellis, with versiform intercalary swellings 9.5-16 $\mu \mathrm{m}$ diam, with refractive, yellow to golden contents; medullary hyphae 5-16 $\mu \mathrm{m}$ diam, cylindrical, hyaline, inamyloid, thinwalled. Caulocystidia similar to the cheilocystidia, versiform. Clamp connections present.

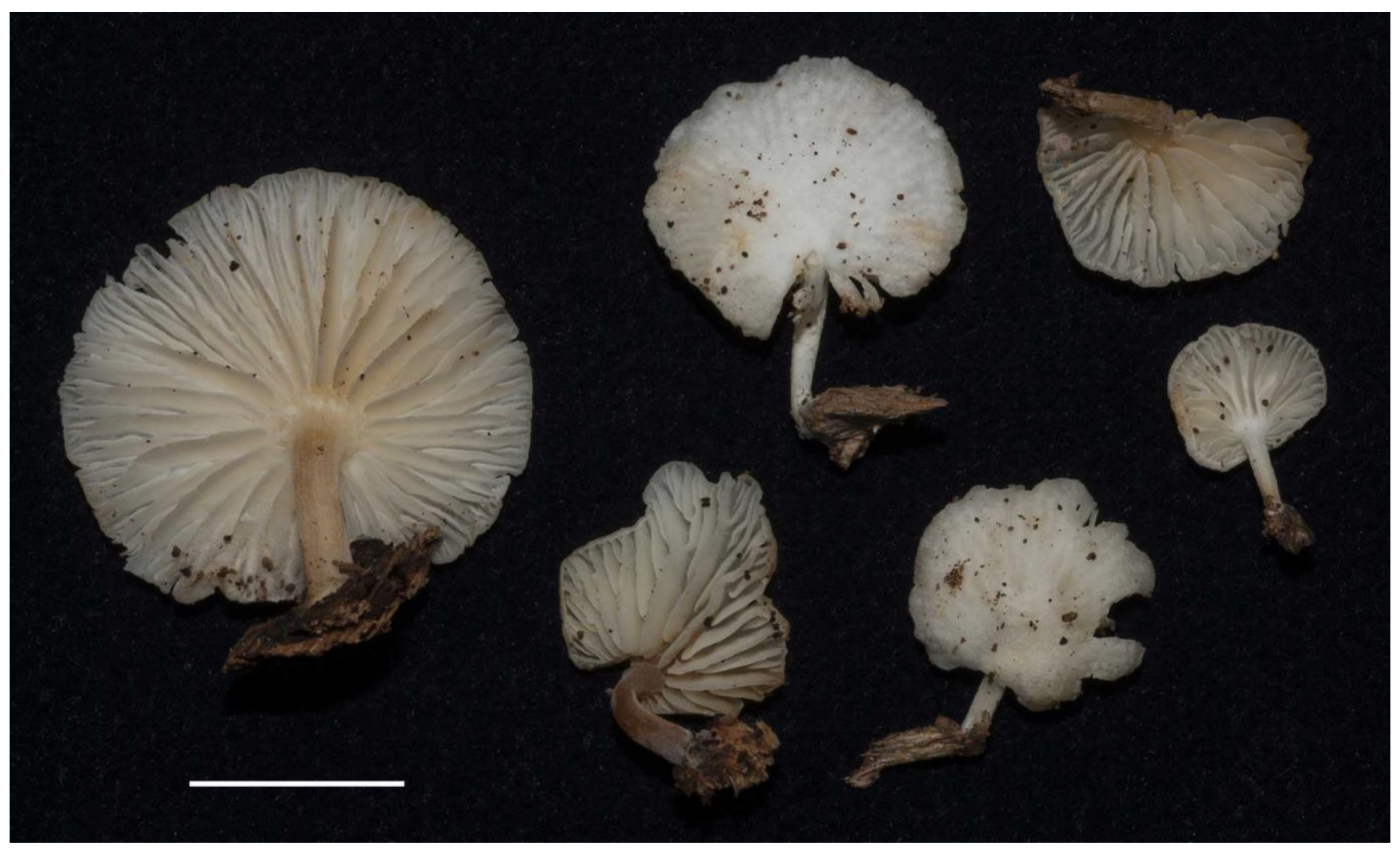

Fig. 29 - Basidiomes of Lactocollybia variicystis (BAP 598). Scale bar $=10 \mathrm{~mm}$

Habitat and known distribution - gregarious on decaying wood in coastal forest with cacao and banana. Africa (São Tomé).

Material examined - AFRICA. São Tomé, along road EN1 near Conde, N00 22.802', E06 39.334', 12 April 2008, coll. by B.A. Perry and D.E. Desjardin, BAP 598 (MF100971, SFSU).

Notes - Lactocollybia variicystis was described from material collected in South Africa (Reid and Eicker 1998). The common pantropical L. epia (Berk. \& Broome) Pegler differs in forming larger basidiomes (pileus 10-55 mm diam, stipe 20-80 $\times 2-5 \mathrm{~mm})$ with more elongate basidiospores $\left(\mathrm{x}_{\mathrm{m}}=\right.$ $8.5 \times 4.5 \mu \mathrm{m} ; \mathrm{Q}=1.88$ ) and more consistently cylindrical-clavate cheilocystidia (Pegler 1977, 1986).

Pairwise comparisons of aligned, overlapping ITS sequences of Lactocollybia variicystis with two GenBank sequences of L. epia (KP840552 - Sicily; KU320581 - India) showed only $90.8 \%$ and $85.6 \%$ similarity, respectively. 

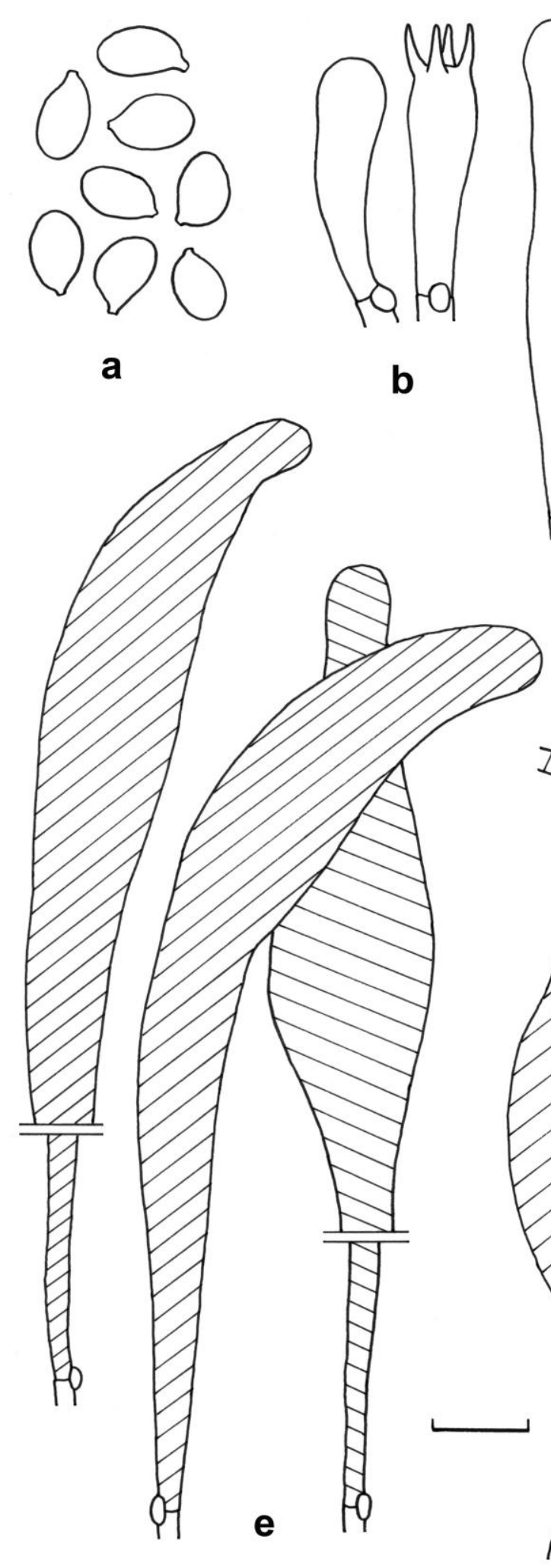

Fig. 30 - Micromorphological features of Lactocollybia variicystis (BAP 598). a. Basidiospores. b. Basidium and basidiole. c. Pleurocystidia. d. Cheilocystidia. e. Chrysocystidia-like gloeocystidia from lamellar sides. f. Pileipellis terminal cells and elements of the gloeosystem. Scale bar $=10 \mu \mathrm{m}$ 
Setulipes afibulatus Antonín, Mycotaxon 88: 69. 2003.

Figs 31, 32a-e

Holotype - AFRICA. Malawi, Nyika National Park, Gîte Chelinda, 4 Dec. 1981, J. Rammeloo 7652 (BR 11989-58).

MycoBank: MB821166; Facesoffungi number: FoF03743

Pileus 4-10 mm diam, convex to plano-convex or plane, centrally depressed in age, rugulosesulcate to striate; surface dull, dry, glabrous; disc light brown (7D5-6), margin greyish orange (6BC3). Context $<1 \mathrm{~mm}$ thick, buff. Lamellae adnate to a pseudocollarium, distant (11-13) with 1 series of lamellulae, moderately broad $(1-1.5 \mathrm{~mm})$, greyish orange (6B3). Stipe $12-20 \times 0.2 \mathrm{~mm}$, central, filiform, wiry, tough, insititious; surface dull, dry, glabrous or minutely pruinose $(20 \times$ hand lens $)$, dark brown (8F7-8) overall; rhizomorphs absent.

Basidiospores 7.4-8.3 × 3.5-4.0 $\mu \mathrm{m}\left[\mathrm{x}_{\mathrm{m}}=7.8 \pm 0.28 \times 3.8 \pm 0.17 \mu \mathrm{m}, \mathrm{Q}=1.8-2.2, \mathrm{Q}_{\mathrm{m}}=2.07 \pm\right.$ $0.07, \mathrm{n}=20, \mathrm{~s}=1$ ], ellipsoid to subcylindrical, smooth, hyaline, inamyloid, thin-walled. Basidia 22-26 $\times 6.5-7.5 \mu \mathrm{m}$, clavate, 4-spored. Basidioles clavate to subfusoid. Pleurocystidia absent. Cheilocystidia abundant, lamellar edge mostly sterile, of Siccus-type broom cells; main body 13-30 × 8-16 $\mu$ m, broadly clavate to vesiculose, often lobed, hyaline, inamyloid, thin-walled; apical setulae/diverticula 1.5-3.5 $\times 1-2 \mu \mathrm{m}$, rod-like to knob-like, obtuse, hyaline, thin-walled. Pileipellis a cutis to nearly a Rameales-structure of radially arranged hyphae 3-6 $\mu \mathrm{m}$ diam, non-diverticulate or with scattered diverticula, brown-incrusted, non-gelatinous, thin-walled; terminal cells of Siccus-type broom cells similar to the cheilocystidia. Pileus trama of loosely interwoven hyphae 2.5-6 $\mu \mathrm{m}$ diam, cylindrical, non-diverticulate, smooth or incrusted, hyaline to pale yellowish brown, inamyloid. Stipitipellis a cutis of cylindrical hyphae 2.5-4 $\mu \mathrm{m}$ diam, smooth, dark brown, dextrinoid, thick-walled, giving rise to scattered caulocystidia; medullary hyphae 3-8 $\mu \mathrm{m}$ diam, cylindrical, hyaline to pale brown, weakly dextrinoid, thin-walled. Caulocystidia 10-42 × 3-6.5 $\mu \mathrm{m}$, cylindrical to fusoid or acicular, sometimes geniculate, hyaline to pale brown, contents strongly dextrinoid; walls smooth, inamyloid to weakly dextrinoid, 0.5-1 $\mu \mathrm{m}$ thick. Clamp connections absent in all tissues.

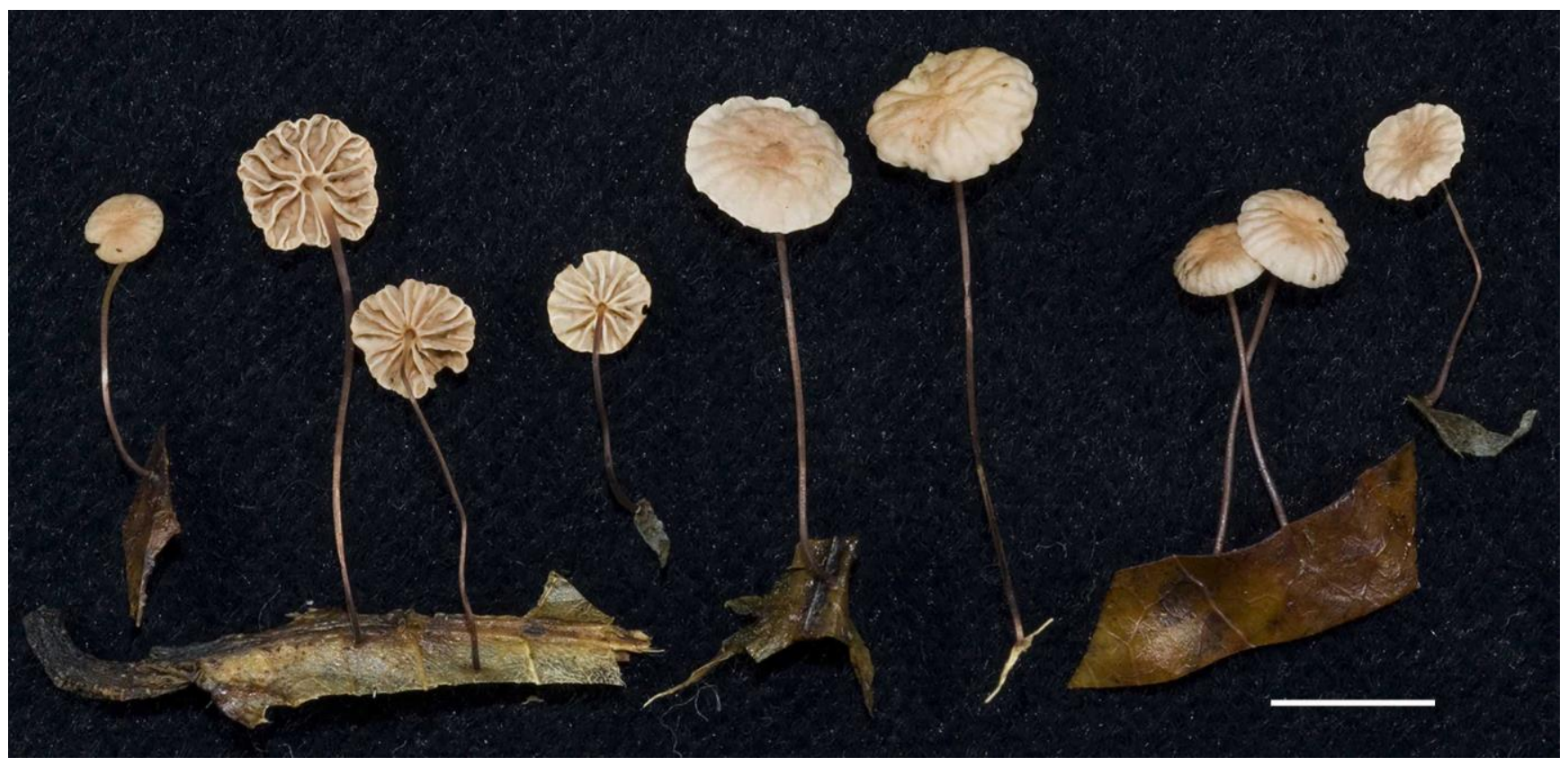

Fig. 31 - Basidiomes of Setulipes afibulatus (DED 8208). Scale bar = $10 \mathrm{~mm}$

Habitat and known distribution - Solitary, scattered on leaves of undetermined dicotyledonous trees in primary forest. Africa (Burundi, DR Congo, Malawi, Nigeria, São Tomé, Tanzania). 
Material examined - AFRICA. São Tomé, Macambrara, radio antenna area, $1300 \mathrm{~m}$ elev., N00 16.557', E06 36.326', 11 April 2008, coll. by B.A. Perry and D.E. Desjardin, DED 8208 (MF100972, SFSU); same location, 25 April 2006, coll. by D.E. Desjardin (material lost).

Notes - Setulipes was established by Antonín (1987) to encompass what was once considered Marasmius sect. Androsacei. Mata et al. (2007) presented ITS sequence data that indicated that the type species of the genera Gymnopus (G. fusipes) and Setulipes (S. androsaceus), belonged in the same well-supported clade. Accordingly, Mata et al. (2007), Antonín and Noordeloos (2010), and others accept Setulipes as a synonym of Gymnopus. In our ITS phylogeny (Fig. 1), S. afibulatus is distantly related to $G$. fusipes and outside any clade containing currently recognized Gymnopus species, indicating the species does not belong in Gymnopus. Moreover, S. afibulatus is distantly related to the type species of Setulipes, with which it shares most morphological features, and hence does not belong in Setulipes, which we recognize as a synonym of Gymnopus. However, it holds an isolated position in the ITS phylogeny, sister to Connopus, a genus with which it shares few morphological features. Until additional molecular sequences data from additional loci are available to help clarify its taxonomic position, we refrain from transferring the species to a different genus or from establishing a new genus, and refer to it here as $S$. afibulatus.

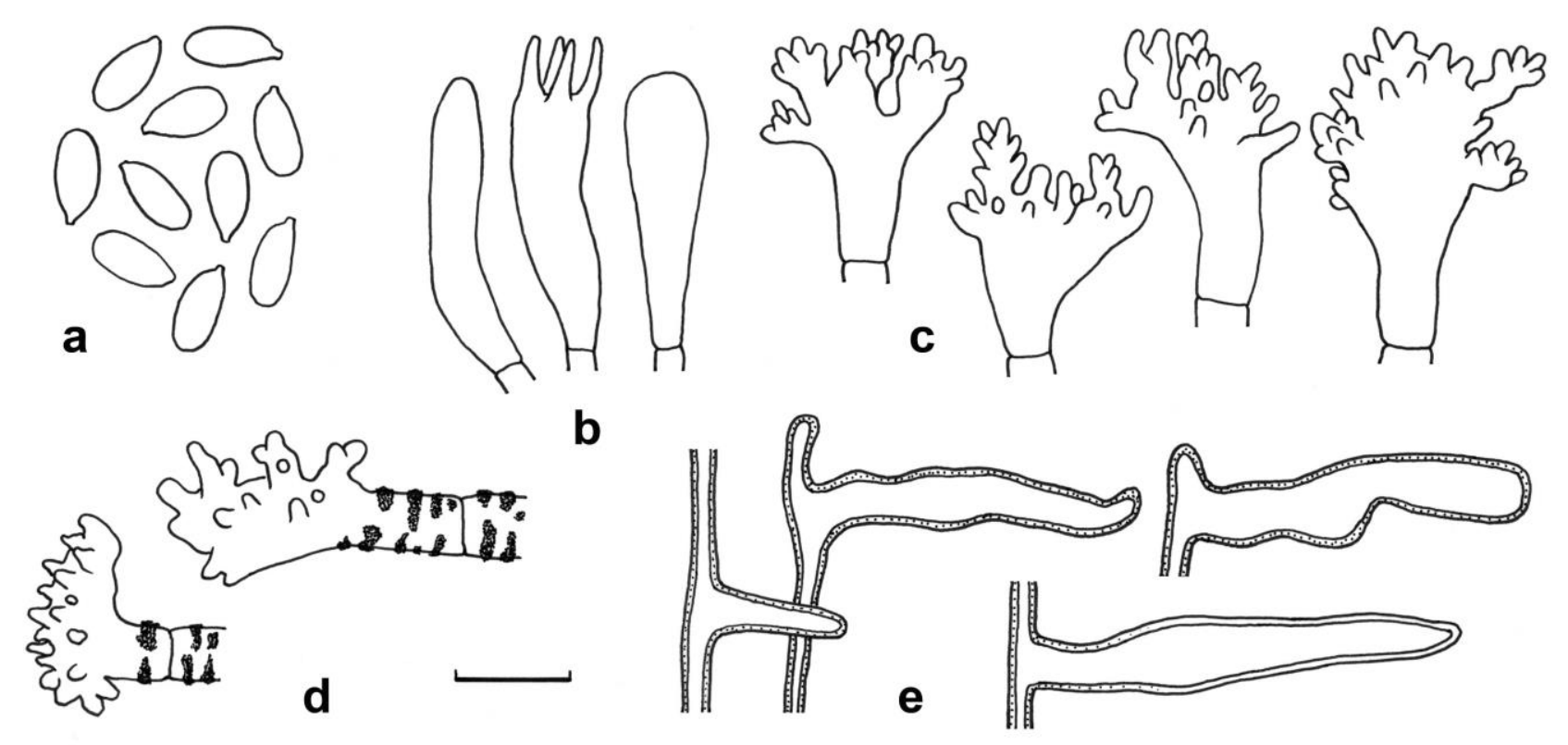

Fig. 32 - Micromorphological features of Setulipes afibulatus (DED 8208). a. Basidiospores. b. Basidium and basidioles. c. Cheilocystidia. d. Pileipellis terminal cells. e. Caulocystidia. Scale bar $=10$ $\mu \mathrm{m}$

Setulipes afibulatus is distinguished by a small, greyish orange, rugulose-sulcate pileus, distant, greyish orange lamellae, a wiry, dark brown, insititious stipe, basidiospores with mean $7.8 \times 3.8 \mu \mathrm{m}$, Siccus-type cheilocystidia and pileipellis terminal cells, brown-incrusted pileipellis hyphae, dextrinoid stipe tissues, thick-walled, cylindrical to fusoid, dextrinoid caulocystidia, an absence of clamp connections, and growth on dicot leaves. The material from São Tomé matches nicely with other African material reported by Antonín (2007), although the basidiospores are in the shorter part of the range. The distinctly dextrinoid tissues distinguish this taxon from other unclamped species in Marasmiellus sect. Defibulati sensu Singer (1973). Overall Setulipes morphology suggests an affinity with Marasmius pallidocephalus, another species with small basidiomes with wiry insititious stipe, 
dextrinoid stipe tissues, Siccus-type pigment-incrusted pileipellis cells and lacks clamp connections. The latter differs, however, in lacking cheilocystidia and caulocystidia, forms rhizomorphs, and grows on conifer needles in North America (Desjardin 1987, 1989, 1990).

Pairwise comparisons of aligned, overlapping ITS sequences of Setulipes afibulatus with the top ten BLAST results indicate a closest match (80.9-81.0\% similarity, 94.39-94.89\% coverage) to Gymnopus sp. from Korea (KF251067, KF251068).

Setulipes afibulatus may represent what was reported from São Tomé by Bresadola and Roumeguère (1890) as Marasmius splachnoides (Hornem.) Fr., the latter considered by some authors as a synonym of Gymnopus quercophilus (Pouzar) Antonín \& Noordel and by others as a nomen dubium.

Gymnopus irresolutus Desjardin \& B.A. Perry, sp. nov.

Figs 33, 34a-e

MycoBank: MB821161; Facesoffungi number: FoF03744

Holotype - AFRICA. São Tomé, Macambrara, radio antenna area, $1300 \mathrm{~m}$ elev., N00¹6.557', E06 36.326', 11 April 2008, coll. by B.A. Perry and D.E. Desjardin, DED 8209 (SFSU).

Etymology - irresolutus (Latin) = doubtful, referring to the uncertainty in its generic placement.

Diagnosis - Pileus 2-6 mm diam, convex to plano-convex or plane-depressed; margin decurved, striate; surface dull, dry, glabrous; disc dark brown (7F6-8), margin paler to greyish brown (7D3). Context $<1 \mathrm{~mm}$ thick, soft, off-white. Lamellae horizontal, shallowly adnate, non-collariate, distant with 1 series of lamellulae, broad $(-1 \mathrm{~mm})$, pale brownish grey $(6 \mathrm{C} 3)$. Stipe $8-10(-15) \times 0.1-0.2 \mathrm{~mm}$,

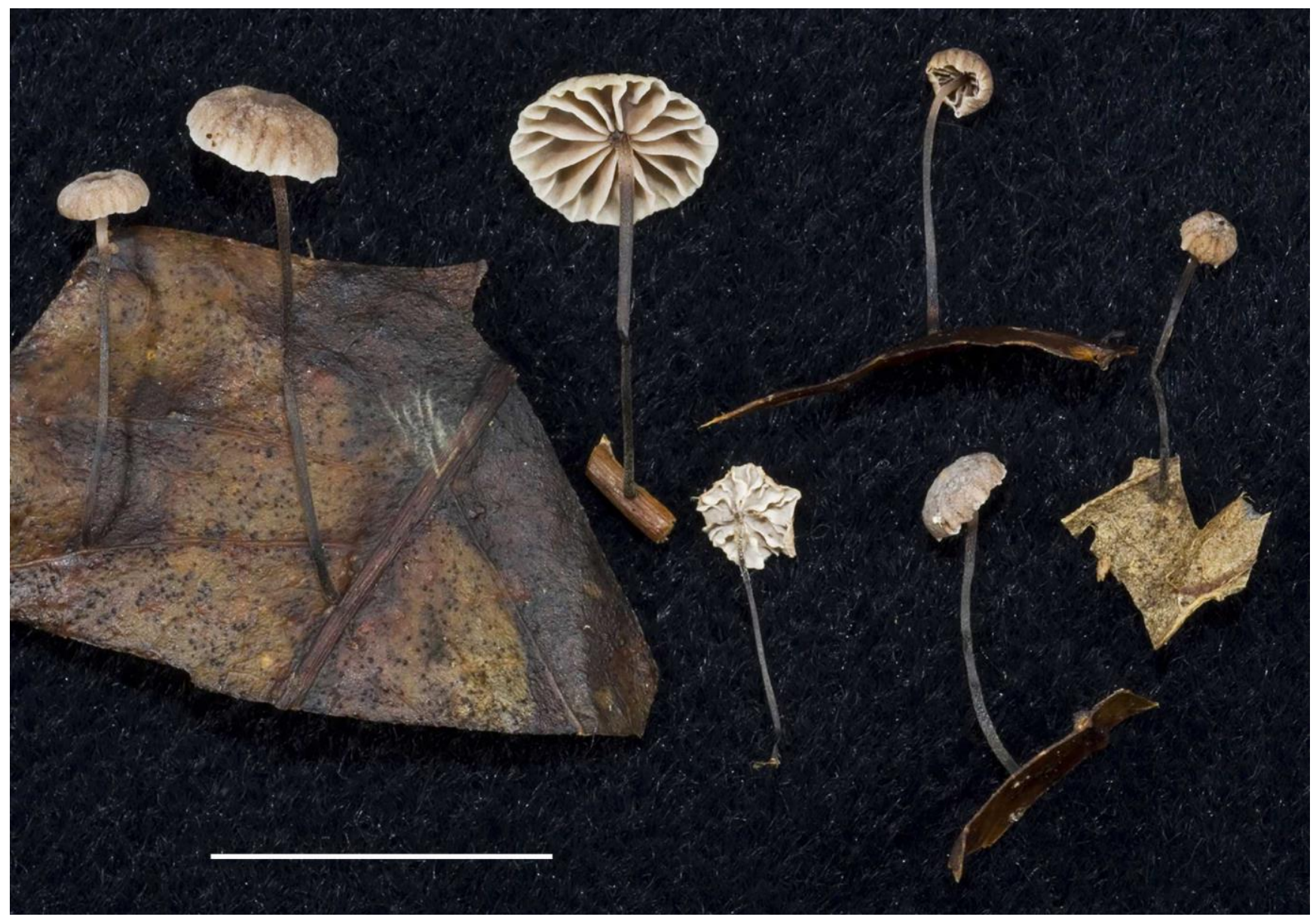

Fig. 33 - Basidiomes of Gymnopus irresolutus (Holotype, DED 8209). Scale bar = $10 \mathrm{~mm}$ 
central, filiform, wiry, solid, insititious; surface dull, dry, minutely pruinose; apex pale greyish brown (6C3), base black; rhizomorphs absent. Odor and taste not distinctive.

Basidiospores 7-8.3 $\times 3.2-3.8 \mu \mathrm{m}\left[\mathrm{x}_{\mathrm{m}}=7.8 \pm 0.43 \times 3.5 \pm 0.21 \mu \mathrm{m}, \mathrm{Q}=2.1-2.4, \mathrm{Q}_{\mathrm{m}}=2.23 \pm\right.$ $0.15, \mathrm{n}=21, \mathrm{~s}=1]$, ellipsoid, smooth, hyaline, inamyloid, thin-walled. Basidia 19-24 $\times 6-7 \mu \mathrm{m}$, clavate, 4-spored, rarely 2 -spored, unclamped. Basidioles clavate. Pleurocystidia absent. Lamellar edge heteromorphous, fertile. Cheilocystidia scattered, $14.5-20 \times 5-8 \mu \mathrm{m}$, broadly clavate to irregularly cylindrical, often bifid, hyaline, inamyloid, thin-walled. Pileipellis a cutis of repent hyphae 3-6 $\mu \mathrm{m}$ diam, smooth or brown-incrusted, non-diverticulate or with rare knob-like projections (not a Rameales-structure), hyaline to pale brown, inamyloid, non-gelatinous; terminal cells lobed or branched, with large bulbous knobs 3-10 $\mu \mathrm{m}$ diam, smooth or incrusted, hyaline, inamyloid, thinwalled. Pileus and lamellar trama of hyphae 3-6 $\mu \mathrm{m}$ diam, smooth, hyaline, inamyloid, thin-walled. Stipitipellis a cutis of parallel, cylindrical hyphae 2-7 $\mu \mathrm{m}$ diam, smooth, pale brown, inamyloid, slightly thick-walled, giving rise to caulocystidia; medullary hyphae 3-8 $\mu \mathrm{m}$ diam, cylindrical, hyaline, inamyloid. Caulocystidia clustered to scattered, 5-20 $\times 3-5 \mu \mathrm{m}$, cylindrical to subclavate, obtuse, sometimes broadly knobby like the pileipellis terminal cells, hyaline to brown, inamyloid, slightly thick-walled $(-0.5 \mu \mathrm{m})$, thicker walled and darker near stipe base. Clamp connections absent in all tissues.

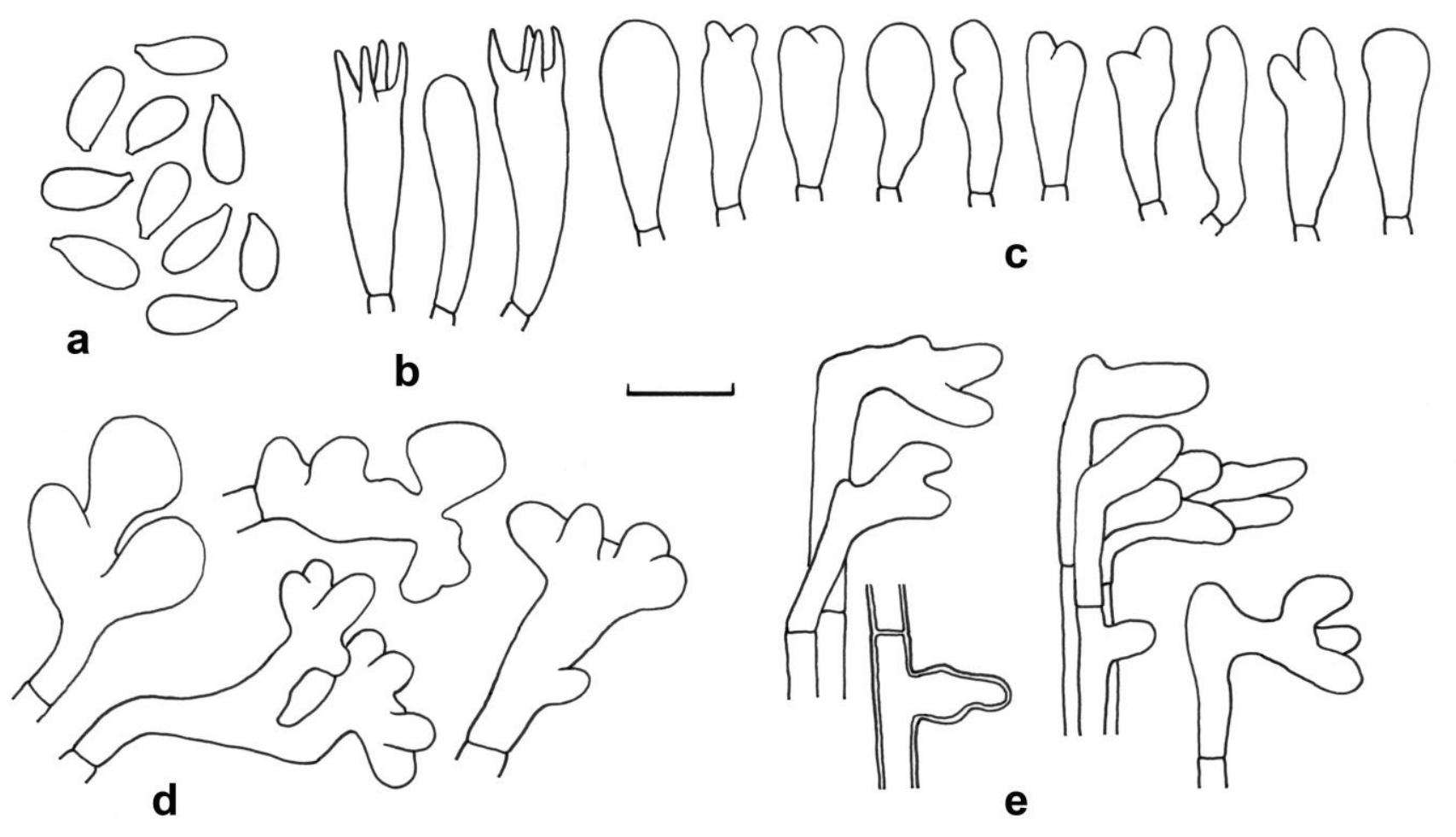

Fig. 34 - Micromorphological features of Gymnopus irresolutus (Holotype, DED 8209). a. Basidiospores. b. Basidia and basidiole. c. Cheilocystidia. d. Pileipellis terminal cells. e. Caulocystidia. Scale bar $=10 \mu \mathrm{m}$

Habitat and known distribution - Solitary on leaves of undetermined dicotyledonous trees in primary forest. Africa (São Tomé). 
Material examined - AFRICA. São Tomé, Macambrara, radio antenna area, $1300 \mathrm{~m}$ elev., N00 $16.557^{\prime}$, E06 36.326', 11 April 2008, coll. by B.A. Perry and D.E. Desjardin, DED 8209 (Holotype, MF100973, SFSU).

Notes - Gymnopus irresolutus is characterized by small, Setulipes-like basidiomes with brown, striate pileus, distant pale brownish grey lamellae, a black, wiry, insititious stipe, no rhizomorphs, basidiospores with mean $7.8 \times 3.5 \mu \mathrm{m}$, no pleurocystidia, broadly clavate and often bifid cheilocystidia, a cutis-type pileipellis with broadly knobby terminal cells, cylindrical to subclavate or apically knobby caulocystidia, non-gelatinous, inamyloid (non-dextrinoid) tissues, an absence of clamp connections, and growth on dicotyledonous leaves. In combination, these features suggest placement in Marasmiellus sect. Defibulati, subsect. Subcoracini of Singer (1973), where the African taxon would key close to $M$. picipes (Murr.) Singer, a species known from Cuba, Mexico and Brazil. The latter species differs in a paler pileus (Arabian brown to auburn), white lamellae, a chestnut brown stipe, and much larger caulocystidia $(6-85 \times 4-11 \mu \mathrm{m})$, many of which are subacute. Gymnopus irresolutus shows many similarities to Marasmius atlanticus Singer, a species described from Florida, USA that belongs in the Setulipes clade of Gymnopus. The latter differs in a reddish brown pileus with white margin, white lamellae, a fibrillose-furfuraceous stipe, cheilocystidia with more knob-like outgrowths, larger caulocystidia $(32-48 \times 8-12.5 \mu \mathrm{m})$, and dextrinoid stipe cortical hyphae (Holotype F!). Gymnopus irresolutus does not match any of the taxa from Africa referable to Marasmiellus, Gymnopus or Setulipes by Antonín (2007: 146-160; Excluded and doubtful taxa).

Pairwise comparisons of aligned, overlapping ITS sequences of Gymnopus irresolutus with the top ten BLAST results indicate closest similarity (90.5-91.6\%) to unidentified Agaricales spp., uncultured fungus clones, or Marasmius androsaceus (JN943605-Sweden, GU234007-Sweden, FR717227-Czech Republic). In the ITS phylogeny (Fig. 1), G. irresolutus is sister to G. fusipes (type species of Gymnopus) and G. androsaceus (0.91 PP).

Gymnopus hirtellus (Berk. \& Broome) Desjardin \& B.A. Perry, comb. nov.

Fig. 35a-d

Basionym: Marasmius hirtellus Berk. \& Broome, J. Linn. Soc., Bot. 14(73): 39. 1873 (1875).

$=$ Collybia hirtella (Berk. \& Broome) Dennis, Trans. Brit. Mycol. Soc. 34: 444. 1951.

= Marasmiellus hirtellus (Berk. \& Broome) Pegler, Kew Bull., Addit. Ser. 6: 130. 1977.

Holotype - SRI LANKA. Kandy District, Peradeniya, on dead herbaceous plants, Nov. 1867, Thwaites 102 p.p. (K).

MycoBank: MB821168; Facesoffungi number: FoF03745

Pileus 7-15 mm diam, convex, soon broadly plano-convex to plane, depressed in age; margin decurved to straight, rugulose-striate when young, often striate to disc in age; surface dull, dry, glabrous, dull brown (8E-F4) overall when young, fading in age to greyish orange (6B3), dingy cream (4A3) or tan-buff. Context thin $(-0.5 \mathrm{~mm})$, soft, white. Lamellae horizontal, adnate, close to crowded with 2-3 series of lamellulae, narrow $(0.5-1 \mathrm{~mm})$, greyish orange $(6 \mathrm{~B} 3)$ to white; edges pruinose. Stipe 10-20 × 1 mm, central, terete, cylindrical, tough, pliant, hollow, insititious; surface dull, dry, pruinose to hispid; apex greyish orange (6B3), base brown to dark brown (7E-F4-6); rhizomorphs absent.

Basidiospores 6.4-7.4 × 3.2-3.8 $\mu \mathrm{m}\left[\mathrm{x}_{\mathrm{m}}=6.7 \pm 0.31 \times 3.5 \pm 0.23 \mu \mathrm{m}, \mathrm{Q}=1.7-2.1, \mathrm{Qm}_{\mathrm{m}}=1.93 \pm\right.$ $0.13, \mathrm{n}=10, \mathrm{~s}=1$ ], ellipsoid, smooth, hyaline, inamyloid, thin-walled. Basidia 16-20 $\times 6-6.8 \mu \mathrm{m}$, clavate, 4-spored. Basidioles subfusoid. Pleurocystidia absent. Lamellar edge sterile. Cheilocystidia 20-30 $\times 5-8 \mu \mathrm{m}$, irregularly clavate, usually with 1-3 (-4) broadly rounded apical lobes, hyaline, thinwalled. Pileipellis a cutis of radially arranged, repent hyphae 4-5.5 $\mu \mathrm{m}$ diam, cylindrical, most with brown, annular to helical pigment incrustations, few smooth, non-diverticulate, inamyloid, nongelatinous; terminal cells cylindrical to subclavate, often with a few scattered, broad, knob-like outgrowths, not a Rameales-structure. Pileus and lamellar trama of loosely interwoven hyphae 4-6 $\mu \mathrm{m}$ 
diam, cylindrical, smooth, hyaline, inamyloid, non-gelatinous, thin-walled. Stipe tissue monomitic; hyphae 3-6 $\mu \mathrm{m}$ diam, cylindrical, hyaline to pale brown, inamyloid, smooth, non-gelatinous. Caulocystidia abundant, 32-160 × 7-12 $\mu \mathrm{m}$, cylindrical to wavy-cylindrical, hyaline, inamyloid, thickwalled, tip seldom bifid. Clamp connections present.

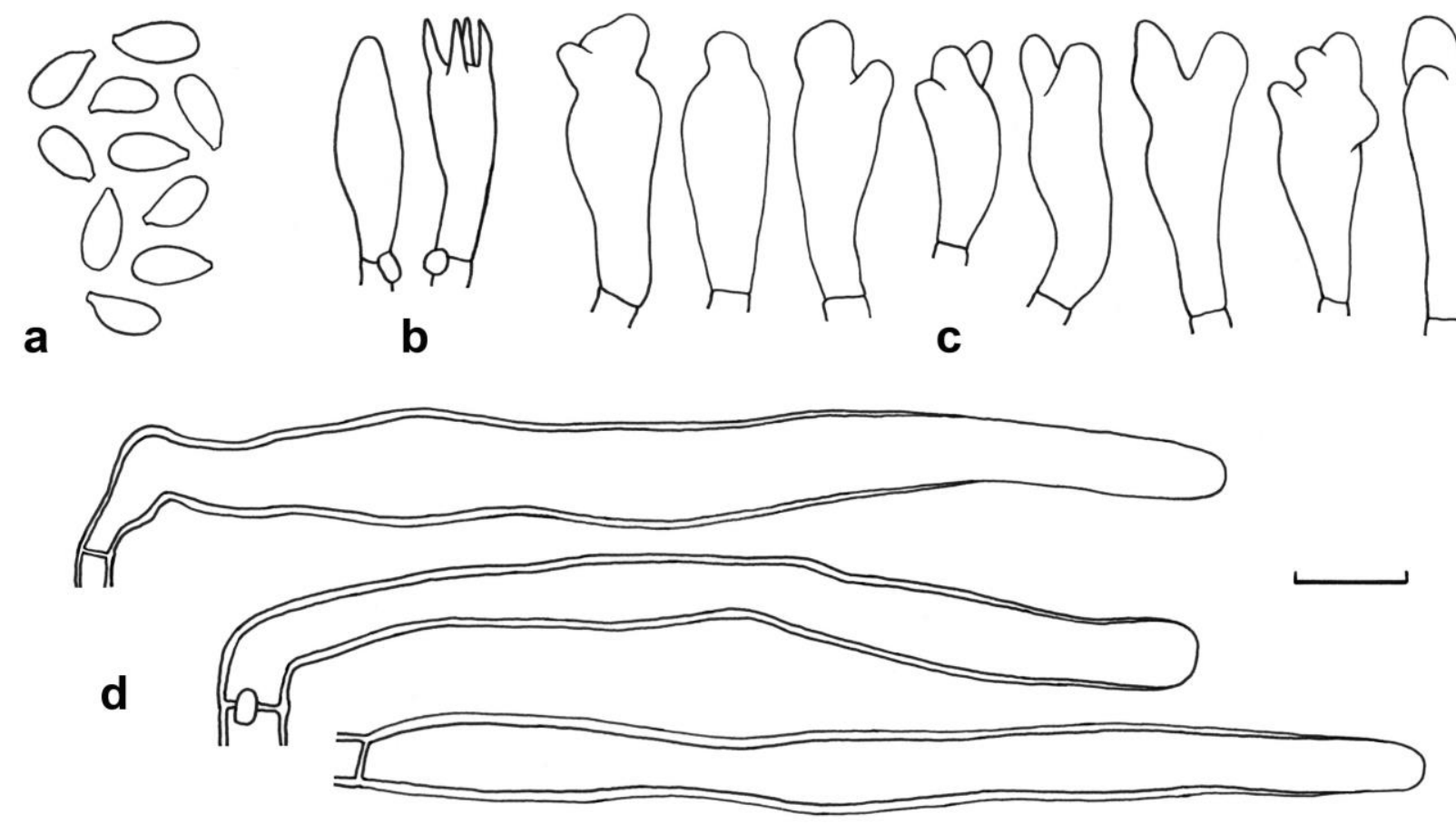

Fig. 35 - Micromorphological features of Gymnopus hirtellus (DED 8299). a. Basidiospores. b. Basidium and basidiole. c. Cheilocystidia. d. Caulocystidia. Scale bar $=10 \mu \mathrm{m}$

Habitat and known distribution - Scattered to gregarious on undetermined dicotyledonous leaves and twigs in secondary forest. Africa (Kenya, Príncipe, Tanzania, Uganda), Sri Lanka.

Material examined - AFRICA. Príncipe, Roça Pico Papagaio, N01 37.182', E07²3.474', 21 April 2008, coll. by D.E. Desjardin, DED 8299 (MF100974, SFSU).

Notes - Gymnopus hirtellus is characterized by a small, striate, brown to greyish orange pileus, adnate, crowded lamellae with pruinose edges, an insititious, pruinose stipe, relatively small ellipsoid basidiospores with mean $6.7 \times 3.5 \mu \mathrm{m}$, irregularly clavate, apically lobed cheilocystidia, a pileipellis of non-diverticulate, brown-incrusted hyphae, numerous hyaline, thick-walled, cylindrical caulocystidia, and growth on leafy debris. The species was described originally from Sri Lanka (Berkeley and Broome 1875, as Marasmius) and reported subsequently from East Africa (Pegler 1977, as Marasmiellus).

Pairwise comparisons of aligned, overlapping ITS sequences of G. hirtellus with the top ten BLAST results indicate $92.1 \%$ similarity to Gymnopus sp. (KF430218) from Thailand, and 91.992.1\% similarity to $G$. villosipes (KJ416255-New Zealand, DQ450058-USA). In the ITS phylogeny (Fig. 1) Gymnopus hirtellus belongs in a well-supported clade (93\% BS, 1.0 PP) with eight other Gymnopus species whose relationships with each other show low support.

Gymnopus hirtelloides Desjardin \& B.A. Perry, sp. nov.

Fig. 36a-d

MycoBank: MB821160; Facesoffungi number: FoF03746 
Holotype - AFRICA. Príncipe, Dois Irmãos area, N01³4.889', E07²5.548', elev. 100 m, 23 April 2008, coll. by D.E. Desjardin, DED 8318 (SFSU).

Etymology - hirtelloides, similar to Gymnopus hirtellus.

Diagnosis - Pileus 4-12 mm diam, convex, soon plano-convex to plane, margin non-striate or seldom faintly rugulose-striatulate; surface dull, dry, appressed-felted, dull brown (7E4) overall. Lamellae adnate, crowded with 3-4 series of lamellulae, narrow $(<1 \mathrm{~mm})$, white; edges granulose, concolorous. Stipe 15-20 × $1 \mathrm{~mm}$, central, terete, cylindrical, tough, pliant, insititious; surface dull, dry, pruinose overall; apex white, centrally light brown (7D5-6), base brown (7E4); rhizomorphs absent. Odor indistinct.

Basidiospores 6.0-8.0 $\times 3.5-4.5 \mu \mathrm{m}\left[\mathrm{x}_{\mathrm{m}}=7.06 \pm 0.72 \times 3.93 \pm 0.28 \mu \mathrm{m}, \mathrm{Q}=1.6-2.1, \mathrm{Q}_{\mathrm{m}}=1.8 \pm\right.$ $0.06, \mathrm{n}=20, \mathrm{~s}=1]$, ellipsoid, smooth, hyaline, inamyloid, thin-walled. Basidia 16-23 $\times 5-7 \mu \mathrm{m}$, clavate, 4-spored. Basidioles clavate to subfusoid. Pleurocystidia absent. Lamellar edge sterile. Cheilocystidia 19-36 × 4.5-8 $\mu$ m, irregularly cylindrical with broad knob-like outgrowths, often apically lobed, hyaline, inamyloid, thin-walled. Pileipellis a cutis of repent, radially arranged hyphae 3.5-6.5 $\mu \mathrm{m}$ diam, cylindrical, non-diverticulate, coarsely incrusted with brown, granular pigments; walls thin, hyaline, inamyloid, non-gelatinous; terminal cells undifferentiated. Pileus trama interwoven; hyphae 2.5-8 (-10) $\mu \mathrm{m}$ diam, cylindrical, branched, hyaline, inamyloid, non-incrusted, non-gelatinous, thin-walled. Lamellar trama regular; hyphae similar to pileus trama. Stipitipellis a cutis with clustered caulocystidia; cortical hyphae 2.5-7 $\mu \mathrm{m}$ diam, parallel, cylindrical, non-diverticulate, hyaline (apex) to pale yellowish brown (base), inamyloid, non-incrusted, non-gelatinous, thick-walled $(0.5-1 \mu \mathrm{m})$; medullary hyphae 3-10 $\mu \mathrm{m}$ diam, cylindrical, hyaline, inamyloid, non-gelatinous, thinwalled or with walls up to $0.8 \mu \mathrm{m}$ thick. Caulocystidia $32-70 \times 5-8 \mu \mathrm{m}$, cylindrical to subclavate, broadly obtuse, hyaline, inamyloid, thick-walled $(0.5-1 \mu \mathrm{m})$. Clamp connections common in all tissues.

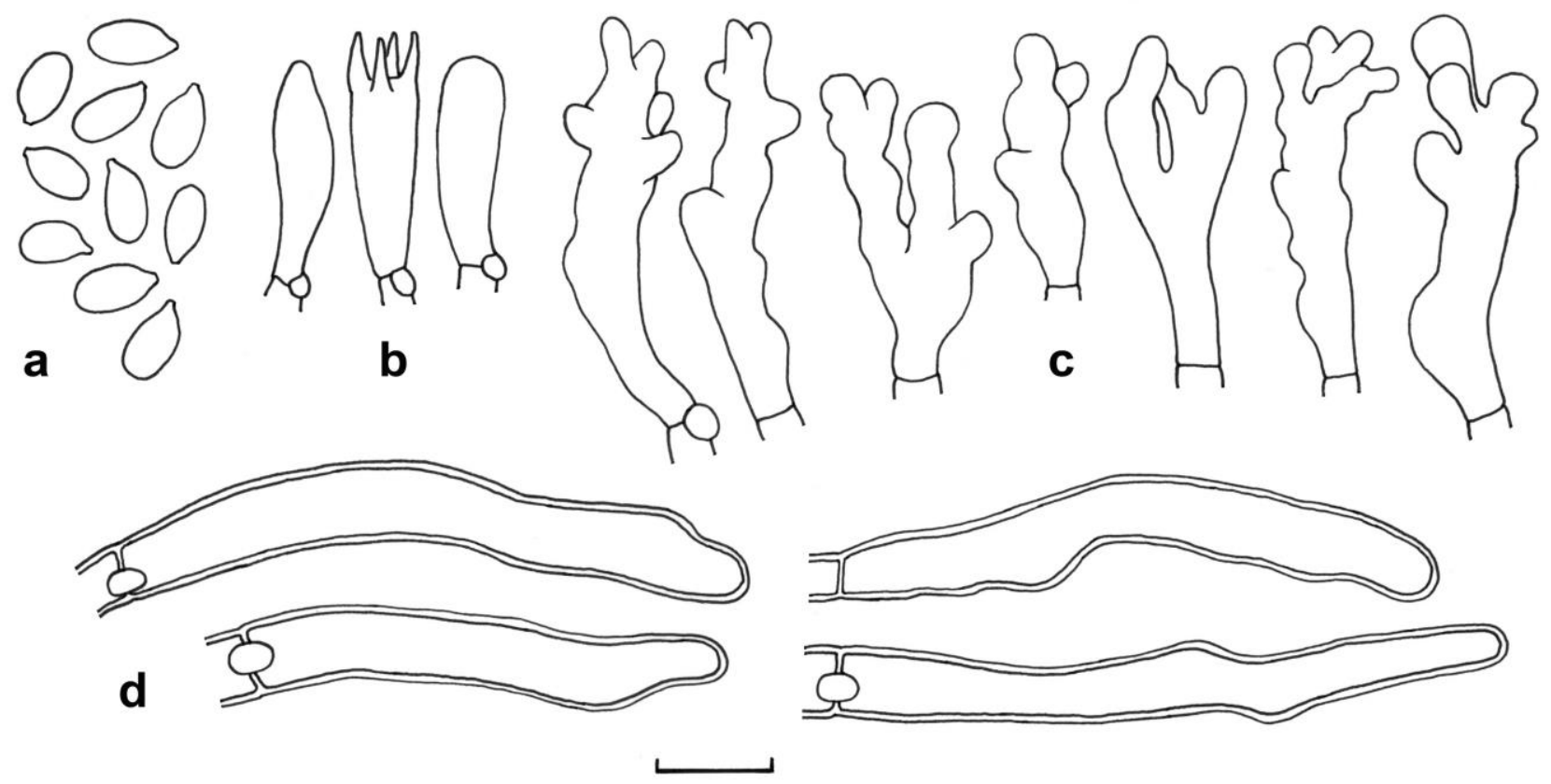

Fig. 36 - Micromorphological features of Gymnopus hirtelloides (Holotype, DED 8318). a. Basidiospores. b. Basidium and basidioles. c. Cheilocystidia. d. Caulocystidia. Scale bar $=10 \mu \mathrm{m}$ 
Habitat and known distribution - Gregarious on undetermined dicotyledonous leaves in secondary coastal forest. Africa (Príncipe).

Material examined - AFRICA. Príncipe, Dois Irmãos area, N01³4.889', E07²5.548', elev. 100 m, 23 April 2008, coll. by D.E. Desjardin, DED 8318 (Holotype, MF100975, SFSU).

Notes - Macro- and micromorphological features of Gymnopus hirtelloides are nearly indistinguishable from those of G. hirtellus, and indeed, without molecular data DED 8318 was considered conspecific with other material from Príncipe determined as G. hirtellus (DED 8299). However, pairwise comparisons of aligned, overlapping ITS sequences of DED 8318 (G. hirtelloides) with DED 8299 (G. hirtellus) showed only 91.1\% similarity. Subtle morphological differences include: a primarily non-striate, felted, dull brown pileus, basidiospores with mean $7 \times 3.9 \mu \mathrm{m}$, and cheilocystidia with numerous knob-like outgrowths in $G$. hirtelloides, compared to a rugulose-striate, glabrous, greyish orange pileus, basidiospores with mean $6.7 \times 3.5 \mu \mathrm{m}$, and cheilocystidia with few knob-like outgrowths in G. hirtellus. Gymnopus johnstonii (Murrill) A.W. Wilson, Desjardin \& E. Horak is similar to G. hirtelloides, but differs in forming fewer lamellae, a non-insititious stipe, and less nodulose cheilocystidia (Wilson et al. 2004).

Pairwise comparisons of aligned, overlapping ITS sequences of G. hirtelloides with the top ten BLAST results indicate $93.9 \%$ similarity to Gymnopus sp. (AB512321) from Japan, 92\% similarity to Gymnopus sp. (AY781255) from Sweden, and 91.8\% similarity to an uncultured Agaricales clone (FJ179476) from the Caribbean island of Guadeloupe. In the ITS phylogeny (Fig. 1), G. hirtelloides belongs to the same clade well-supported clade as G. hirtellus (93\% BS, 1.0 PP).

Gymnopus ocellus Desjardin \& B.A. Perry, sp. nov.

Figs 37, 38a-d

MycoBank: MB821163; Facesoffungi number: FoF03747

Holotype - AFRICA. Príncipe, along road to Roça Pico Papagaio, N01³8.600', E07²3.827', 21 April 2008, coll. by D.E. Desjardin, DED 8280 (SFSU).

Etymology - ocellus (Latin) = eye, referring to the iris-like pigmentation pattern on the pileus surface

Diagnosis - Pileus 20-55 (-70) mm diam, broadly convex to plano-convex with a depressed disc; margin wavy-undulate, sometimes cleft, decurved, rugulose-pellucid-striatulate; surface dull, moist to dry, hygrophanous, glabrous; disc brown (7E6-8), margin streaked light brown (6D5-6) to brownish grey or greyish orange $(6 \mathrm{~B}-\mathrm{C} 3)$, fading to dingy cream (4A3) or white with moisture loss and in age. Context $1 \mathrm{~mm}$ thick, soft, white. Lamellae adnate to shallowly adnexed, crowded with 3-4 series of lamellulae, narrow to moderately broad $(2-4 \mathrm{~mm})$, off-white. Stipe 40-70 $\times 2-5$ (apex) $\times 4-8$ (base) $\mathrm{mm}$, central, terete, apex flared, cylindrical below to an enlarged base, twisted-striate, fibrous, tough, pliant, non-insititious; surface dull, dry, pubescent; apex buff, base greyish brown (6D-E3) to dark greyish brown (7E3-4). Odor strongly fungal.

Basidiospores not observed; material apparently sterile. Basidia not observed. Basidioles 17.5-21 $\times 4-5 \mu \mathrm{m}$, clavate to subfusoid. Pleurocystidia scattered, common, 32-40 x 8-11 $\mu \mathrm{m}$, broadly clavate to fusoid-ventricose, pedicellate, hyaline, inamyloid, thin-walled. Lamellar edge sterile. Cheilocystidia $32-58 \times 6.5-16 \mu \mathrm{m}$, versiform, pedicellate, fusoid-ventricose to lageniform, subcylindrical or clavate, hyaline, inamyloid, thin-walled or with walls up to $0.5 \mu \mathrm{m}$ thick. Pileipellis a cutis of repent, radially arranged hyphae 4.5-9.5 $\mu \mathrm{m}$ diam, cylindrical, non-diverticulate, hyaline with scattered brown granulose incrustations, non-gelatinous, thin-walled; terminal cells undifferentiated, repent to suberect, cylindrical to subclavate. Pileus trama interwoven; hyphae 3-6.5 $\mu \mathrm{m}$ diam, cylindrical, branched, hyaline, inamyloid, non-incrusted, non-gelatinous, thin-walled. Lamellar trama regular; hyphae 2.5-6.5 $(-10) \mu \mathrm{m}$, cylindrical, hyaline, inamyloid, subgelatinous, thin-walled. Stipitipellis an interwoven lattice of tangled hyphae with erect caulocystidia; cortical hyphae $2.5-6 \mu \mathrm{m}$ diam, wavy-cylindrical, hyaline, inamyloid, non-incrusted, non-gelatinous, thin-walled; medullary hyphae 3-10 mm diam, cylindrical, 
hyaline, inamyloid, thick-walled $(0.5-1 \mu \mathrm{m})$; with scattered hyaline oleiferous hyphae interspersed. Caulocystidia 16-78 $\times 3-5 \mu \mathrm{m}$, sinuous to cylindrical, obtuse, seldom with a small lobe, hyaline, inamyloid, thin-walled. Clamp connections present in all tissues.

Habitat and known distribution - Scattered on decaying wood in secondary forest. Africa (Príncipe).

Material examined - AFRICA. Príncipe, along road to Roça Pico Papagaio, N01 38.600', E07²3.827', 21 April 2008, coll. by D.E. Desjardin, DED 8280 (Holotype, MF100976, SFSU).

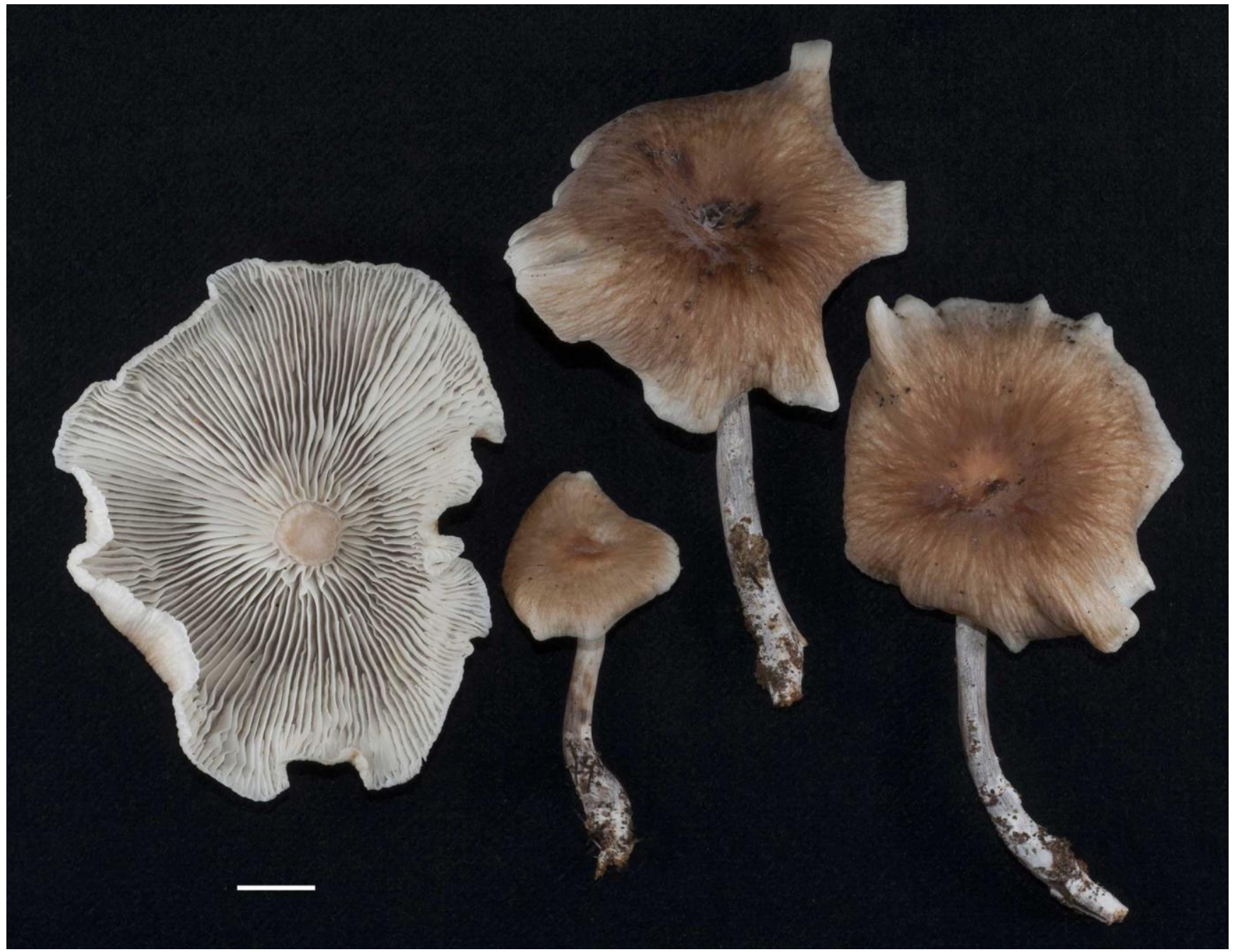

Fig. 37 - Basidiomes of Gymnopus ocellus (Holotype, DED 8280). Scale bar = $10 \mathrm{~mm}$

Notes - Gymnopus ocellus is characterized by a glabrous, hygrophanous, plane-depressed pileus with brown disc and streaked brown-white margin, crowded, narrow, off-white lamellae, a stout pubescent stipe, clavate to fusoid-ventricose, pedicellate pleurocystidia and cheilocystidia, inamyloid and non-dextrinoid, clamped hyphae, narrow $(3-5 \mu \mathrm{m})$, sinuous caulocystidia, and growth on rotten logs. The presence of large, conspicuous pleurocystidia is unusual in Gymnopus, with the Príncipe material showing morphological affinity to G. termiticola (Corner) A.W. Wilson, Desjardin \& E. Horak, G. omphalodes (Berk.) Halling \& J.L. Mata, G. lodgeae (Singer) J.L. Mata and $G$. pseudolodgeae J.L. Mata. Gymnopus termiticola, from Java, differs in forming a conspicuously rugulose-sulcate, greyish red pileus, distant lamellae, much longer basidioles $(21-38 \mu \mathrm{m})$, lobed cheilocystidia, lanceolate pleurocystidia, and growth on old termite nests (Wilson et al. 2004). 
Gymnopus omphalodes, described from Brazil, forms a more conspicuously striate, paler ("cartridge buff") pileus, narrower stipe (1-2 mm), and irregularly cylindrical cheilocystidia 5-9 $\mu \mathrm{m}$ diam (Dennis 1951, Pegler 1983). Gymnopus lodgeae, from Costa Rica, differs in conspicuously striate-sulcate pileus, subdistant to distant lamellae, dark purplish brown stipe, and dimorphic hymenial cystidia with one type acute-fusoid (Singer 1989), while G. pseudolodgeae has a deeply sulcate pileus, distant pinkish brown lamellae, and apically diverticulate cheilocystidia (Mata et al. 2004).

Pairwise comparisons of aligned, overlapping ITS sequences of Gymnopus ocellus with the top ten BLAST results indicate closest similarity (89.4-90.5\%) to three specimens of G. omphalodes

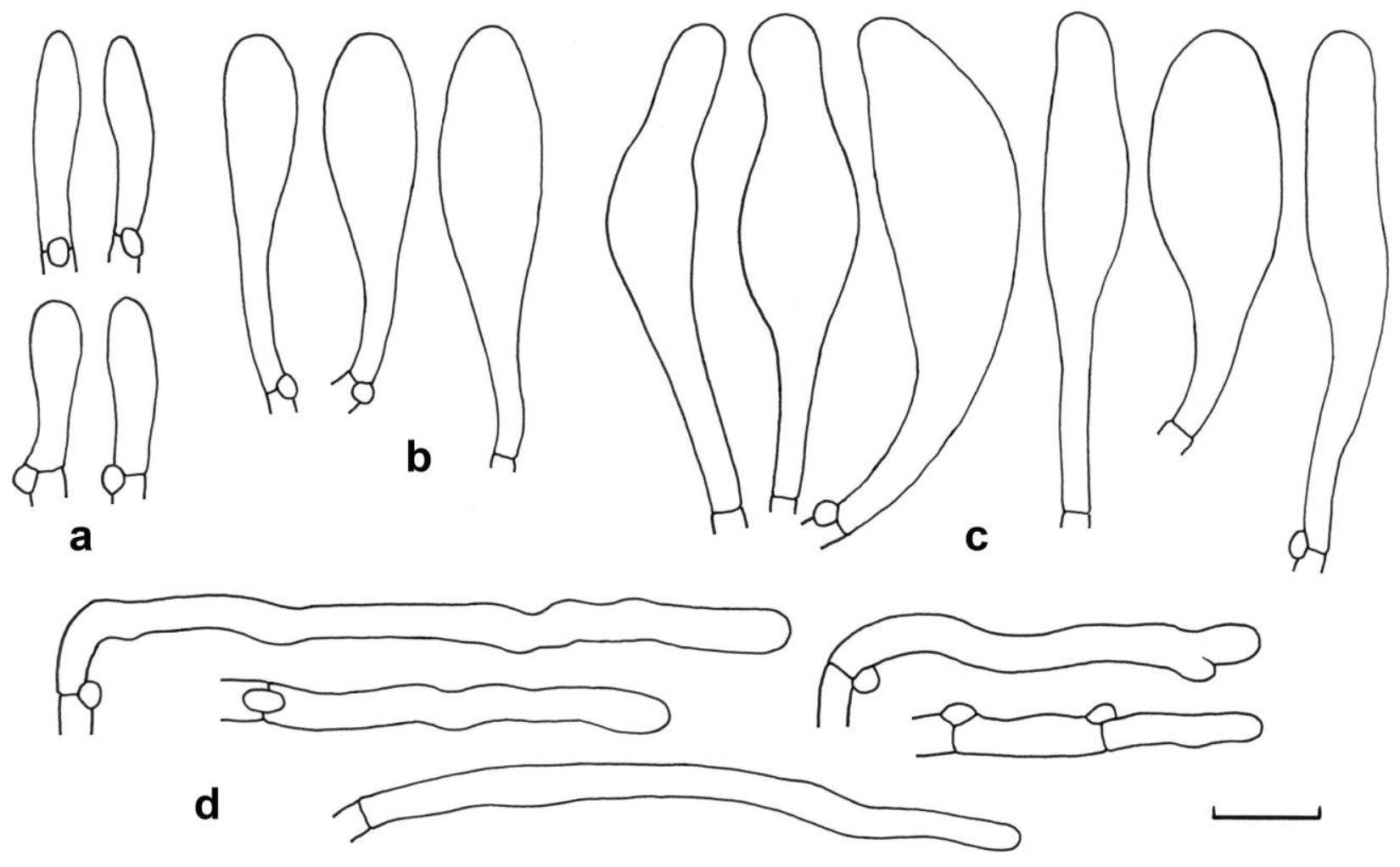

Fig. 38 - Micromorphological features of Gymnopus ocellus (Holotype, DED 8280). a. Basidioles. b. Pleurocystidia. c. Cheilocystidia. d. Caulocystidia. Scale bar $=10 \mu \mathrm{m}$

(AF505761, AY256700 - Costa Rica; KJ609160 - Korea). Gymnopus ocellus forms a clade with $G$. omphalodes (72\% BS, 0.94 PP) in our ITS phylogeny (Fig. 1), but interestingly, they are distantly related to the other morphologically similar pleurocystidia-formers, G. lodgeae, G. pseudolodgeae and G. termiticola, who form a well-supported clade (100\% BS, 1.0 PP) sister to G. dichrous.

Gymnopus pleurocystidiatus Desjardin \& B.A. Perry, sp. nov.

Figs 39, 40a-e

MycoBank: MB821164; Facesoffungi number: FoF03748

Holotype - AFRICA. Príncipe, Dois Irmãos area, N01³4.889', E07²5.548', elev. 100 m, 23 April 2008, coll. by B.A. Perry and D.E. Desjardin, BAP 651 (SFSU).

Etymology - referring to the abundant pleurocystidia, unusual in species of Gymnopus.

Diagnosis - Pileus 15-33 mm diam, broadly convex, smooth to minutely rugulose, margin shortstriatulate; surface dull, dry, glabrous to appressed-fibrillose or felted, cream (4A3) with brown fibrils on the disc. Context thin $(-1 \mathrm{~mm})$, white. Lamellae adnate to shallowly adnexed, subdistant with 3-4 
series of lamellulae, narrow (1-2 mm), off-white to buff, edges concolorous. Stipe $22-33 \times 1.5-2.5$ $\mathrm{mm}$, central to slightly eccentric, cylindrical above a slightly broader or subbulbous base, though, pliant, hollow, insititious; surface dull, dry, white-pruinose overall; apex off-white to buff, grading below to brown or dark brown (7-8E5-6).

Basidiospores 7.7-10 × 2.5-3.5 $\mu \mathrm{m}\left[\mathrm{x}_{\mathrm{m}}=8.8 \pm 0.7 \times 3.0 \pm 0.28 \mu \mathrm{m}, \mathrm{Q}=2.4-3.4, \mathrm{Q}_{\mathrm{m}}=2.99 \pm\right.$ $0.19, \mathrm{n}=20, \mathrm{~s}=1$ ], subcylindrical to elongate-ellipsoid or subfusoid, smooth, hyaline, inamyloid, thinwalled. Basidia not observed, presumably 4-spored (spore-tetrads observed). Basidioles 16-24 × 4.5-6 $\mu \mathrm{m}$, cylindrical to fusoid, clamped. Hymenial cystidia abundant, present as cheilocystidia (lamellar edge primarily sterile) and pleurocystidia, exudative, arising from the lamellar trama; 45-60 × 8-13 (16) $\mu \mathrm{m}$, subcylindrical to clavate or fusoid, seldom subfusoid, pedicellate, obtuse, hyaline, inamyloid, thin-walled. Pileipellis a cutis of repent, radially arranged to slightly interwoven hyphae 2.5-6.5 (-8) $\mu \mathrm{m}$ diam, cylindrical, smooth or weakly incrusted, non-diverticulate or with scattered rod-like to knoblike outgrowths (a poorly developed Rameales-structure), pale yellow to yellowish brown, pigments intraparietal, inamyloid, non-gelatinous, thin-walled or with walls up to $0.8 \mu \mathrm{m}$ thick; terminal cells undifferentiated or with a few broad, cylindrical to knob-like outgrowths. Pileus trama interwoven; hyphae 3-13 $\mu \mathrm{m}$ diam, cylindrical, hyaline, inamyloid, non-gelatinous, thin-walled. Lamellar trama subparallel to nearly divergent; hyphae 3-13 $\mu \mathrm{m}$ diam, cylindrical, hyaline, inamyloid, non-gelatinous, thin-walled or with walls up to $0.8 \mu \mathrm{m}$ thick. Stipitipellis a cutis with abundant, scattered to clustered caulocystidia; cortical hyphae 2.5-6.5 $\mu \mathrm{m}$ diam, cylindrical, hyaline (apex) to yellowish brown (base), inamyloid, non-incrusted, non-gelatinous, thin-walled; medullary hyphae 2.5-10 $\mu \mathrm{m}$ diam, cylindrical, hyaline, inamyloid, thin-walled. Caulocystidia 22-64 (-86) $\times 4-10 \mu \mathrm{m}$, cylindrical to subfusoid,

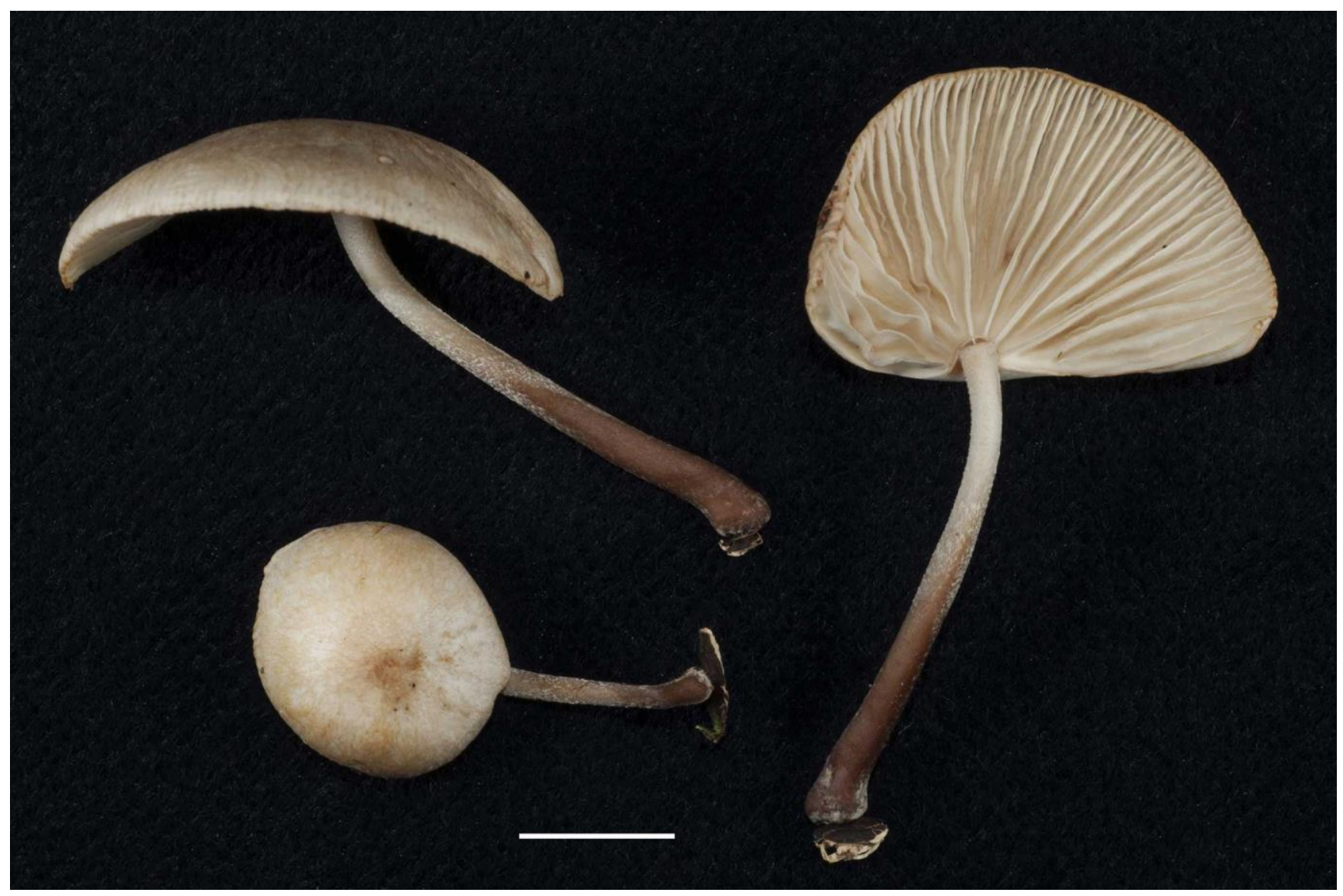

Fig. 39 - Basidiomes of Gymnopus pleurocystidiatus (Holotype, BAP 651). Scale bar = $10 \mathrm{~mm}$ 
obtuse, sometimes geniculate, hyaline, inamyloid, thin-walled or with walls up to $1 \mathrm{~mm}$ thick. Clamp connections present in all tissues.

Habitat and known distribution - Scattered on decaying wood in secondary coastal forest. Africa (Príncipe).

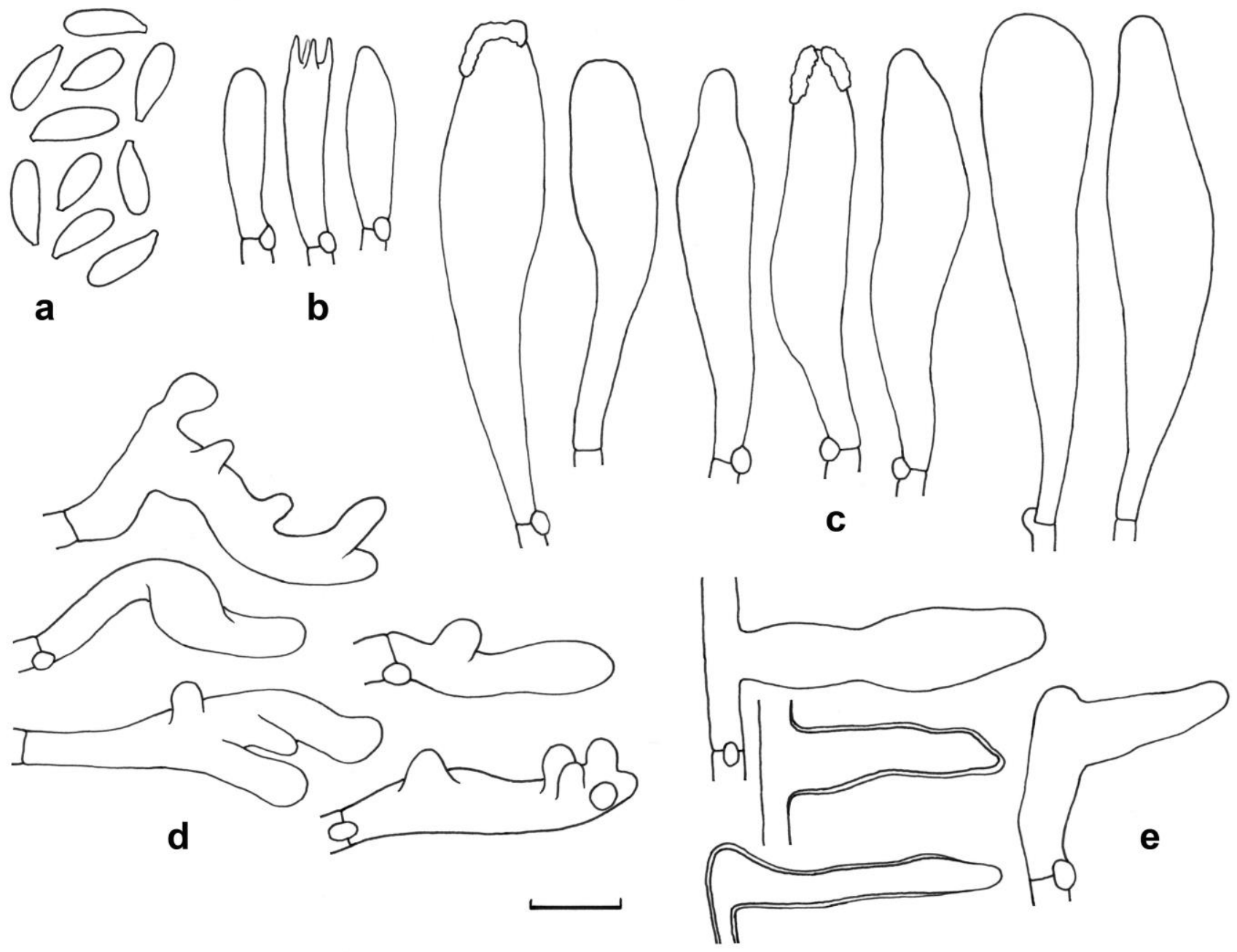

Fig. 40 - Micromorphological features of Gymnopus pleurocystidiatus (Holotype, BAP 651). a. Basidiospores. b. Basidium and basidioles. c. Hymenial cystidia (pleurocystidia and cheilocystidia). d. Pileipellis terminal cells. e. Caulocystidia. Scale bar $=10 \mu \mathrm{m}$

Material examined - AFRICA. Príncipe, Dois Irmãos area, N01 34.889', E07²5.548', elev. 100 m, 23 April 2008, coll. by B.A. Perry and D.E. Desjardin, BAP 651 (Holotype, MF100977, SFSU).

Notes - Gymnopus pleurocystidiatus is characterized by convex, felted, cream-colored pileus with central brown fibrils, subdistant, buff lamellae, a white-pruinose, buff to brown stipe, relatively long and narrow basidiospores with mean $8.8 \times 3.0 \mu \mathrm{m}$, abundant, cylindrical to fusoid cheilocystidia, pleurocystidia and caulocystidia, clamp connections, and growth on woody debris. This may represent what Pegler (1977) reported as Marasmiellus omphalodes (Berk.) Singer (= Gymnopus omphalodes (Berk.) Halling \& J.L. Mata) from Uganda, although he described the lamellae as drying brown and with smaller basidiospores, 6-8.3 $\times 2-3 \mu \mathrm{m}\left(\mathrm{x}_{\mathrm{m}}=7.5 \times 2.4 \mu \mathrm{m}\right)$. We consider Gymnopus omphalodes, described originally from Brazil, as distinct from the taxon reported by Pegler (1977), differing in 
forming a more well-developed Rameales-structure on the pileipellis and stipitipellis (with diverticulate cortical hyphae), smaller basidiospores $(6.0-7.8 \times 1.8-3 \mu \mathrm{m})$, some diverticulate cheilocystidia, shorter pleurocystidia $(16-32 \mu \mathrm{m})$, and shorter $(-20 \mu \mathrm{m})$, diverticulate caulocystidia (Singer 1973).

Pairwise comparisons of aligned, overlapping ITS sequences of Gymnopus pleurocystidiatus with the top ten BLAST results indicate closest similarity $(92.5-94.7 \%)$ to uncultured, undetermined Agaricales clones. Comparisons with ITS sequences of Gymnopus omphalodes from Costa Rica (DQ450010, DQ450011, AY256700, AF505761) showed only 86-87\% similarity. Indeed, in the ITS phylogeny (Fig. 1) G. pleurocystidiatus belongs in a clade (76\% BS, $1.0 \mathrm{PP}$ ) with taxa once considered typical for Marasmiellus sect. Rameales, distant from G. omphalodes.

Gymnopus gibbosus (Corner) A.W. Wilson, Desjardin \& E. Horak, Sydowia 56: 175. 2004.

Basionym: Marasmius gibbosus Corner, Beih. Nova Hedwigia 111: 55.1996.

Figs 41, 42a-c

Facesoffungi number: FoF03749

Pileus 18-24 mm diam, convex; margin decurved, non-striate, eroded and split in age; surface dull, dry, appressed-fibrillose, disc brown (5-6F6-7), margin cream-brown (4-5C-D4-5). Context 1-2 $\mathrm{mm}$ thick, soft, white. Lamellae adnate with a short decurrent tooth, close with 2 series of lamellulae, moderately broad, cream (4A3), edges concolorous. Stipe 45-50 × 2.5-3 mm, central, cylindrical, terete or flattened, sometimes once-cleft, stuffed, non-insititious; surface dull, dry, glabrous, fibrousstreaked; apex pale greyish brown (5-6E3-4), base dark greyish brown (5-6F4-5), with white basal tomentum.

Basidiospores only 5 seen, 8-9.2 $\times 4.5-4.8 \mu \mathrm{m}\left[\mathrm{x}_{\mathrm{m}}=8.5 \times 4.7 \mu \mathrm{m}\right]$, ellipsoid, smooth, hyaline, inamyloid, thin-walled. Basidia few seen, clavate, 4-spored. Basidioles 25-32 × 5.5-7.5 $\mu$ m, clavate to fusoid-ventricose. Pleurocystidia absent. Cheilocystidia scattered, few seen (lamellar edges eroded); $28-42 \times 3.5-6.5 \mu \mathrm{m}$, irregularly cylindrical, with or without a few knob-like outgrowths, hyaline, inamyloid, thin-walled. Pileipellis a cutis of radially arranged hyphae 3-7 $\mu \mathrm{m}$ diam, cylindrical, nondiverticulate, smooth or brown-incrusted, yellowish brown to brown, inamyloid, weakly gelatinous, thin-walled; terminal cells repent, similar to the cheilocystidia. Pileus trama interwoven to radially arranged; hyphae 4.5-10 $\mu \mathrm{m}$ diam, cylindrical, hyaline, inamyloid, non-gelatinous, thin-walled. Lamellar tama regular; hyphae 3-12 $\mu \mathrm{m}$ diam, cylindrical or inflated, hyaline, inamyloid, nongelatinous, thin-walled. Stipitipellis a cutis with scattered caulocystidia; cortical hyphae 3-6.5 $\mu \mathrm{m}$ diam, cylindrical, non-diverticulate, smooth, hyaline to pale brown, inamyloid, non-gelatinous, thinwalled; medullary hyphae 4-8 $\mu \mathrm{m}$ diam, hyaline, otherwise like cortical hyphae. Caulocystidia repent, similar to the cheilocystidia. Clamp connections present.

Habitat and known distribution - Solitary on tough, persistent bracts of baobab fruits. Africa (São Tomé), Indonesia (Java), Singapore.

Material examined - AFRICA. São Tomé, along main road (EN1) on north side of island at 16.5 km marker, N00²4.374', E06³7.092', 17 Apr. 2008, coll. by B.A. Perry and D.E. Desjardin, BAP 620 (MF100978, SFSU).

Notes - Described originally from Singapore (Corner 1996), Gymnopus gibbosus was redescribed from material collected in Java (Wilson et al. 2004). The São Tomé specimen matches nicely with the Javanese material. Gymnopus gibbosus has a moderately-sized, appressed-fibrillose pileus with brown disc and cream-brown margin, close cream-colored lamellae, a brown stipe, basidiospores with mean $8.5 \times 4.7 \mu \mathrm{m}$, irregularly cylindrical cheilocystidia, caulocystidia and pileipellis terminal cells, a cutis-type pileipellis of non-diverticulate, brown-incrusted hyphae, nondextrinoid tissues, clamp connections, and growth on woody debris. An ITS sequence of BAP 620 showed 99.3-99.9\% similarity to nine GenBank sequences determined as Gymnopus gibbosus in 


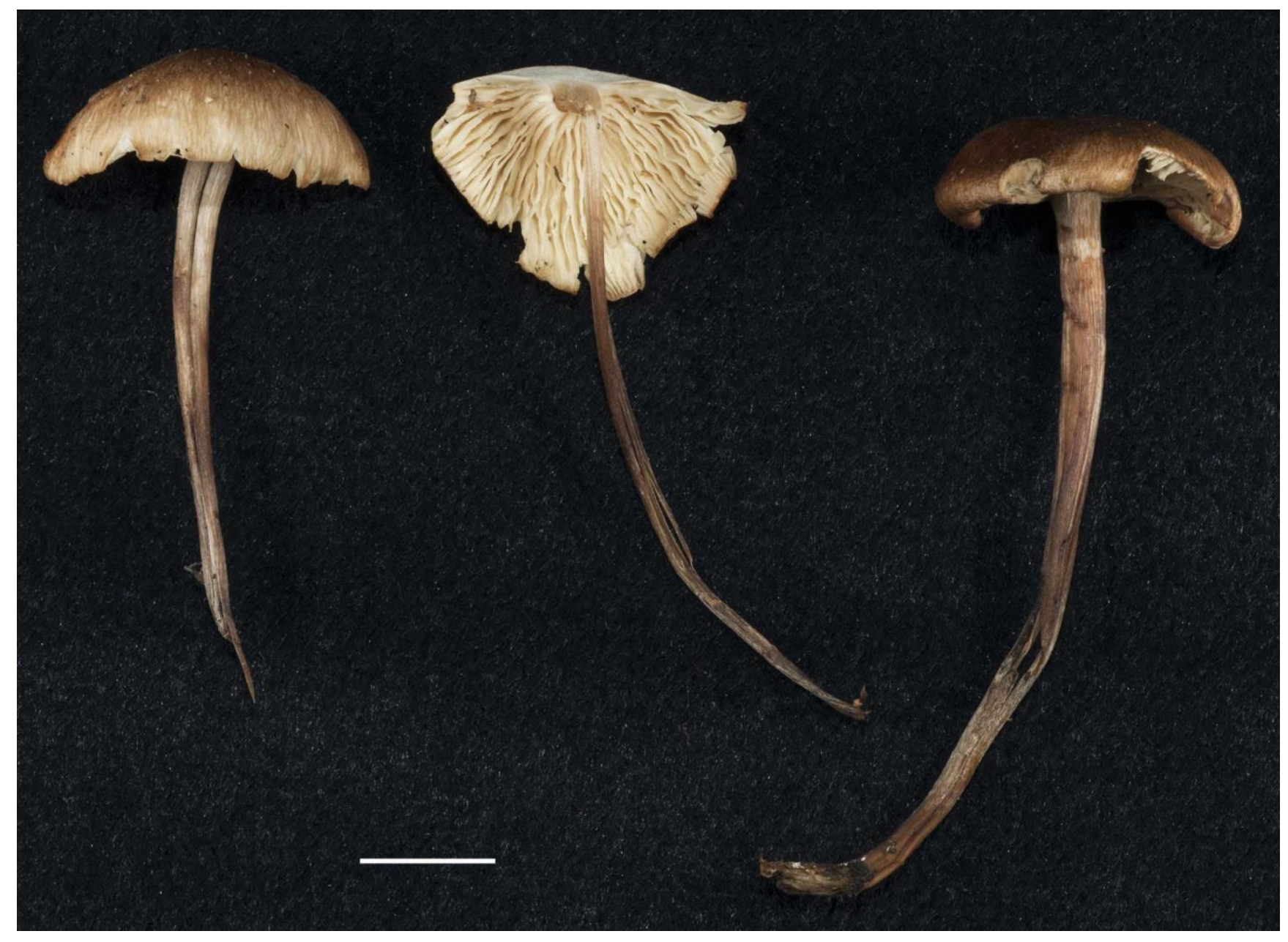

Fig. 41 - Basidiomes of Gymnopus gibbosus (BAP 620). Scale bar = $10 \mathrm{~mm}$

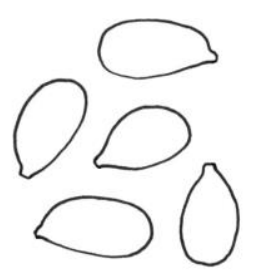

a

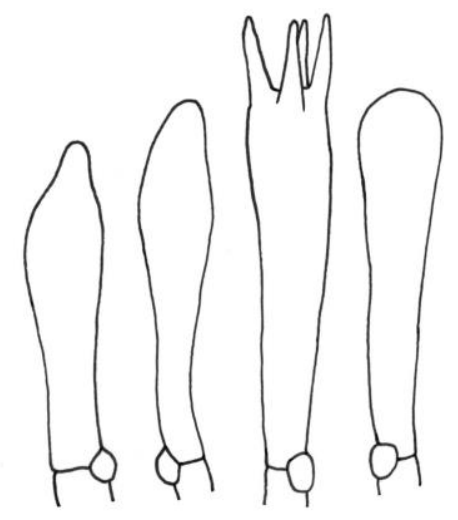

b

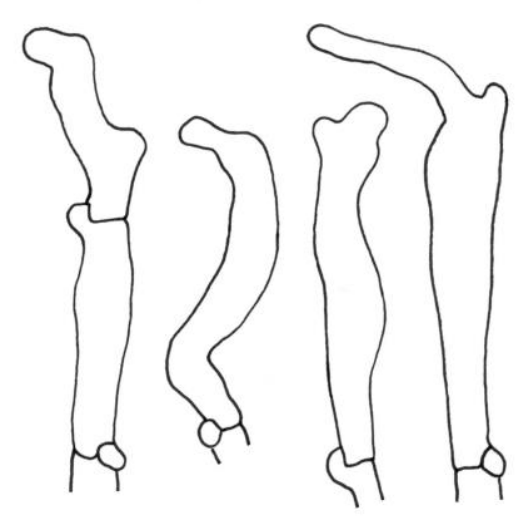

C

Fig. 42 - Micromorphological features of Gymnopus gibbosus (BAP 620). a. Basidiospores. b. Basidium and basidioles. c. Cheilocystidia. Scale bar $=10 \mu \mathrm{m}$

pairwise comparisons of aligned, overlapping sequences. Gymnopus gibbosus is sister to $G$. 
brunneigracilis with $93 \%$ BS and 1.0 PP support (Fig. 1).

Gymnopus aff. polygrammus (Mont.) J.L. Mata, in Mata \& Petersen, Mycotaxon 86: 313. 2003.

Figs 43, 44a-e

Basionym: Marasmius polygrammus Mont., Annls. Sci. Nat., Bot., Sér. 4(1): 118. 1854.

= Chamaeceras polygrammus (Mont.) Kuntze, Revis. Gen. Pl. (Leipzig) 3(2): 456. 1898.

= Collybia polygramma (Mont.) Dennis, Trans. Brit. Mycol. Soc. 34(4): 447. 1951.

Facesoffungi number: FoF03750

Pileus 17-70 mm diam, hemispherical or convex to shallowly campanulate, soon planedepressed with wavy-undulate, often split margin, initially smooth to striatulate, in age rugulosesulcate to the disc; surface dull, dry, glabrous to minutely pruinose, at first dark grayish brown (5-6EF4) overall, subhygrophanous, disc soon brown (5E5-6) to pale brownish orange (5C4), margin fading to pale greyish brown, beige, tan or dingy cream (<4A3). Context 1-2 mm thick, soft to tough and pliant, white under pileipellis, brown closer to the lamellae. Lamellae ascending-adnexed to adnate, close with 2-4 series of lamellulae, narrow to moderately broad $(1-4 \mathrm{~mm})$, when young yellowish white to cream (4A2-3), in age becoming pale greyish brown (5D3-4) and often spotted reddish brown; edges concolorous, short-ciliate. Stipe 35-60 × 2-5 mm, central, terete, cylindrical or gradually enlarged downward, hollow, tough, pliant, non-insititious; surface dull, dry, fibrous; apex felted, cream (4A3) to pale whitish grey; base tomentose, pale brownish orange (5C3) to brownish grey (3-4E3-4), covered with white tomentum. Odor and taste indistinct.

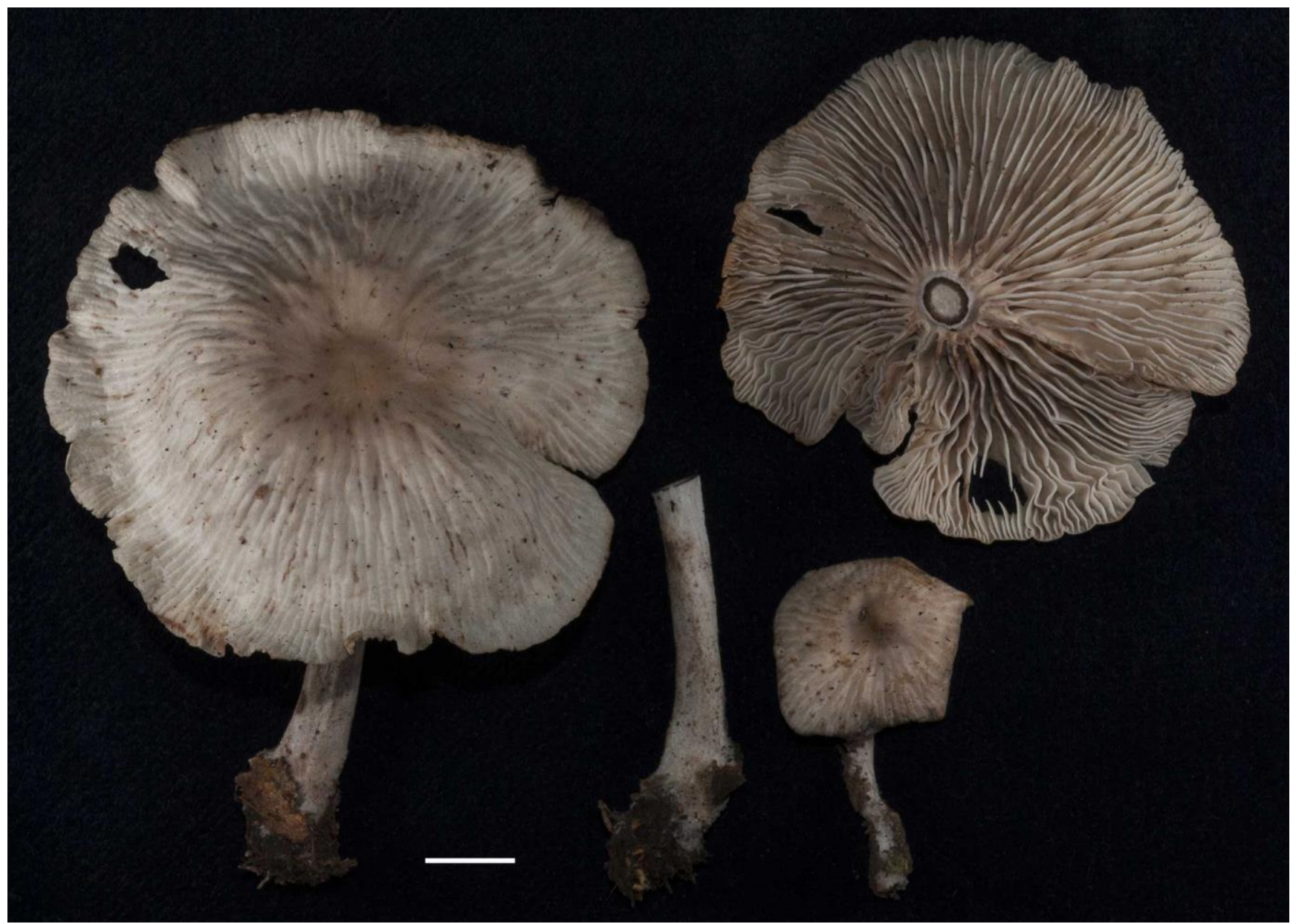

Fig. 43 - Basidiomes of Gymnopus aff. polygrammus (DED 8324). Scale bar = $10 \mathrm{~mm}$ 
Basidiospores 8-10.2 × 4.0-5.0 $\mu \mathrm{m}\left[\mathrm{x}_{\mathrm{m}}=9.2 \pm 0.66 \times 4.6 \pm 0.28 \mu \mathrm{m}, \mathrm{Q}=1.8-2.1, \mathrm{Q}_{\mathrm{m}}=2.0 \pm\right.$ $0.06, \mathrm{n}=20, \mathrm{~s}=1]$, a few $12-13 \times 4.8-5.0 \mu \mathrm{m}$ from 2-spored basidia, ellipsoid, smooth, hyaline, inamyloid, non-dextrinoid, thin-walled. Basidia 28-32 × 6.5-8 $\mu \mathrm{m}$, clavate, 4-spored, rarely 2-spored. Basidioles subclavate to subfusoid. Pleurocystidia absent. Lamellar edge sterile. Cheilocystidia catenulate; terminal cells $22-60 \times 3.2-8 \mu \mathrm{m}$, irregularly cylindrical to subfusoid, subclavate, narrowly ventricose or sinuous, often with one or more knob-like outgrowths, seldom lobed, hyaline, inamyloid, thin-walled; subtending cells 3.2-12 $\mu \mathrm{m}$ diam, inflated, otherwise like terminal cells. Pileipellis a cutis with numerous repent to erect pileocystidia; hyphae $3.2-8 \mu \mathrm{m}$ diam, radially arranged, cylindrical, non-diverticulate, non-incrusted or weakly incrusted with brown granular pigments, hyaline or pale brown, inamyloid, non-gelatinous, thin-walled; pileocystidia scattered, as lateral outgrowths or as repent to erect terminal cells, $12.5-36 \times 3.5-8 \mu \mathrm{m}$, irregularly cylindrical to clavate or narrowly ventricose, obtuse, often geniculate, hyaline, inamyloid, thin-walled. Pileus trama of slightly interwoven hyphae 3-13 $\mu \mathrm{m}$ diam, cylindrical or irregular in outline, branched, hyaline to very pale brown, inamyloid, non-incrusted, non-gelatinous, thin-walled or with walls up to $1.2 \mu \mathrm{m}$ thick. Lamellar trama regular; hyphae 2.5-10 $\mu \mathrm{m}$ diam, cylindrical to slightly inflated, hyaline, inamyloid, non-gelatinous, walls up to $0.5 \mu \mathrm{m}$ thick. Stipitipellis a lattice of tangled hyphae giving rise to erect caulocystidia; cortical hyphae 3-6.5 $\mu \mathrm{m}$ diam, cylindrical, parallel, non-incrusted, hyaline, dextrinoid, non-gelatinous, thin-walled; medullary hyphae similar but up to $13 \mu \mathrm{m}$ diam. Caulocystidia similar to cheilocystidia, single or catenulate, $25-80 \times 3.5-6.5 \mu \mathrm{m}$, cylindrical to sinuous, obtuse, lacking outgrowths, hyaline, inamyloid, non-gelatinous, thin-walled. Clamp connections common in all tissues.

Habitat and known distribution - Scattered to gregarious on decayed wood in primary forests or cacao-banana groves. Africa (São Tomé), British Honduras, Guyana, India, Martinique, Puerto Rico, Trinidad,

Material examined - AFRICA. São Tomé, Macambrara, radio antenna area, N00 $16.557^{\prime}$, E06 36.326', elev. 1300 m, 25 April 2008, coll. by D.E. Desjardin, DED 8324 (MF100979, SFSU); road EN1 near Santa Catarina, N0¹4.458', E06 28.278', elev. 10 m, 27 April 2008, coll. by D.E. Desjardin and B.A. Perry, BAP 668 (MF100980, SFSU).

Notes - The São Tomé material is characterized by a rather large, broadly campanulate to planedepressed, rugulose-sulcate, greyish brown pileus, close, moderately broad lamellae with ciliate margin, a felted-tomentose, non-insititious, lignicolous, brownish grey stipe, basidiospores with mean $9.2 \times 4.6 \mu \mathrm{m}$, sinuous-catenulate cheilocystidia, a cutis-type pileipellis with numerous short, cylindrical pileocystidia, and a tangled lattice of cylindrical-sinuous caulocystidia. Our material differs slightly from published accounts of $G$. polygrammus, wherein the pileus is reported as pinkish cinnamon to pale greyish cream (Pegler 1983), the lamellae as buff to creamy white (Dutta et al. 2015), and the stipe as reddish brown to cinnamon brown (Pegler 1983) or dark brown to black (Mata and Petersen 2003). Our São Tomé material is also similar to G. allegretii (De Seynes) A.W. Wilson, Desjardin \& E. Horak, but the latter species has fewer lamellae with less ciliate edges, slightly smaller basidiospores with mean $8 \times 4.3 \mu \mathrm{m}$ (Java; Wilson et al. 2004) or $7 \times 3.3 \mu \mathrm{m}$ (Africa; Pegler 1977), and the pileus was described by De Seynes (1897) as "roseo isabellino pallescente 3 cent. lato".

Pairwise comparisons of aligned, overlapping ITS sequences of Gymnopus aff. polygrammus with the top ten BLAST results indicate closest similarity (96.6-97.4\%) to five specimens of $G$. polygrammus (AY842954, AY256701, DQ450029 - Puerto Rico; KJ778752 - India; KJ609162 Korea). Because of the slight morphological differences, geographic distinction, and about $3 \%$ difference with ITS sequences annotated as representing $G$. polygrammus, we recognize our material as Gymnopus aff. polygrammus. In the ITS phylogeny (Fig. 1), Gymnopus aff. polygrammus is sister to G. polygrammus with $100 \%$ BS and 1.0 PP support. 


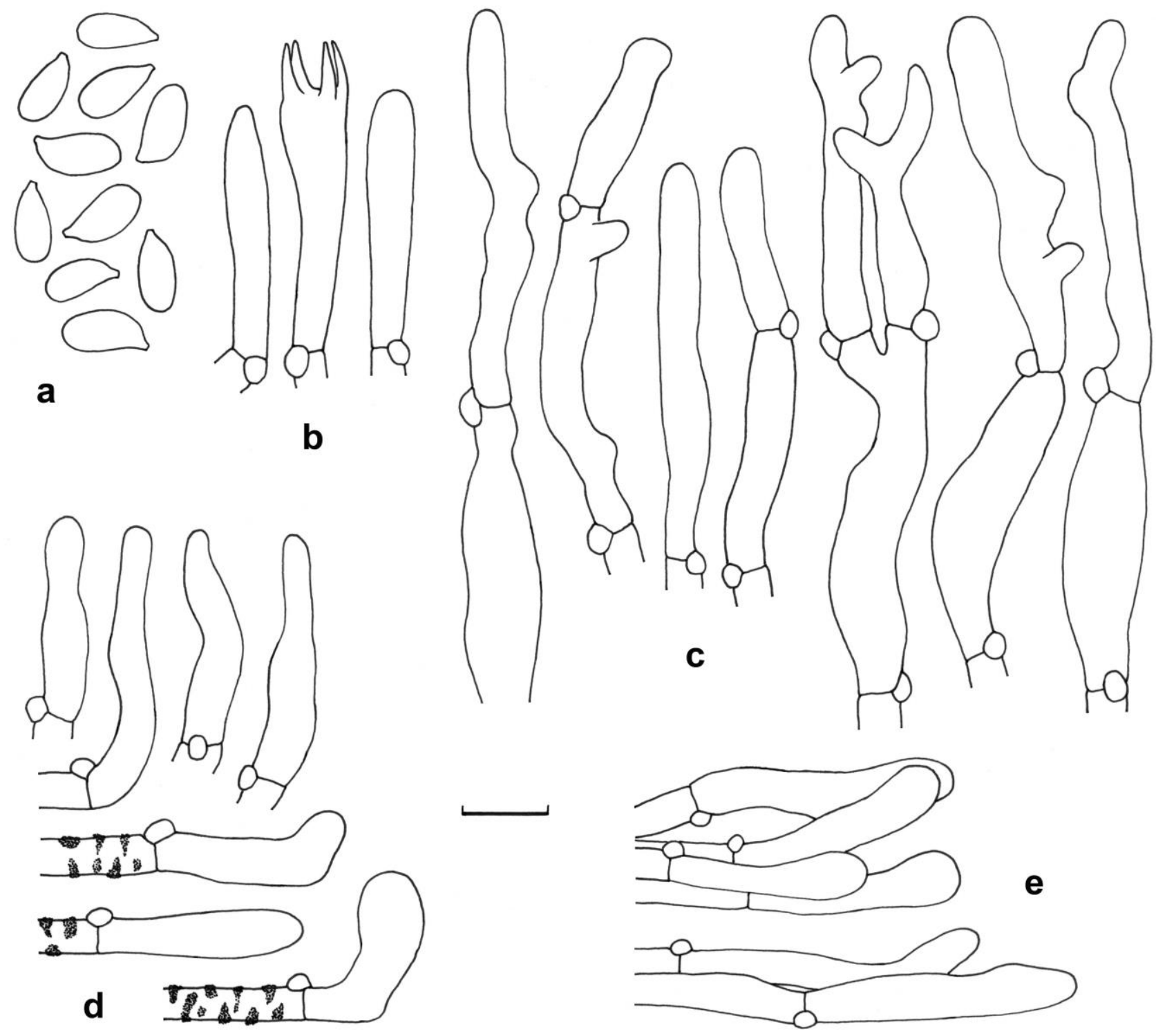

Fig. 44 - Micromorphological features of Gymnopus aff. polygrammus (DED 8324, BAP 668). a. Basidiospores. b. Basidium and basidioles. c. Cheilocystidia. d. Pileocystidia and pileipellis terminal cells. e. Caulocystidia. Scale bar $=10 \mu \mathrm{m}$

Gymnopus rodhallii Desjardin \& B.A. Perry, sp. nov.

MycoBank: MB821165; Facesoffungi number: FoF03751

Figs 45, 46a-d

Holotype - AFRICA. São Tomé, along main road EN1 at $33 \mathrm{~km}$ marker, N00 ${ }^{\circ} 19.606$ ', E06 30.667', 18 April 2008, coll. by D.E. Desjardin and B.A. Perry, BAP 627 (SFSU).

Etymology - named in honor of Roderick C. M. "Rod" Hall who has supported this project since its inception.

Diagnosis - Pileus (8-) 16-40 mm diam, hemispherical to broadly convex, expanding to planoconvex, centrally depressed, when young margin decurved, in age uplifted in places, split and eroded, striate to sulcate to the disc; surface dull, dry, glabrous, slightly polished, disc pale brownish grey to cream, or beige to cream (4A3) overall. Context up to $1 \mathrm{~mm}$ thick, buff, soft. Lamellae adnate, close with 2-3 series of lamellulae, occasionally forked, narrow $(1-2 \mathrm{~mm})$, cream (4A3) with concolorous 
edges. Stipe (30-) 45-70 × 2-3 mm, central, terete to compressed, cylindrical or with a slightly flared apex, tough, pliant, hollow, non-insititious; surface dull, dry, densely white-pruinose overall, dark greyish brown (6-7F3-4) to greyish brown (5-6E-F4) overall; arising from clusters of coarse white rhizomorphs. Odor somewhat sweet; taste indistinct.

Basidiospores 6.4-7.0 $\times 3.0-3.5 \mu \mathrm{m}$, only 6 observed in two specimens, ellipsoid to sublacrymoid, smooth, hyaline, inamyloid, thin-walled. Basidia not observed. Basidioles $18-25 \times 4.5-$ $6.5 \mu \mathrm{m}$, fusoid. Pleurocystidia absent. Cheilocystidia abundant, lamellar edge sterile; 38-66 × 7-11.5 $\mu \mathrm{m}$, clavate to nearly sphaeropedunculate or irregular in outline, typically non-lobed, occasionally with one lobe, hyaline, inamyloid, thin-walled. Pileipellis a cutis of repent, radially arranged hyphae 3.5-7.5 $\mu \mathrm{m}$ diam, cylindrical, non-diverticulate, smooth or weakly incrusted, hyaline or with pale yellowish brown incrustations, inamyloid, non-gelatinous, thin-walled; terminal cells undifferentiated, repent. Pileus trama of interwoven hyphae similar to those in the pileipellis but with walls up to $1 \mu \mathrm{m}$ thick. Lamellar trama regular; hyphae 2.5-6.5 $\mu \mathrm{m}$ diam, cylindrical, hyaline, inamyloid, non-gelatinous, thinwalled. Stipitipellis a cutis with erect caulocystidia; cortical hyphae $2.5-6 \mathrm{~mm}$ diam, parallel, cylindrical, non-diverticulate, smooth, hyaline, inamyloid, non-gelatinous, thin-walled or with walls up to $1 \mu \mathrm{m}$ thick; medullary hyphae $3.5-15 \mu \mathrm{m}$ diam, cylindrical, hyaline to pale brown, inamyloid, walls up to $1.5 \mu \mathrm{m}$ thick. Caulocystidia $32-64 \times 5-8 \mu \mathrm{m}$, cylindrical to irregularly cylindrical, subclavate or



Fig. 45 - Basidiomes of Gymnopus rodhallii (Holotype, BAP 627). Scale bar $=10 \mathrm{~mm}$ 
rarely ventricose, often in chains, apex broadly obtuse, hyaline, inamyloid, thin-walled or with walls up to $0.5 \mu \mathrm{m}$ thick. Clamp connections present.

Habitat and known distribution - Cespitose on soil and debris of cacao in coastal cacao-banana groves under secondary forest, and on palm debris in coastal forest. Africa (Príncipe, São Tomé).

Material examined - AFRICA. Príncipe, Bom Bom Resort area on Bom Bom Island, 20 April 2008, coll. by D.E. Desjardin and B.A. Perry, BAP 630 (MF100981, SFSU); São Tomé, along main road EN1 at $33 \mathrm{~km}$ marker, N00¹9.606', E06 30.667', 18 April 2008, coll. by D.E. Desjardin and B.A. Perry, BAP 627 (Holotype, MF100982, SFSU).

Notes - Gymnopus rodhallii is distinguished by a striate, glabrous, beige-cream pileus, close and narrow cream-colored lamellae, a dark greyish brown stipe covered with white pruinae that arises from clusters of coarse white rhizomorphs, small basidiospores $(6.4-7 \times 3.0-3.5 \mu \mathrm{m})$, clavate-pedicellate to

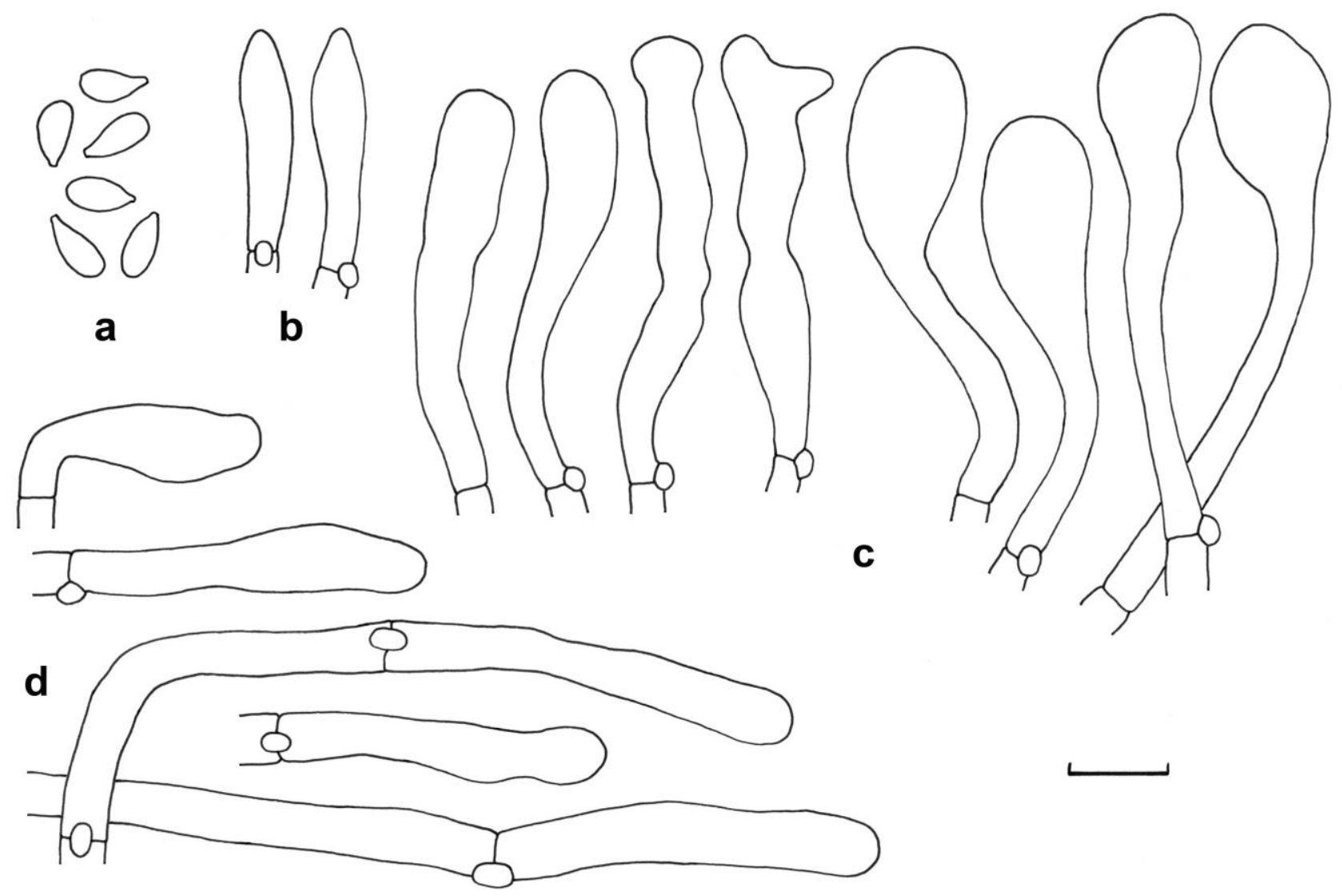

Fig. 46 - Micromorphological features of Gymnopus rodhallii (Holotype, BAP 627). a. Basidiospores. b. Basidioles. c. Cheilocystidia (left-BAP 630, right-BAP 627). d. Caulocystidia. Scale bar $=10 \mu \mathrm{m}$

irregularly cylindrical cheilocystidia, and rather broad, cylindrical, obtuse caulocystidia that often occur in chains. Gymnopus rodhallii is similar to a number of members of Sect. Vestipedes, including G. menehune Desjardin, Halling \& Hemmes, G. johnstonii (Murrill) Dennis, G. subpruinosus (Murrill) Desjardin, Halling \& Hemmes, G. omphalodes (Berk.) Halling \& J.L. Mata, and G. coracicolor (Berk. \& M.A. Curtis) J.L. Mata. Gymnopus menehune, described from Hawaii, differs in a darker brown pileus, larger basidiospores $(7.5-9.5 \times 3.5-4.2 \mu \mathrm{m})$, cylindrical-lobed cheilocystidia, and nodulose pileipellis terminal cells (Desjardin et al. 1999). Gymnopus johnstonii, described from Puerto Rico, has a darker brown pileus, distant and broader lamellae $(2-3 \mathrm{~mm})$, larger basidiospores $(8-10 \times 3-5 \mu \mathrm{m})$, 
shorter cheilocystidia ( $-35 \mu \mathrm{m}$ long), and more strongly brown-incrusted pileipellis hyphae (Dennis 1951, Pegler 1983). Gymnopus subpruinosus has a darker brown to greyish brown pileus, distant and broader lamellae (1-4 mm), a paler stipe with greyish orange apex, larger basidiospores $(8-10 \times 4.5-$ $5.2 \mu \mathrm{m}$ ), and conspicuous pileocystidia for which the species is named (Desjardin et al. 1999). Basidiomes of Gymnopus rodhallii look very similar to those of G. omphalodes reported from Trinidad by Dennis (1951; Pl. 21, Fig. 10), but the latter species forms a paler pileus (nearly white), conspicuous pleurocystidia, narrower basidiospores $(2.5-3 \mu \mathrm{m})$, and more hair-like caulocystidia $(-140 \times-5 \mu \mathrm{m})$. Gymnopus coracicolor, described from Cuba, differs in forming a smaller (8-22 $\mathrm{mm}$ diam), cinnamon brown to chestnut brown pileus, distant and broader lamellae (2-3 mm), a smaller (15-45 $\times 1-2 \mathrm{~mm})$, paler stipe, and lacks white rhizomorphs (Dennis 1951, Pegler 1983). Mata and Ovrebo (2009) reported G. coracicolor as having scattered pleurocystidia, absent in G. rodhallii.

Pairwise comparisons of aligned, overlapping ITS sequences of Gymnopus rodhallii with the top ten BLAST results indicate closest similarity (92.2-92.4\%) to four specimens of Gymnopus menehune (AY263426-Holotype, KJ855237, KJ778753, JN182864). Comparisons with ITS sequences of $G$. johnstonii (AY822014), G. subpruinosus (AY842952, DQ450025 DQ450026, DQ450027) and $G$. omphalodes (KJ609160, AF505761, DQ450011, AY256700, DQ450010) show 87\%, 84.6-85.9\% and 80.1-81.9\% similarity, respectively. No ITS sequences of $G$. coracicolor are available for comparison. In the ITS phylogeny (Fig. 1), G. rodhallii belongs in a well-supported clade (93\% BS, 1.0 PP) with eight other Gymnopus species, including G. hirtellus and G. hirtelloides reported herein from Príncipe.

\section{Gymnopus aff. brunneigracilis (Corner) A.W. Wilson \& Desjardin, Sydowia 56(1): 171. 2004.}

Basionym: Marasmius brunneigracilis Corner, Beih. Nova Hedwigia 111: 39. 1996.

Figs 47, 48a-c

Facesoffungi number: FoF03752

Pileus $30-70 \mathrm{~mm}$ diam, broadly convex to plano-convex, sometimes with a shallow central depression; margin striate to pellucid-striate, eroded and seldom uplifted in age; surface dull, dry to moist, glabrous, hygrophanous, disc brown (7D6-8) to dark brown (5-6F7-8), margin cream (3-4A2), in age. Context thin, pliant, white. Lamellae adnexed to adnate, occasionally with a short decurrent tooth, subdistant with 2-3 series of lamellulae, thin, broad (2-5 mm), cream (4A3) with concolorous edge. Stipe $40-80 \times 2.5-6 \mathrm{~mm}$, central, terete, cylindrical or with slightly enlarged base, sometimes twisted, solid to stuffed, non-insititious; surface dull, dry, minutely white-pruinose, fibrous-striate, apex cream (4A2-3), base brown (7D6-8) to dark greyish brown (5-6E-F4-5); base with white tomentum. Odor and taste not distinctive, pleasant.

Basidiospores not observed, material sterile. Basidioles 24-33 $\times 4.0-6.5 \mu \mathrm{m}$, clavate to fusoid. Lamellar edge sterile. Cheilocystidia 24-30 × 4.8-7 $\mu \mathrm{m}$, irregularly cylindrical to subclavate, occasionally with a few apical lobes or knobs, hyaline, inamyloid, thin-walled. Pleurocystidia absent. Pileipellis a cutis of repent, radially arranged hyphae 3-7 $\mu \mathrm{m}$ diam, cylindrical, branched, nondiverticulate, non-incrusted, hyaline to pale yellow, inamyloid, non-gelatinous, thin-walled; terminal cells undifferentiated, repent. Pileus trama of interwoven hyphae similar to those in the pileipellis but up to $12 \mu \mathrm{m}$ diam. Lamellar trama regular; hyphae 3-10 $\mu \mathrm{m}$ diam, cylindrical, hyaline, inamyloid, non-gelatinous, thin-walled. Stipitipellis a trichodermium of erect caulocystidia; cortical hyphae 3-5 $\mu \mathrm{m}$ diam, parallel, cylindrical, non-diverticulate, smooth, hyaline, inamyloid or weakly dextrinoid, non-gelatinous, thin-walled; medullary hyphae 5-12 $\mu \mathrm{m}$ diam, cylindrical, hyaline, inamyloid, thinwalled. Caulocystidia 24-64 × 3-5 $\mu \mathrm{m}$, irregularly cylindrical, flexuous, seldom with one or more knob-like outgrowths, hyaline, inamyloid, thin-walled. Clamp connections common.

Habitat and known distribution - Scattered on decaying wood in secondary coastal forest. Africa (São Tomé), Indonesia (Java), Singapore. 


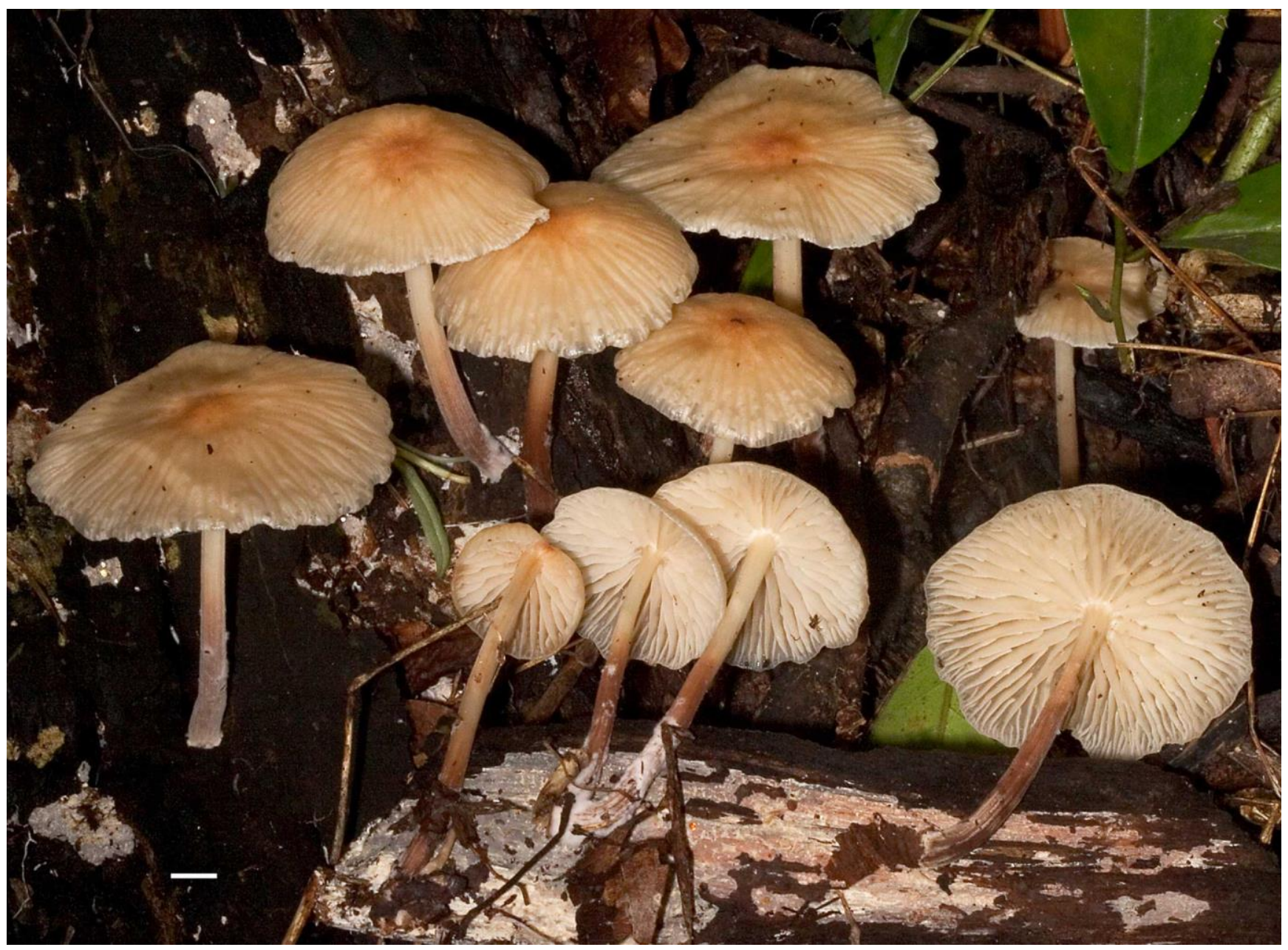

Fig. 47 - Basidiomes of Gymnopus aff. brunneigracilis (BAP 621). Scale bar $=10 \mathrm{~mm}$

Material examined - AFRICA. São Tomé, along road EN-1 on north side of island at $18.25 \mathrm{~km}$ marker, N00²3.687', E06 36.302', 17 April 2008, coll. by D.E. Desjardin and B.A. Perry, BAP 621 (MF100983, SFSU).

Notes - Gymnopus aff. brunneigracilis is characterized by a rather large, striate pileus with brown disc and cream margin, subdistant, cream-colored lamellae, a non-insititious, white-pruinose stipe with cream-colored apex and dark greyish brown base, irregularly cylindrical cheilocystidia and caulocystidia with or without a few knob-like projections, non-diverticulate pileipellis hyphae, and growth on decaying wood. The São Tomé specimen reported here is sterile and yielded no basidiospores or mature basidia. Material from Java (Wilson et al. 2004) differs slightly in forming a more evenly brown to reddish brown pileus and a less pruinose stipe with fewer caulocystidia. Type material from Singapore differs in forming smaller basidiomes (pileus10-28 mm diam, stipe 8-16 $\times 1-$ $1.5 \mathrm{~mm}$; Corner 1996).

Pairwise comparisons of aligned, overlapping ITS sequences of Gymnopus aff. brunneigracilis with the top ten BLAST results indicate closest similarity $(98.4 \%)$ to a Java specimen of $G$. brunneigracilis (AY263434), and show 96.3-96.7\% similarity to nine specimens of G. luxurians (Peck) Murrill. Gymnopus aff. brunneigracilis forms a clade (78\% BS, 1.0 PP) with G. brunneigracilis and G. gibbosus (Fig. 1). 


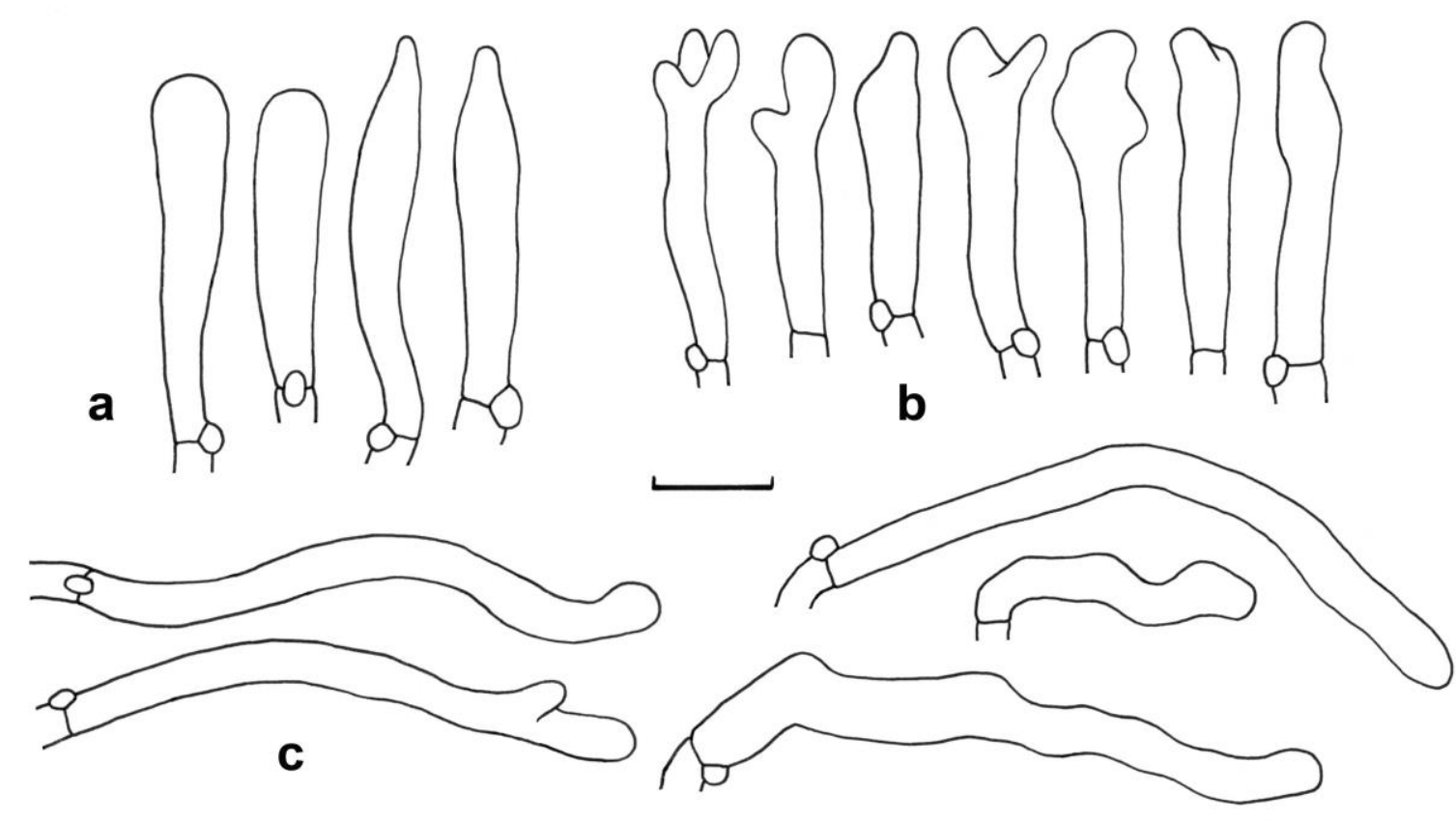

Fig. 48 - Micromorphological features of Gymnopus aff. brunneigracilis (BAP 621). a. Basidioles. b.Cheilocystidia. c. Caulocystidia. Scale bar $=10 \mu \mathrm{m}$

Gymnopus cervinus (Henn.) Desjardin \& B.A. Perry, comb. nov.

Figs49, 50a-e Basionym: Marasmius cervinus Henn., Bot. Jb. 23: 551. 1897.

Holotype - Cameroon, Lolodorf, on dead wood and leaves, 8 Sept. 1895, Staudt 437 (not found).

MycoBank: MB821167; Facesoffungi number: FoF03753

Pileus 10-25 mm diam, convex becoming plano-convex, centrally depressed in age, sulcate to rugulose-sulcate; margin decurved to uplifted, sometimes undulate; surface dull, moist to dry, glabrous, disc and sulcae dark brown (6-7F5-8), brown (6-7E4-8) elsewhere. Context very thin (0.5 $\mathrm{mm}$ ), concolorous with surface. Lamellae horizontal, adnexed, sometimes with a thin pseudocollarium, distant (12-15) or subdistant (15-18) with 2 series of lamellulae, narrow (1-1.5 mm), seldom slightly intervenose, brown (7E6-8) to greyish brown (7D-E3) with paler edges, non-marginate. Stipe 8-20 $\times$ 0.5-1.5 mm, central, terete, cylindrical or narrowed downward, tough, pliant, hollow, insititious; surface dull, dry, velutinous to pubescent overall; apex brown (7E5-8), base dark brown (7-8F6-8); rhizomorphs absent.

Basidiospores 6.4-8.3 $\times 3.5-4.2 \mu \mathrm{m}\left[\mathrm{x}_{\mathrm{m}}=7.3 \pm 0.60 \times 3.8 \pm 0.27 \mu \mathrm{m}, \mathrm{Q}=1.8-2.1, \mathrm{Q}_{\mathrm{m}}=1.93 \pm 0.08\right.$, $\mathrm{n}=20, \mathrm{~s}=1$ ], ellipsoid, smooth, hyaline, inamyloid, thin-walled. Basidia 15-26 $\times 5-7 \mu \mathrm{m}$, clavate, 4spored, clamped. Basidioles clavate to subfusoid. Pleurocystidia absent. Cheilocystidia abundant, main body $13-26 \times 5-8 \mu \mathrm{m}$, clavate or irregularly cylindrical, sometimes lobed, with few to numerous finger-like projections $2-11 \times 1.5-3.5 \mu \mathrm{m}$, hyaline, inamyloid, thin-walled. Pileipellis a cutis of radially arranged, slightly interwoven, repent hyphae (2.5-) 4-10 (-12) $\mu \mathrm{m}$ diam, cylindrical or irregular in outline, with few scattered, broad, knob-like projections (not a Rameales-structure), with walls up to $2.0 \mu \mathrm{m}$ thick coarsely incrusted with dark brown pigments, inamyloid, non-gelatinous; terminal cells undifferentiated or with coarse, knob-like projections. Pileus and lamellar trama of hyphae 2-10 (-12) $\mu \mathrm{m}$ diam, cylindrical or irregular in outline, thin-walled or with walls up to $2 \mu \mathrm{m}$ thick, hyaline, smooth or pale brown-incrusted, non-gelatinous. Stipitipellis composed of numerous, erect caulocystidia. Stipe cortical hyphae 3-8 $\mu \mathrm{m}$ diam, parallel, cylindrical, smooth or with pale 
brown incrustations, hyaline or pale brown, inamyloid, thick-walled $(-3 \mu \mathrm{m})$, non-gelatinous; medullary hyphae 3-22 $\mu \mathrm{m}$ diam, cylindrical, smooth, hyaline or pale brown, thin-walled or with walls up to $3 \mu \mathrm{m}$ thick, non-gelatinous. Caulocystidia 30-160 $\times 5-10 \mu \mathrm{m}$, subcylindrical to acicular or lanceolate, obtuse to subacute, smooth, hyaline (stipe apex) to brown (stipe base), inamyloid, thickwalled $(1-3 \mu \mathrm{m})$. Clamp connections common in all tissues.

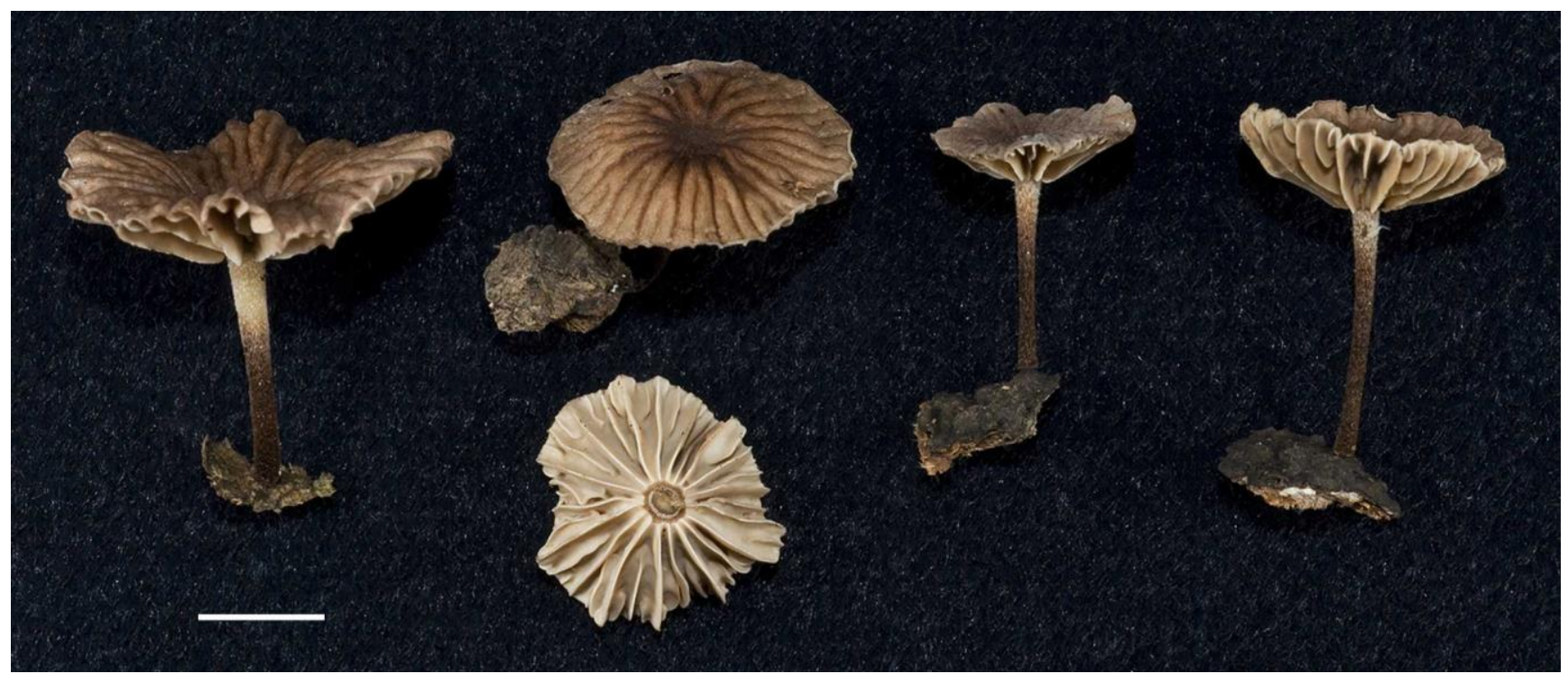

Fig. 49 - Basidiomes of Gymnopus cervinus (BAP 623). Scale bar $=10 \mathrm{~mm}$

Habitat and known distribution - scattered to gregarious on decaying woody debris in secondary forest. Africa (Príncipe, São Tomé).

Material examined - AFRICA. Príncipe, Roça Pico Papagaio, N01 ³7.182', E07²3.474', 21 April 2008, coll. by D.E. Desjardin, DED 8298 (MF100984, SFSU). São Tomé, along main road (EN1) on north side of island at $18.25 \mathrm{~km}$ marker, N00 23.687', E06 36.302', 17 April 2008, coll. by B.A. Perry and D.E. Desjardin, BAP 623 (MF100985, SFSU).

Notes - Marasmius cervinus Henn. was described from material collected on dead wood in Lolodorf, Cameroon. According to Antonín (2007: 147), the type specimen is no longer available. The protologue, reproduced below, matches quite nicely with the specimens collected from São Tomé and Príncipe, and the epithet is herein accepted as representing that material.

Protologue (Hennings 1897): "Pileo tenui membranaceo, pellucido-cervino, convexo-explanato, medio depresso, subumbilicato atrobrunneo, radiatim sulcato subplicatoque obscuriore, 9-12 mm diametro, stipite corneo, fistuloso, brunneo velutino tomentoso ad basim atro, 12-15 mm longo vix 1 $\mathrm{mm}$ crasso; lamellis rotundato-adnatis, subdistantibus, inaequilongis, subventricosis. Sporis non visis."

Distinctive features of Gymnopus cervinus include a brown to dark brown, rugulose-sulcate pileus, distant to subdistant, brown lamellae, a velutinous, brown to dark brown, insititious stipe, basidiospores with mean $7.3 \times 3.8 \mu \mathrm{m}$, cheilocystidia with few to numerous broad finger-like projections, a cutis-type pileipellis of coarsely brown-incrusted hyphae with a few knob-like projections, non-gelatinous, inamyloid tissues, numerous thick-walled, acicular caulocystidia, and growth on woody debris. In prior taxonomic constructs, this taxon would belong in Marasmiellus sect. Dealbati, subsect. Quercini sensu Singer (1973), where it would key closest to Marasmiellus pandoensis Singer. The latter species, described from Bolivia, differs in forming a deep rusty ochraceous brown pileus with cinnamon striae, close lamellae, narrower basidiospores $(2.5-3.5 \mu \mathrm{m})$, and more broadly rounded caulocystidia (Singer 1973). Gymnopus cervinus also show similarities to 
Collybia njalensis (Beeli) Pegler, described from Sierra Leone, but the latter has an amber brown pileus, crowded, ochraceous tawny lamellae, a much longer stipe $(25-60 \mathrm{~mm})$, narrower basidiospores $(2.5-3.5 \mu \mathrm{m})$, and pointed-fusiform cheilocystidia that lack apical projections (Pegler 1968).



Fig. 50 - Micromorphological features of Gymnopus cervinus (BAP 623, DED 8298). a. Basidiospores. b. Basidium and basidioles. c. Cheilocystidia. d. Pileipellis terminal cells. e. Caulocystidia. Scale bar $=10 \mu \mathrm{m}$

Pairwise comparisons of aligned, overlapping ITS sequences of $G$. cervinus with the top ten BLAST results indicate closest similarity (90.9-93.4\%) to uncultured Marasmiaceae isolates (LC013358, LC013361). In the ITS phylogeny (Fig. 1), G. cervinus forms a well-supported clade (100\% BS, 1.0 PP) with $G$. mustachius, sister to $G$. omphalodes, G. ocellus, G. peronatus and $G$. subnudus.

Gymnopus ugandensis (Pegler) Desjardin \& B.A. Perry, comb. nov.

Figs 51, 52a-e

Basionym: Marasmiellus ugandensis Pegler, Kew Bull., Addit. Ser. 6: 120. 1977.

Lectotype hic designari - AFRICA. Uganda, Buganda Province, Mengo District, Mpanga Res. For., on fallen debris, alt. 1241 m, 8 June 1968, Pegler 1323 (K).

MycoBank: MB821169; Facesoffungi number: FoF03754

Pileus 3-13 mm diam, convex to subcampanulate; smooth to rugulose, short-striate; surface dull, dry, glabrous; disc pale brownish grey (6C3) to orangish white (5A2-3); margin buff to off-white with a hint of pink or orangish white. Context $<1 \mathrm{~mm}$ thick, soft, white. Lamellae adnate, close to subdistant with 1-2 series of lamellulae, narrow, white to buff. Stipe 5-13 $\times 0.5-1 \mathrm{~mm}$, central, terete, cylinrical, 
tough, insititious; surface dull, dry, covered with white pruinae; apex white to buff, base greyish red (8C4-5) to reddish brown (8E4-5) or dark brown (8F4-5). Odor not distinctive.

Basidiospores 6.5-8 × 3.5-4 $\mu \mathrm{m}\left[\mathrm{x}_{\mathrm{m}}=7.05 \pm 0.52 \times 3.7 \pm 0.19 \mu \mathrm{m}, \mathrm{Q}=1.7-2.1, \mathrm{Q}_{\mathrm{m}}=1.91 \pm 0.12, \mathrm{n}=\right.$ $20, \mathrm{~s}=1$ ], ellipsoid, smooth, hyaline, inamyloid, thin-walled. Basidia 24-28 × 6-7 $\mu \mathrm{m}$, clavate, 4spored. Basidioles cylindrical to subclavate. Pleurocystidia absent. Lamellar edge sterile. Cheilocystidia 24-42 × 11-20 (-22) $\mu \mathrm{m}$, broadly clavate, apically diverticulate, hyaline, thin-walled; diverticula 1.5-5 $\times 1-3 \mu \mathrm{m}$, cylindrical to irregular in outline, sometimes branched, hyaline. Pileipellis a Rameales-structure; hyphae 2.2-5 $\mu \mathrm{m}$ diam, cylindrical, diverticulate, hyaline, inamyloid, smooth or weakly incrusted, non-gelatinous, thin-walled; diverticula 1.5-15 $\times 1.5-3.2 \mu \mathrm{m}$, cylindrical to irregular in outline, hyaline. Pileus trama interwoven; lamellar trama regular; hyphae 3-10 $\mu \mathrm{m}$ diam, cylindrical, hyaline, inamyloid, smooth, non-gelatinous, thin-walled. Stipitipellis a cutis with numerous erect caulocystidia; stipe cortical hyphae 3-8 $\mu \mathrm{m}$ diam, cylindrical, parallel, hyaline to pale brown, inamyloid, smooth, non-gelatinous, thin-walled; medullary hyphae 3.5-10 $\mu \mathrm{m}$ diam, hyaline, inamyloid, non-gelatinous, thin-walled. Caulocystidia 12-64 $\times 6.5-10 \mu \mathrm{m}$, cylindrical to fusoid or irregular in outline, sometimes lobed, apex broadly obtuse, hyaline, inamyloid, thin-walled. Clamp connections present.

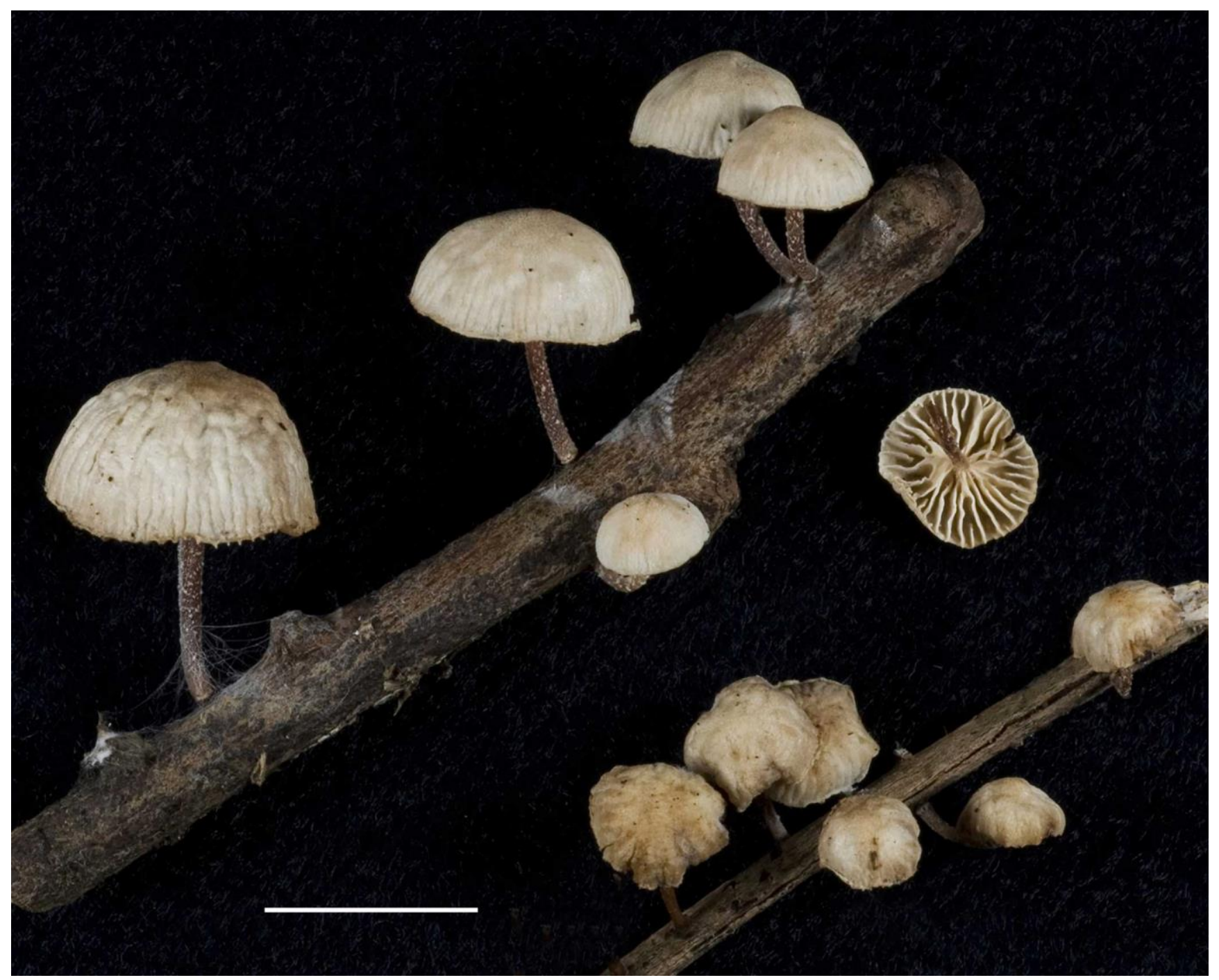

Fig. 51 - Basidiomes of Gymnopus ugandensis (BAP 614). Scale bar $=10 \mathrm{~mm}$ 
Habitat and known distribution - Scattered to gregarious on undetermined dicotyledonous twigs in primary forest. Africa (São Tomé, Tanzania, Uganda).

Material examined - AFRICA. São Tomé, Parque Nacional Obo, along trail from Bom Succeso to Lagoa Amelia, between N00 ${ }^{\circ} 17.112^{\prime}, \mathrm{E}^{\circ} 6^{\circ} 35.967^{\prime}$ and $\mathrm{N} 00^{\circ} 16.922^{\prime}, \mathrm{E}^{\circ} 6^{\circ} 36.062^{\prime}, 14$ April 2008, coll. by B.A. Perry, BAP 614 (MF100986, SFSU).

Notes - Gymnopus ugandensis is distinguished by a small pileus with greyish brown to orangish white disc and off-white margin, close to subdistant white lamellae, a short, insititious, brown to reddish brown stipe covered with white pruinae, relatively small basidiospores with mean $7 \times 3.7 \mu \mathrm{m}$, broadly clavate cheilocystidia (11-20 $\mu \mathrm{m}$ diam) with short apical diverticula, a Rameales-type pileipellis, broadly obtuse, clavate, thin-walled caulocystidia, and growth on twigs. The São Tomé material differs slightly from the east African specimens, which have more crowded lamellae, slightly smaller basidiospores (mean $6.5 \times 3 \mu \mathrm{m}$ ), and narrower cheilocystidia $(8-12 \mu \mathrm{m})$ (Pegler 1977). However, the unusual cheilocystidia and thin-walled caulocystidia are diagnostic.

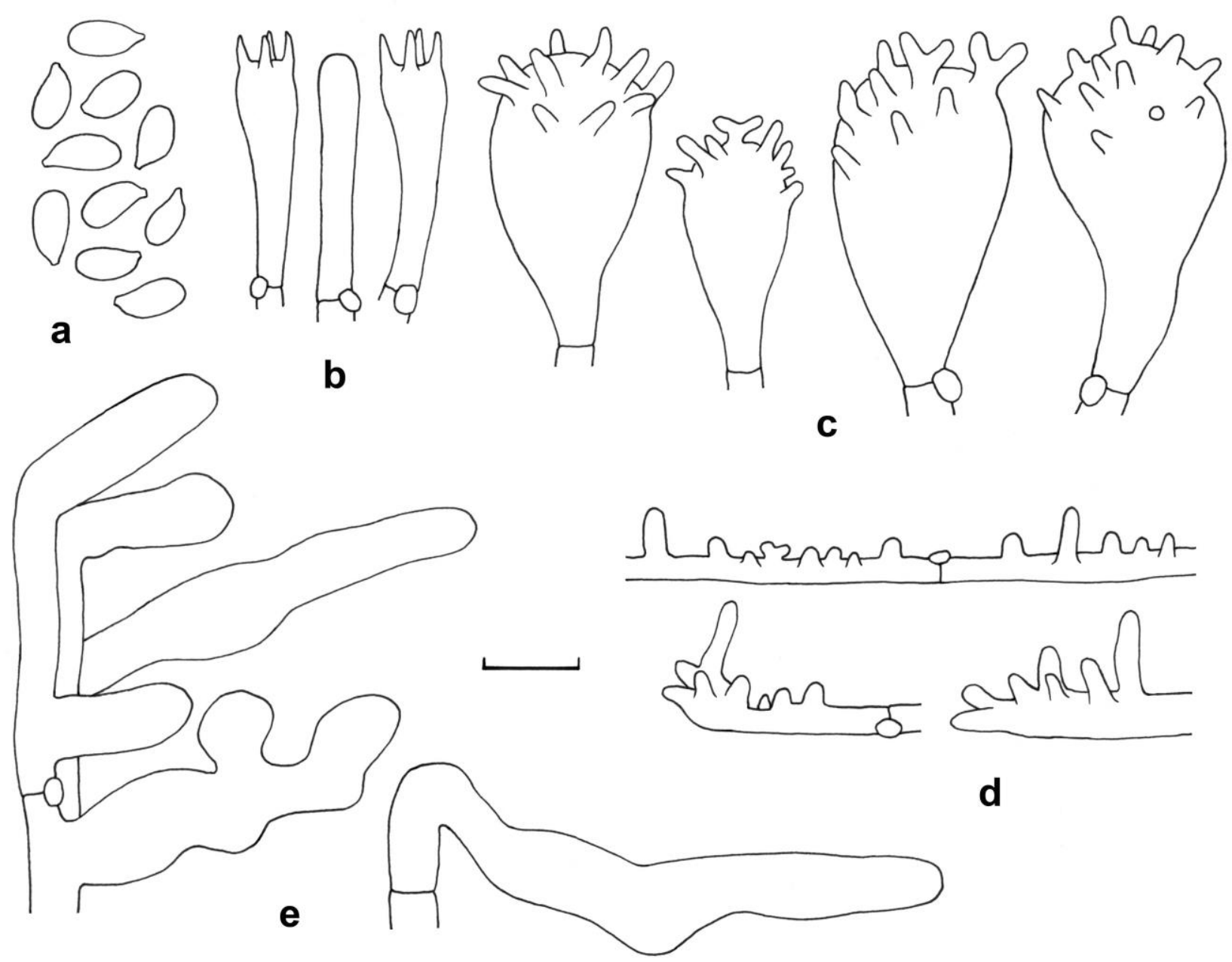

Fig. 52 - Micromorphological features of Gymnopus ugandensis (BAP 614). a. Basidiospores. b. Basidia and basidiole. c. Cheilocystidia. d. Pileipellis hyphae and terminal cells. e. Caulocystidia. Scale bar $=10 \mu \mathrm{m}$

Pairwise comparisons of aligned, overlapping ITS sequences of G. ugandensis with the top ten 
BLAST results indicate closest similarity (92.9-96\%) to uncultured Agaricales clones, and 91.9\% similarity to Marasmiellus foliiphilus A.K. Dutta, K. Acharya \& Antonín. The latter species, described recently from India, differs from $G$. ugandensis in forming more distant lamellae, a longer (15-29 $\mathrm{mm}$ ), greyish yellow to buff-brown stipe, slightly longer basidiospores (mean $7.8 \times 3.7 \mu \mathrm{m}$ ), narrower (9-12 $\mu \mathrm{m}$ ) cheilocystidia with much longer (up to $18 \mu \mathrm{m}$ ) and broader apical diverticula, thick-walled caulocystidia, and growth on leaves (Dutta et al. 2015). In the ITS phylogeny (Fig. 1), G. ugandensis belongs in a supported clade (76\% BS, 1.0 PP) with G. ramealis (Bull.) Gray, M. foliiphilus and $G$. pleurocystidiatus.

Gymnopus ugandensis may represent what was reported from São Tomé by Bresadola and Roumeguère (1890) and Coutinho (1925) as Marasmius amadelphus (Bull.) Fr., the latter recognized as a synonym of $G$. ramealis.

Gymnopus mustachius Desjardin \& B.A. Perry, sp. nov.

Fig. 53a-d

MycoBank: MB821162; Facesoffungi number: FoF03755

Holotype - AFRICA. São Tomé, Parque Nacional Obo, on trail to Lagoa Amelia, between N00 17.122', E06K35.967' and N00 ${ }^{\circ} 16.922^{\prime}$, E06 ${ }^{\circ} 36.062^{\prime}, 28$ Apr. 2008, coll. by B.A. Perry and D.E. Desjardin, BAP 670 (SFSU).

Etymology - mustachius, referring to the cells on the lamellar edge looking like a brown mustache.

Diagnosis - Pileus 3-13 mm diam, convex to plano-convex, centrally depressed in age, striate; surface dull, dry, minutely appressed-fibrillose to furfuraceous, dark reddish brown (7-8F7-8) with darker ornamentation. Context $0.5 \mathrm{~mm}$ thick, pale brownish grey. Lamellae horizontal, adnate to a pseudocollarium, subdistant with 1 series of lamellulae, moderately broad, pale brownish grey with dark brown edges. Stipe 14-32 × 0.5-1 mm, central, cylindrical, terete or compressed, base twistedstriate, tough, hollow, insititious; surface dull, dry, densely hispid with brownish black ornamentation, brownish black overall; associated with narrower, wiry, brownish black rhizomorphs but not arising from them. Odor indistinct.

Basidiospores 8.5-10 × 3.5-4 $\mu \mathrm{m}\left[\mathrm{x}_{\mathrm{m}}=9.2 \pm 0.37 \times 3.7 \pm 0.17 \mu \mathrm{m}, \mathrm{Q}=2.4-2.6, \mathrm{Q}_{\mathrm{m}}=2.47 \pm\right.$ $0.05, \mathrm{n}=20, \mathrm{~s}=1$ ], elongate-ellipsoid, smooth, hyaline, inamyloid, thin-walled. Basidia 30-37 $\times 6.5-8$ $\mu \mathrm{m}$, clavate, 4-spored. Basidioles 28-36 ×5-6.5 $\mu \mathrm{m}$, subfusoid to fusoid. Pleurocystidia absent. Lamellar edge sterile, composed of repent to erect, irregularly cylindrical cheilocystidia $25-48 \times 3.8-$ $6.5 \mu \mathrm{m}$, often lobed or with a few knob-like outgrowths, strongly incrusted with granular to annular or plaque-like dark brown pigments; walls thin or up to $0.5 \mu \mathrm{m}$ thick, hyaline to brown, non-gelatinous. Pileipellis a cutis of radially arranged, slightly interwoven hyphae 3-8 $\mu \mathrm{m}$ diam, cylindrical, nondiverticulate, very coarsely and strongly incrusted with granular to annular or plaque-like dark brown pigments (up to $0.6 \mu \mathrm{m}$ thick), brown, inamyloid, non-gelatinous; terminal cells undifferentiated, cylindrical to subclavate, non-diverticulate (not Siccus-type), coarsely brown-incrusted. Pileus trama interwoven; lamellar trama regular; hyphae 2.2-7 $\mu \mathrm{m}$ diam, cylindrical, much-branched, smooth or incrusted, hyaline, inamyloid, non-gelatinous, thin-walled or with walls up to $0.5 \mu \mathrm{m}$ thick. Stipe cortical hyphae 2.2-6 $\mu \mathrm{m}$ diam, cylindrical, non-diverticulate, very coarsely and strongly incrusted with granular to annular or plaque-like dark brown pigments, hyaline to brown, inamyloid, nongelatinous, thin-walled; medullary hyphae similar but hyaline, non-incrusted. Caulocystidia abundant, 32-85 × 6.5-12 $\mu \mathrm{m}$, cylindrical to subfusoid, obtuse, hyaline to brown, smooth or brown-incrusted, non-gelatinous, walls $0.5-1.3 \mu \mathrm{m}$ thick. Clamp connections present. Tomé).

Habitat and known distribution - Gregarious on woody sticks in primary forest. Africa (São

Material examined - AFRICA. São Tomé, Parque Nacional Obo, on trail to Lagoa Amelia,

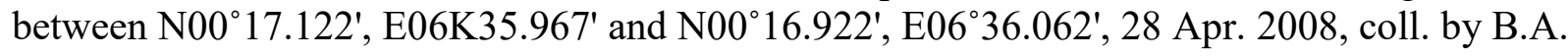






Fig. 53 - Micromorphological features of Gymnopus mustachius (Holotype, BAP 670). a. Basidiospores. b. Basidium and basidioles. c. Cheilocystidia. d. Caulocystidia. Scale bar $=10 \mu \mathrm{m}$

Notes - Gymnopus mustachius is characterized by rather small, dark reddish brown, appressedfibrillose pileus, subdistant, pale brownish grey lamellae with dark brown edges, a densely hispid, insititious, brownish black stipe, basidiospores with mean $9.2 \times 3.7 \mu \mathrm{m}$, irregularly cylindrical, brown pigmented-incrusted cheilocystidia, a cutis-type pileipellis of non-diverticulate, coarsely and strongly incrusted brown hyphae, cylindrical, obtuse, brown, thick-walled caulocystidia, and growth on woody sticks. Marasmius brunneimarginatus Corner, described from Singapore, is similar, but has a pale brown pileus, pale pink lamellae, no rhizomorphs, smaller basidiospores $(6-7 \times 3 \mu \mathrm{m})$, broader $(9-20$ $\mu \mathrm{m})$, subglobose to broadly clavate cheilocystidia, tufts of erect pileocystidia, and grows on leaves (Corner 1996). Marasmiellus pandoensis Singer, described from Bolivia, shares pileipellis and stipitipellis morphologies with G. mustachius, but forms a deep rusty brown pileus, non-marginate lamellae, smaller basidiospores (mean 7-7.5 × 3-3.5 $\mu \mathrm{m}$ ), and broadly clavate cheilocystidia with apical diverticula (Singer 1973).

Pairwise comparisons of aligned, overlapping ITS sequences of Gymnopus mustachius with the top ten BLAST results indicate closest similarity (91.2\%) to several Gymnopus dichrous (Berk. \& M.A. Curtis) Halling sequences (JF313694, DQ480115) from North Carolina, USA. Gymnopus mustachius forms a well-supported clade (100\% BS, 1.0 PP) with G. cervinus (Fig. 1). 
Gymnopus melanopus A.W. Wilson, Desjardin \& E. Horak, Sydowia 56: 181. 2004.

Figs 54, 55a-d

Facesoffungi number: FoF03756

Pileus 5-20 mm diam, convex to campanulate, expanding to plano-convex, rugulose-striate to the disc; surface dull, dry, glabrous, disc greyish brown (6-7C4-5), margin paler to greyish orange (6B3-4) to beige (5A3). Context $<1 \mathrm{~mm}$ thick, soft, buff. Lamellae adnate, close to subdistant with 2-3 series of lamellulae, narrow, pale cream $(<4 \mathrm{~A} 3)$, darkening to greyish orange $(6-7 \mathrm{~B}-\mathrm{C} 4)$. Stipe $8-30 \times$ 1-2 mm, central, cylindrical above a slightly enlarged base, terete or compressed, fistulose-stuffed, tough, subinsititious; surface dull, dry, white-pruinose overall, apex brownish grey (5-6C3), base dark brown to black; rhizomorphs absent. Odor and taste indistinct.

Basidiospores 7-8.5 $\times 3.5-4.2 \mu \mathrm{m}$, only 7 seen $\left[\mathrm{x}_{\mathrm{m}}=7.7 \times 3.9 \mu \mathrm{m}, \mathrm{Q}_{\mathrm{m}}=1.95\right]$, ellipsoid, smooth, hyaline, inamyloid, thin-walled. Basidia not observed. Basidioles 21-29 $\times 5-6.5 \mu \mathrm{m}$, clavate to subfusoid. Pleurocystidia absent. Lamellar edge sterile. Cheilocystidia 28-57 $\times 8-16 \mu \mathrm{m}$, clavate, often with one or more lobes or broad knob-like outgrowths, broadly obtuse, hyaline, inamyloid, thinwalled. Pileipellis a cutis of radially arranged, repent hyphae 2.5-7 $\mu \mathrm{m}$ diam, cylindrical, nondiverticulate, smooth or brown-incrusted, hyaline, inamyloid, non-gelatinous, thin-walled; terminal cells undifferentiated. Pileus trama radially arranged to interwoven; hyphae similar to pileipellis but up to $10 \mu \mathrm{m}$ diam. Lamellar trama regular; hyphae 3.5-16 $\mu \mathrm{m}$ diam, cylindrical to inflated, hyaline, inamyloid, thin-walled. Stipitipellis a cutis with numerous clustered caulocystidia; cortical hyphae 2.5$8 \mu \mathrm{m}$ diam, cylindrical, non-diverticulate, smooth or weakly brown-incrusted, hyaline to brown, inamyloid, thin-walled; medullary hyphae 4-16 $\mu \mathrm{m}$ diam, cylindrical to inflated, smooth, hyaline, inamyloid, thin-walled. Caulocystidia $28-57 \times 5.7-11.5 \mu \mathrm{m}$, irregularly cylindrical to clavate, often lobed, broadly obtuse, hyaline, inamyloid, thin-walled. Clamp connections present.

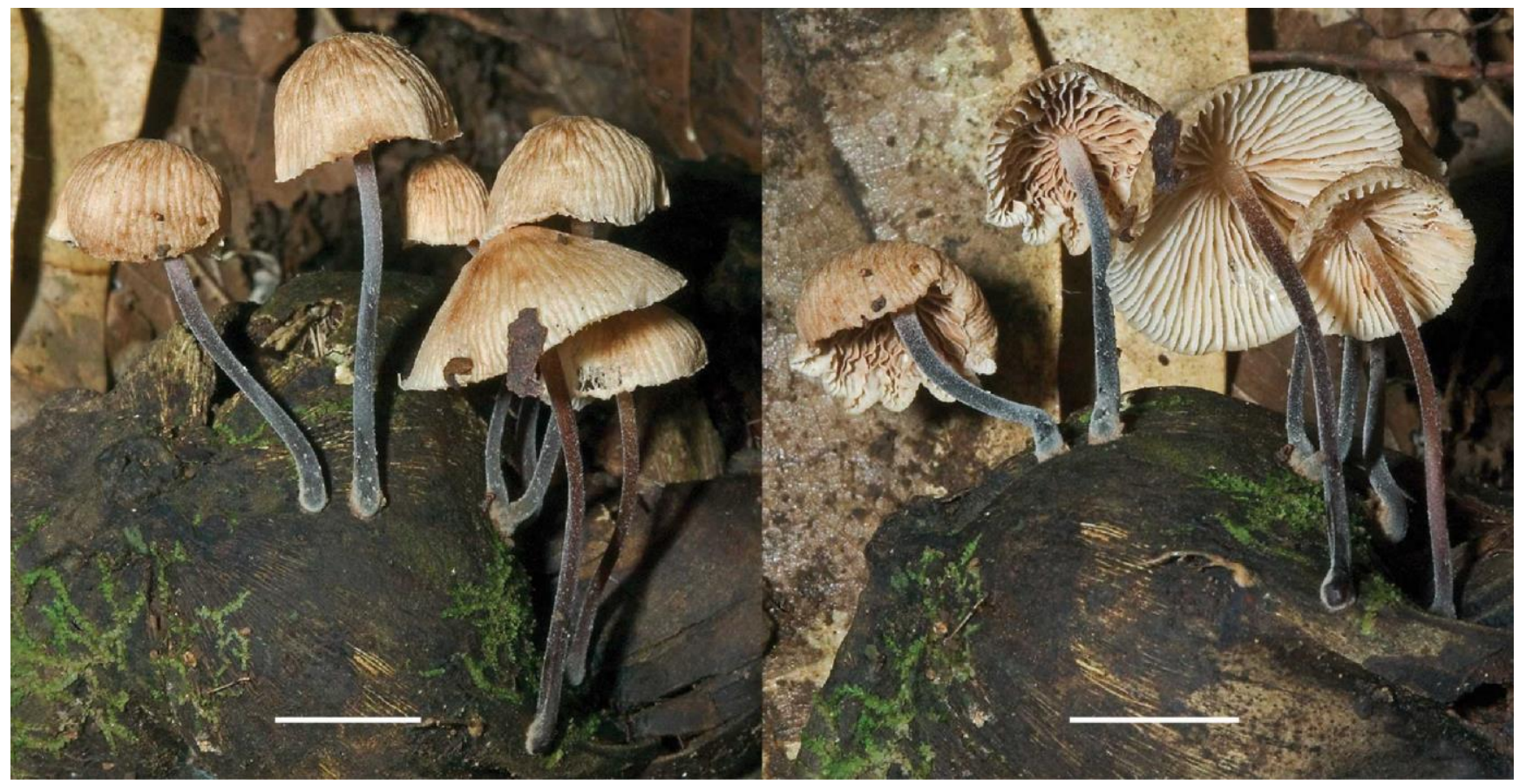

Fig. 54 - Basidiomes of Gymnopus melanopus (BAP 607). Scale bar $=10 \mathrm{~mm}$

Habitat and known distribution - Gregarious on coconut fruit hulls in coastal coconut-cacao grove. Africa (São Tomé), India, Indonesia (Java). 
Material examined - AFRICA. São Tomé, along main road (EN2) on south side of island approx. $200 \mathrm{~m}$ east of $38 \mathrm{~km}$ marker, N0008.500', E06 39.650', 13 Apr. 2008, coll. by B.A. Perry, BAP 607 (MF100988, SFSU).

Notes - Gymnopus melanopus was described from material collected in the Bogor Botanical Garden in Java (Wilson et al. 2004) and reported subsequently from India (Dutta et al. 2015). Distinctive features include a small, rugulose-striate, greyish brown to cream pileus, close to subdistant, narrow lamellae, a subinsititious, black stipe covered with white pruinae, basidiospores with mean range 7.7-8.5 × 3.8-4.0 $\mu \mathrm{m}$, broadly clavate, often knobby cheilocystidia, irregularly cylindrical caulocystidia, and growth on woody debris. An ITS sequence of BAP 607 was 99.7-99.8\% similar to four GenBank sequences determined as Gymnopus melanopus (AY263442 [Holotype], AY263425, KR348866, KM896875) in pairwise comparisons of aligned, overlapping sequences. In the ITS phylogeny (Fig. 1), G. melanopus is sister to G. juniperinus (type species of Marasmiellus) with $70 \%$ BS and 0.96 PP support.

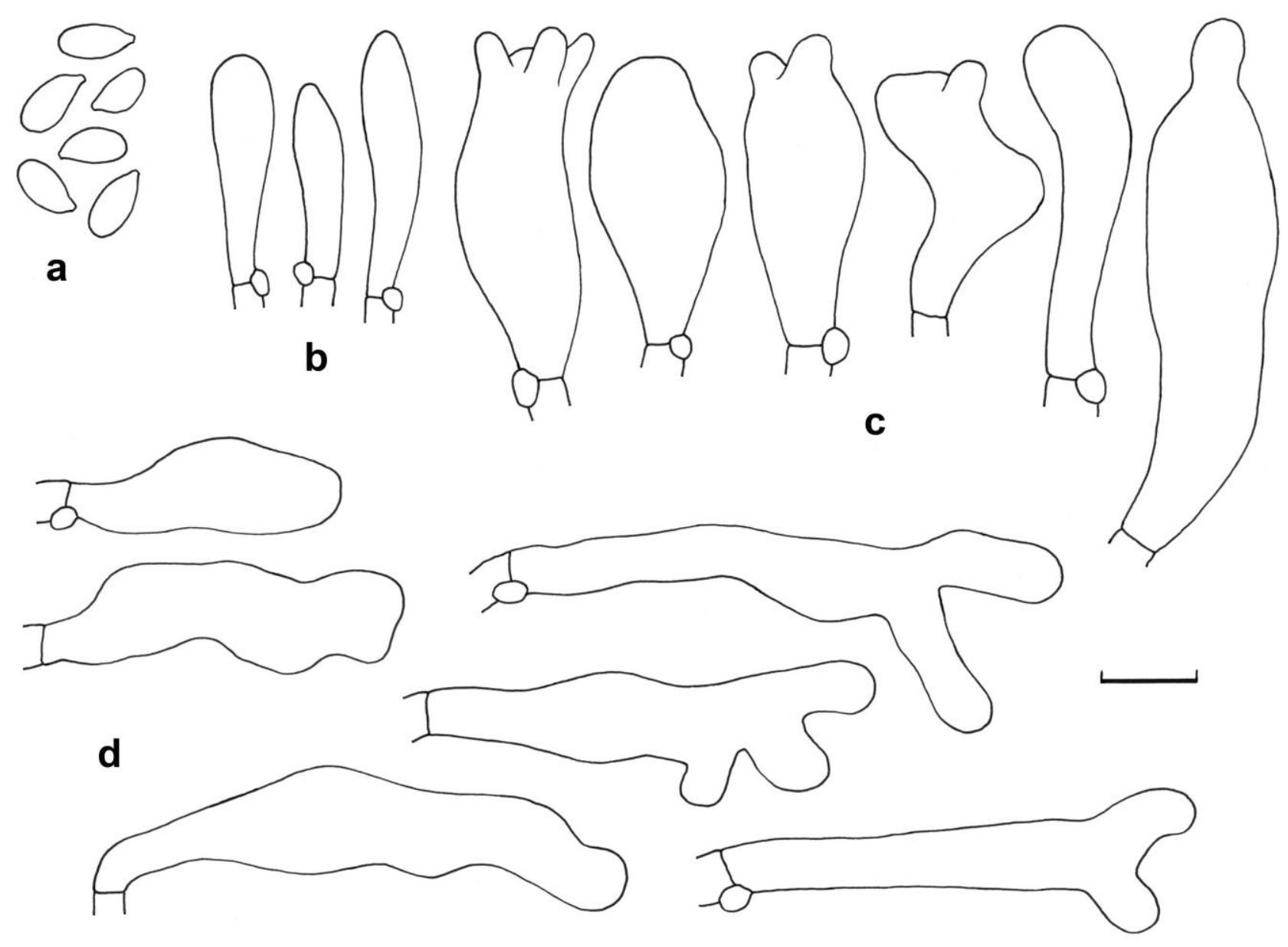

Fig. 55 - Micromorphological features of Gymnopus melanopus (BAP 607). a. Basidiospores. b. Basidioles. c. Cheilocystidia. d. Caulocystidia. Scale bar $=10 \mu \mathrm{m}$

Gymnopus billbowesii Desjardin \& B.A. Perry, sp. nov.

Figs $56,57 \mathrm{a}-\mathrm{d}$ MycoBank MB 821172; Facesoffungi number: FoF 03757

Holotype - AFRICA. São Tomé, along main road (EN-1) on north side of island at $16.5 \mathrm{~km}$ marker, N00²4.374', E06³7.092', 17 April 2008, collected by D.E. Desjardin, DED 8250 (SFSU). 
Etymology - named in honor of William K. "Bill" Bowes Jr. who has supported this project since its inception.

Diagnosis - Pileus 3-15 mm diam, convex, margin striate to striatulate; surface dull, moist to dry, sometimes rugulose, glabrous to felted, subhygrophanous, disc brown (7-8E5-6) to pale greyish orange ( $<6 \mathrm{~B} 3)$, margin cream $(4 \mathrm{~A} 3)$ to buff or white, in age buff overall or with a small greyish orange disc, often bruising reddish brown. Context $<1 \mathrm{~mm}$ thick, soft, white. Lamellae adnexed to ascendingadnate with a very short decurrent tooth, distant with 2 series of lamellulae, broad (2-4 mm), white, non-marginate. Stipe $15-25 \times 0.5-1.5 \mathrm{~mm}$, central, terete, cylindrical or narrowed downward, tough, hollow, insititious to subinsititious; surface dull, dry, pruinose, apex white to greyish orange or pale brownish grey (6C2), base brown (6-7E4-5) to dark reddish brown (7-8F6-8). Odor and taste raphanoid.

Basidiospores 5-7 × 3.8-5 $\mu \mathrm{m}\left[\mathrm{x}_{\mathrm{m}}=5.8 \pm 0.43 \times 4.4 \pm 0.33 \mu \mathrm{m}, \mathrm{Q}=1.2-1.4, \mathrm{Q}_{\mathrm{m}}=1.33 \pm 0.05\right.$, $\mathrm{n}=25, \mathrm{~s}=1$ ], ovoid to broadly ellipsoid, smooth, hyaline, inamyloid, thin-walled. Basidia 23-32 $\times$ 5.7-8.0 $\mu \mathrm{m}$, clavate, 4-spored. Basidioles clavate to subcylindrical. Pleurocystidia absent. Lamellar edge fertile. Cheilocystidia scattered, 22-36 × 8-12 $(-20) \mu \mathrm{m}$, broadly clavate to irregular, with

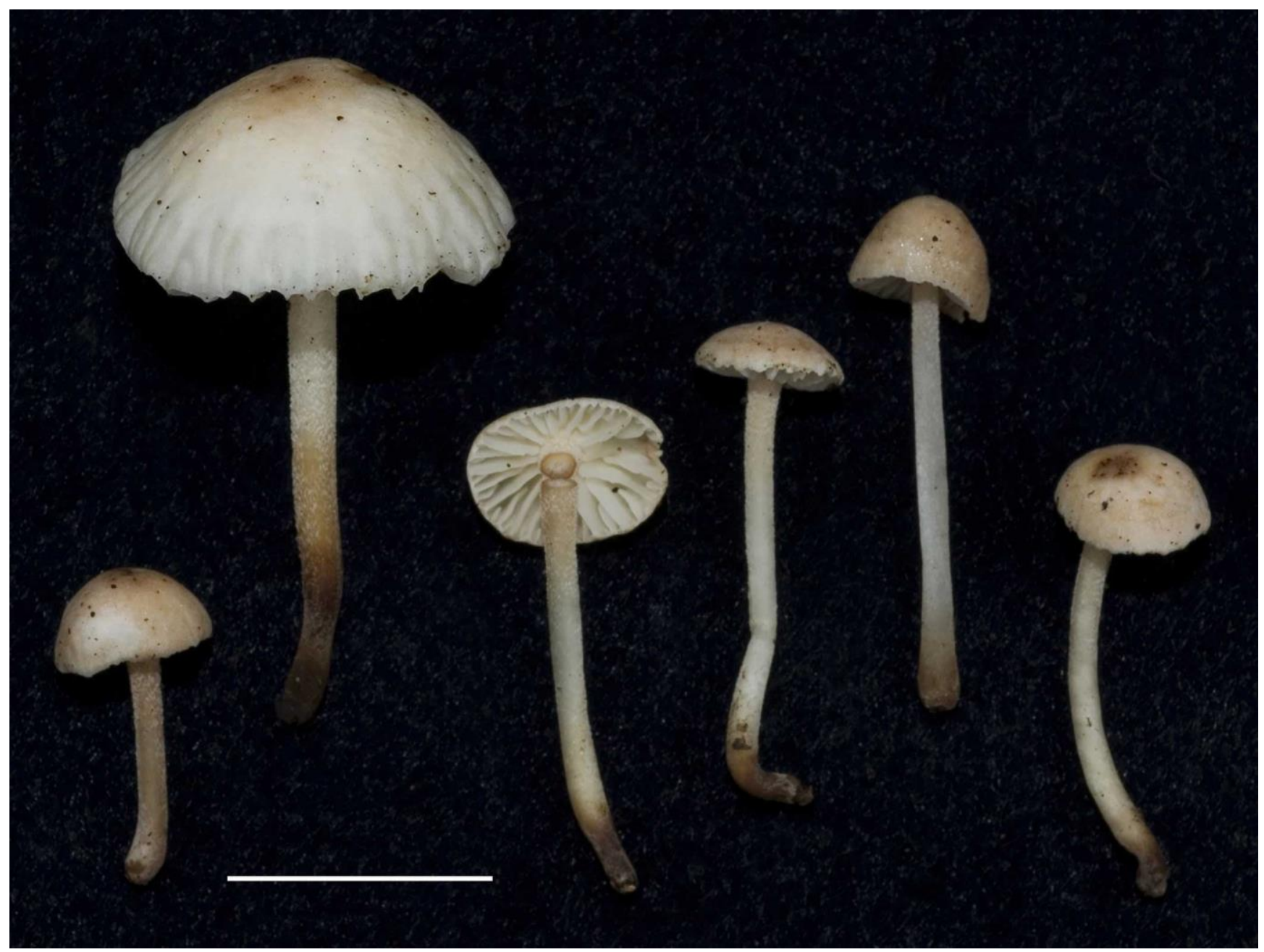

Fig. 56 - Basidiomes of Gymnopus billbowesii (Holotype, DED 8250). Scale bar = $10 \mathrm{~mm}$

or without a few apical knobs, hyaline, inamyloid, thin-walled. Pileipellis a cutis of repent, interwoven hyphae 3-12 $\mu \mathrm{m}$ diam, cylindrical or irregular, branched, non-diverticulate or with broad, knob-like 
outgrowths, non-incrusted or with thin hyaline to pale brown incrustations, hyaline, inamyloid, nongelatinous, thin-walled; terminal cells undifferentiated. Pileus trama interwoven, hyphae 2.5-8 $\mu \mathrm{m}$ diam; lamellar trama regular, hyphae 2-5 $\mu \mathrm{m}$ diam; hyaline, inamyloid, non-incrusted, non-gelatinous, thin-walled. Stipitipellis a cutis with numerous clustered caulocystidia; cortical hyphae 2-6.5 $\mu \mathrm{m}$ diam, cylindrical, non-diverticulate, hyaline to pale brown, inamyloid, thin-walled or with walls up to $0.5 \mu \mathrm{m}$ thick, non-incrusted, non-gelatinous; medullary hyphae 2-9 $\mu \mathrm{m}$ diam, hyaline, inamyloid, thin-walled. Caulocystidia $20-70 \times 3.5-10 \mu \mathrm{m}$, irregularly cylindrical to clavate, sometimes lobed or with a few broad knobs, hyaline to pale brown, inamyloid, thin-walled or with walls up to $0.5 \mu \mathrm{m}$ thick. Clamp connections present in all tissues.

Habitat and known distribution - Solitary on woody debris under baobab trees and mesquite in coastal xerophytic habitat, or on trunk of standing palm in coastal secondary forest. Africa (São Tomé).

Material examined - AFRICA. São Tomé, along main road (EN-1) on north side of island at 16.5 $\mathrm{km}$ marker, N00²4.374', E06 37.092', 17 April 2008, collected by D.E. Desjardin, DED 8250 (Holotype, MF100989, SFSU); São Tomé, along main road (EN1) on north side of island at $18.25 \mathrm{~km}$ marker, N00 23.687', E06 36.302', 17 Apr. 2008, coll. by B.A. Perry and D.E. Desjardin, BAP 624 (MF100990, SFSU).

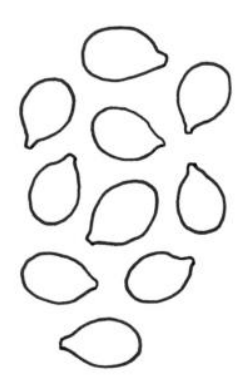

a
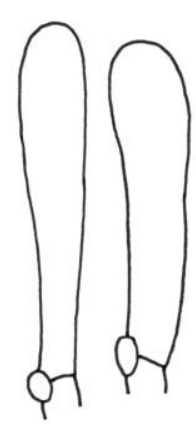

b
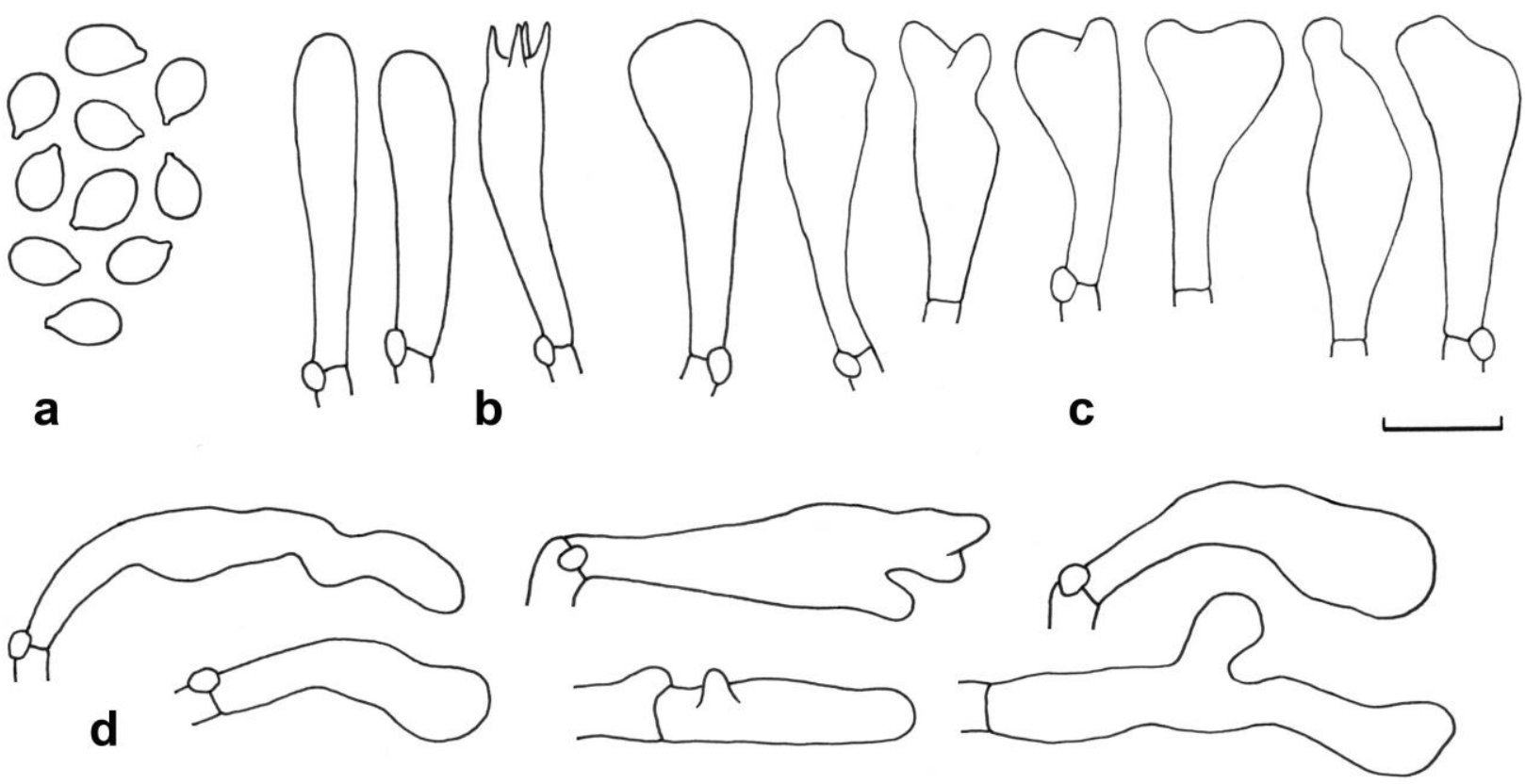

Fig. 57 - Micromorphological features of Gymnopus billbowesii (Holotype, DED 8250). a. Basidiospores. b. Basidium and basidioles. c. Cheilocystidia. d. Caulocystidia. Scale bar $=10 \mu \mathrm{m}$

Notes - Gymnopus billbowesii is characterized by a small white pileus with brown to greyish orange disc that bruises reddish brown, distant white lamellae, a tough, pruinose stipe white at the apex and reddish brown at the base, raphanoid odor and taste, small ovoid basidiospores (mean $5.8 \times 4.4$ $\mu \mathrm{m})$, irregularly clavate cheilocystidia and caulocystidia, a cutis-type pileipellis, non-dextrinoid tissues with clamp connections, and growth on woody debris. Gymnopus billbowesii shows features similar to Gymnopus diminutus (Berk. \& Br.) A.W. Wilson \& Desjardin and its variety G. diminutus var. clavatus A.W. Wilson \& Desjardin, but the latter form a non-striate pileus, close narrow lamellae, indistinct odor and taste, and narrower basidiospores (mean width 2.7-3.3 $\mu \mathrm{m}$ ) (Pegler 1977, 1986; Wilson and Desjardin 2004). Gymnopus indoctus (Corner) A.W. Wilson, Desjardin \& E. Horak, 
known from Indonesia and Singapore, is also similar to G. billbowesii but forms a larger (10-45 mm diam) pileus, closer lamellae, larger basidiospores $\left(\mathrm{x}_{\mathrm{mm}}=8.6 \times 4.1 \mu \mathrm{m}\right)$, and distinct, erect pileocystidia (Wilson et al. 2004).

Pairwise comparisons of aligned, overlapping ITS sequences of Gymnopus billbowesii with the top ten BLAST results indicate closest similarity (87.5-90.2\%) to uncultured, undetermined Agaricales clones. In the ITS phylogeny (Fig. 1), G. billbowesii is on a long branch in a rather isolated position sister to G. ramealis, G. ugandensis, M. foliiphilus and G. pleurocystidiatus.

\section{Acknowledgments}

We thank Dr. Robert C. Drewes (California Academy of Sciences) who continues to initiate, coordinate and lead multiorganism biotic surveys on São Tomé and Príncipe; Eng. Arlindo de Ceita Carvalho, Director General of the Ministry of Environment, Victor Bonfim, Salvador Sousa Pontes and Danilo Barbero for permission to collect and export specimens for study. We are indebted to Société de Conservation et Développement for logistics and housing support, especially the wonderful staffs of Omali Lodge and Bom Bom Island. We are grateful for the support and cooperation of Bastien Loloumb of Zuntabawe and Faustino Oliviera, former Director of the botanical garden at Bom Sucesso. We were assisted in the field by Jose Ramos Maria Vital Pires on Príncipe and by Quintino Quade Cabral, Martinho Nascimiento and Jose Clara on São Tomé. For continuing support, we are most grateful to Ned Seligman, Quintino Quade Cabral and Roberta dos Santos of STePUP. We thank Jonathan del Rosario for assistance with generating the molecular sequence data. We are grateful to the College of Science and Engineering at San Francisco State University for partial funding to support travel to São Tomé and Príncipe, and to the G. Lindsay Field Research Fund of the California Academy of Sciences (CAS) for financially supporting the expedition in 2006 and the Hagey Research Venture Fund (CAS) in 2008. Lastly, we are especially grateful to Roderick C.M. Hall, Coleman P. Burke and William K. Bowes Jr. whose generous philanthropy has supported our research on São Tomé and Príncipe.

\section{References}

Almaliky BSA, Zainal Abidan MA, Kadir J, Wong MY 2011 (2012) - Pathogenicity of Marasmiellus palmivorus (Sharples) Desjardin comb. prov. on oil palm Elaeis guineensis. Wulfenia 19(8), 117.

Antonín V 1987 - Setulipes, a new genus of marasmioid fungi (Tricholomatales). Ceská Mykol. 41, 85-87.

Antonín V, Noordeloos ME 2010 - A monograph of marasmioid and collybioid fungi in Europe. IHW Verlag, Eching, Germany. 480 p.

Antonín V, Ryoo R, Shin H-D 2010 - Two new marasmielloid fungi widely distributed in the Republic of Korea. Mycotaxon 112, 189-199.

Baroni TJ, Bocsusis N, Lodge DJ, Lindner DL 2008 - A new species of Pleurocollybia (Tricholomataceae; Agaricales; Basidiomycetes) from Belize. Mycotaxon 103, 353-363.

Barrasa JM, Esteve-Raventós F, Sánchez C, Bodensteiner P, Agerer R 1998. Glabrocyphella stercoraria, a new cyphellaceous fungus from Spain. Mycological Research 102, 1265-1268.

Beeli M 1928 - Contribution a l'étude de la Flore Mycologique du Congo. Champignons récoltés par $\mathrm{M}^{\mathrm{me}}$ Goossens et déterminés par M. Beeli. Fungi Goossensiani V. Bulletin de la Société de Botanique de Belgique 60(2), 153-174.

Berkeley MJ, Broome CE 1875 (1873) - Enumeration of the fungi of Ceylon. Part 2. Journal of the Linnean Society of London, Botany 14, 29-140. 
Bresadola G, Roumeguère, C 1890 - Nouvelles contributions à la Flore mycologique des Iles SaintThomé et des Princes, recuilles par MM. Ad, F. Moller, F. Quintas, et F. Newton. Revue Mycologique, Toulouse 12(45), 25-40.

Corner EJH 1966 - A monograph of the cantharelloid fungi. Oxford University Press, Oxford, UK. $255 \mathrm{p}$.

Corner EJH 1991 - Trogia (Basidiomycetes). National Parks Board, Singapore Botanical Gardens, Singapore. $100 \mathrm{p}$.

Corner EJH 1996 - The agaric genera Marasmius, Chaetocalathus, Crinipellis, Heimiomyces, Resupinatus, Xerula and Xerulina in Malesia. Beiheft Nova Hedwigia 111, 1-175.

Coutinho AXP 1925 - Florae mycologicae insulae St. Thomae. Anais do Instituto superior de Agronomia Universidade Técnica de Lisboa 2, 1-26.

Darriba D, Taboada GL, Doallo R, Posada D 2012 - jModelTest 2: more models, new heuristics and parallel computing. Nature Methods 9(8), 772.

Dennis RWG 1951 - Some Agaricaceae of Trinidad and Venezuela. Leucosporae: Part 1. Transactions of the British Mycological Society 34, 411-482.

Dennis RWG 1970 - Fungus flora of Venezuela and adjacent countries. Kew Bulletin Additional Series 3, 1-531.

Desjardin DE 1987 - The Agaricales of California. 7. Tricholomataceae I. Marasmioid fungi: the genera Baeospora, Crinipellis, Marasmiellus, Marasmius, Micromphale, and Strobilurus. Mad River Press, Eureka CA. 100 p.

Desjardin DE 1989 - The genus Marasmius from the Southern Appalachian Mountains. PhD Dissertation, University of Tennessee, Knoxville, TN. 880 p.

Desjardin DE 1990 - Culture morphology of Marasmius species. Sydowia 42, 17-87.

Desjardin DE, Halling RE, Hemmes DE 1999 - Agaricales of the Hawaiian Islands. 5. The genera Rhodocollybia and Gymnopus. Mycologia 91, 166-176.

Desjardin DE, Hemmes DE 2011 - Agaricales of the Hawaiian Islands 9. Five new white-spored species from native montane wet forests. Mycologia 103(6), 1441-1450. DOI: 10.3852/11-114.

Desjardin DE, Perry BA 2009 - A new species of Phallus from São Tomé, Africa. Mycologia 101(4), 543-545. DOI: 10.3852/08-166

Desjardin DE, Perry BA 2015a - A new species of Scytinopogon from the island of Príncipe, Republic of São Tomé and Príncipe, West Africa. Mycosphere 6(4), 433-440. DOI: 10.5943/mycosphere/6/4/5

Desjardin DE, Perry BA 2015b - Clavarioid fungi and Gasteromycetes from the Republic of São Tomé and Príncipe, West Africa. Mycosphere 6(4), 515-531. DOI: 10.5943/mycosphere/6/5/2

Desjardin DE, Perry BA 2016 - Dark-spored species of Agaricineae from Republic of São Tomé and Príncipe, West Africa. Mycosphere 7(3), 359-391. DOI: 10.5943/mycosphere/7/3/8

Desjardin DE, Wong GJ, Hemmes DE 1992 - Agaricales of the Hawaiian Islands. I. Marasmioid fungi: new species, new distribution records, and poorly known taxa. Canadian Journal of Botany 70, 530-542.

De Seynes J 1897 - Recherches pour servir à l'histoire naturelle et à la flore des champignons du Congo français, I, 1-29.

Dutta AK, Wilson AW, Antonín V, Acharya K 2015 - Taxonomic and phylogenetic study on gymnopoid fungi from Eastern India. I. Mycological Progress 14, 79. DOI: 10.1007/s11557-0151094-3

Gardes M, Bruns TD 1993 - ITS primers with enhanced specificity for basidiomycetes - application to the identification of mycorrhizae and rusts. Molecular Ecology 2, 113-118.

Guindon S, Gascuel O 2003 - A simple, fast and accurate method to estimate large phylogenies by maximum-likelihood". Systematic Biology 52, 696-704.

Hemmes DE, Desjardin DE 2002 - Mushrooms of Hawai`i. Ten Speed Press, Berkeley, CA. 212 p. 
Hennings P 1897 - Fungi camerunenses. II. Botanische Jahrbücher für Systematik, Pflanzengeschichte und Pflanzengeographie 23, 537-558.

Honan AH, Desjardin DE, Perry BA, Horak E, Baroni TJ 2015 - Towards a better understanding of Tetrapyrgos (Basidiomycota, Agaricales): new species, type studies, and phylogenetic inferences. Phytotaxa 231(2), 101-132. DOI: 10.11646/phytotaxa.231.2.1

Horak E 1979 - Xeromphalina and Heimiomyces in Indomalaya and Australasia. Sydowia 32 (1-6), 131-153.

Huelsenbeck JP, Ronquist F 2001 - MrBayes: Bayesian inference of phylogeny. Bioinformatics 17, 754-755.

Kornerup A, Wanscher JH 1978 - Methuen Handbook of Colour. 3rd ed. Eyre Methuen, London.

Larkin MA, Blackshields G, Brown NP, Chenna R et al. 2007 - Clustal W and Clustal X version 2.0. Bioinformatics 23, 2947-2948.

Lodge DJ, Padamsee M, Matheny PB, Aime MC et al. 2013 - Molecular phylogeny, morphology, pigment chemistry and ecology in Hygrophoraceae (Agaricales). Fungal Diversity 64, 1-99. DOI: $10.1007 / \mathrm{s} 13225-013-0259-0$

Maddison WP, Maddison DR 2015 - Mesquite: a modular system for evolutionary analysis. Version 3.04 (http://mesquiteproject.org).

Mata JL, Halling RE, Petersen RH 2004 - New species and mating system reports in Gymnopus (Agaricales) from Costa Rica. Fungal Diversity 16, 113-129.

Mata JL, Hughes KW, Petersen RH 2007 - An investigation of /omphalotaceae (Fungi: Euagarics) with emphasis on the genus Gymnopus. Sydowia 58, 191-289.

Mata JL, Ovrebo CL 2009 - New reports and illustrations of Gymnopus for Costa Rica and Panama. Fungal Diversity 38, 125-131.

Mata JL, Petersen RH 2003 - Type studies of neotropical Collybia species. Mycotaxon 86, 303-316.

Miller MA, Pfeiffer W, Schwartz T 2010 - "Creating the CIPRES Science Gateway for inference of large phylogenetic trees" in Proceedings of the Gateway Computing Environments Workshop (GCE), 14 Nov. 2010, New Orleans, LA pp 1-8.

Moncalvo J-M, Lutzoni FM, Rehner SA, Johnson J, Vilgalys R 2000 - Phylogenetic relationships of agaric fungi based on nuclear large subunit ribosomal DNA sequences. Systematic Biology 49, 278-305.

Moncalvo JM, Vilgalys R, Redhead SA, Johnson JE, James TY, Aime MC, Horstetter V, Verdium SJW, Larsson E, Baroni TJ, Thorn RG, Jacobsson S, Clémencon H, Miller Jr OK. 2002 - One hundred and seventeen clades of eugarics. Molecular Phylogenetics and Evolution 23, 357400. Pegler DN 1968 - Studies on African Agaricales: I. Kew Bulletin 21(3), 499-533.

Pegler DN 1977 - A preliminary agaric flora of East Africa. Kew Bulletin Additional Series 6, 1-615.

Pegler DN 1983 - Agaric flora of the Lesser Antilles. Kew Bulletin Additional Series 9, 1-668.

Pegler DN 1986 - Agaric flora of Sri Lanka. Kew Bulletin Additional Series 12, 1-519.

Perry BA, Hansen K, Pfister DH 2007 - A phylogenetic overview of the family Pyronemataceae (Ascomycota, Pezizales). Mycological Research 111, 549-571.

Petch T 1948 - A revision of Ceylon Marasmii. Transactions of the British Mycological Society 31, $19-44$.

Petersen RH, Hughes KW 2016 - Micromphale sect. Perforantia (Agaricales, Basidiomycetes); Expansion and phylogenetic placement. MycoKeys 18, 1-122. DOI: 10.3897/mycokeys. 18.10007

Pong VM, Zainal Abidan MA, Almaliky BSA, Kadir J, Wong MY 2012 - Isolation, fruiting and pathogenicity of Marasmiellus palmivorus (Sharples) Desjardin (comb. prov.) in oil palm plantations in West Malaysia. Pertanika Journal of Tropical Agricultural Science 35 (S), 37-48.

Qin J, Yang Z-L 2016 - Cyptotrama (Physalacriaceae, Agaricales) from Asia. Fungal Biology 120, 513-529. 
Redhead SA 1984 - Arrhenia and Rimbachia, expanded generic concepts, and a reevaluation of Leptoglossum with emphasis on musicolous North American taxa. Canadian Journal of Botany 62(5), 865-892.

Redhead SA, Ginns J 1980 - Cyptotrama asprata (Agaricales) from North America and notes on the five other species of Cyptotrama sect. Xerulina. Canadian Journal of Botany 58(6), 731-740.

Redhead SA, Lutzoni F, Moncalvo JM, Vilgalys R 2002. Phylogeny of agarics: partial systematics solutions for core omphalinoid genera in the Agaricales (Euagarics). Mycotaxon 83, 19-57.

Reid DA, Eicker A 1998 - South African fungi 6. The genus Lactocollybia (Basidiomycota) in South Africa. Mycotaxon 66, 153-163.

Retnowati A 2011 - On collections of garlic odorous Marasmiellus ignobilis (Berk. \& Br.) Singer from Indonesia. Floribunda 4(2), 57-61.

Ronquist F, Huelsenbeck JP 2003 - MrBayes 3: Bayesian phylogenetic inference under mixed models. Bioinformatics 19, 1572-1574.

Sharples A 1928 - Palm diseases in Malaya. Malayan Agricultural Journal 16 (9-10), 313-360.

Singer R 1970 - Omphalinae (Clitocybeae-Tricholomataceae, Basidiomycetes). Flora Neotropica 3, 184.

Singer R 1973 - The genera Marasmiellus, Crepidotus and Simocybe in the neotropics. Beihefte zur Nova Hedwigia 44, 1-517.

Singer R 1977 - Keys for identification of the species of Agaricales I. Sydowia 30(1-6), 192-279.

Singer R 1989 - New taxa and new combinations of Agaricales (Diagnoses Fungorum Novorum Agaricalium IV). Fieldiana (Botany) 21, 1-133.

Stamatakis A 2014 - RAxML Version 8: A tool for Phylogenetic Analysis and Post-Analysis of Large Phylogenies. Bioinformatics 10.1093/bioinformatics/btu033.

Swofford DL 2002 - PAUP*. Phylogenetic Analysis Using Parsimony (*and Other Methods). Version 4. Sinauer Associates, Sunderland, Massachusetts.

Turner PD 1981 - Oil palm diseases and disorders. Kuala Lumpur, Malaysia: Oxford University Press.

White TJ, Bruns T, Lee S, Taylor J 1990 - Amplification and direct sequencing of fungal ribosomal RNA genes for phylogenetics. In: Innis MA, Gelfand DH, Sninsky JJ, White TJ, eds. PCR Protocols: a guide to methods and applications. San Diego: Academic Press. p. 315-322.

Wilson AW, Desjardin DE 2005 - Phylogenetic relationships in the gymnopoid and marasmioid fungi (Basidiomycetes, euagarics clade). Mycologia 97(3), 667-679.

Wilson AW, Desjardin DE, Horak E 2004 - Agaricales of Indonesia. 5. The genus Gymnopus from Java and Bali. Sydowia 56, 137-210. 